\title{
Emotional Intelligence Predicts Academic Performance: A Meta-Analysis
}

\author{
Carolyn MacCann ${ }^{\text {a }}$, Yixin Jiang, Luke E R Brown \\ The University of Sydney \\ Kit S. Double \\ University of Oxford \\ Micaela Bucich \\ The University of Sydney \\ Amirali Minbashian \\ University of New South Wales, Sydney
}

\begin{abstract}
${ }^{a}$ Carolyn MacCann, Yixin Jiang, and Luke E. R. Brown, School of Psychology, The University of Sydney; Kit S. Double, Department of Education, University of Oxford; Micaela Bucich, School of Psychology, The University of Sydney; Amirali Minbashian, School of Management, UNSW Business School, University of New South Wales Sydney.

Correspondence concerning this article should be addressed to Carolyn MacCann, School of Psychology, The University of Sydney, Paramatta Road, Sydney, NSW 2037, Australia. Email: carolyn.maccann@sydney.edu.au
\end{abstract}

CAmerican Psychological Association, 2019. This paper is not the copy of record and may not exactly replicate the authoritative document published in the APA journal. Please do not copy or cite without author's permission. The final article is available, upon publication, at: $\underline{\text { http://dx.doi.org/10.1037/bul0000219 }}$ (supplementary materials are available at http://dx.doi.org/10.1037/bul0000219.supp) 


\section{Emotional Intelligence Predicts Academic Performance: A Meta-Analysis}

Keywords: emotional intelligence, personality, intelligence, academic performance, metaanalysis

Public Significance Statement: This meta-analysis shows that emotional intelligence has a small to moderate association with academic performance, such that students with higher emotional intelligence tend to gain higher grades and achievement test scores. The association is stronger for skill-based emotional intelligence tasks than rating scales of emotional intelligence. It is strongest for skill-based tasks measuring understanding emotions and managing emotions.

Funding statement. This research was funded in part by an Australian Research Council Discovery Grant (DP150101158) awarded to the Carolyn MacCann and Amirali Minbashian. 


\begin{abstract}
Schools and universities devote considerable time and resources to developing students' social and emotional skills such as emotional intelligence (EI). The goals of such programs are partly for personal development but partly to increase academic performance. The current meta-analysis examines the degree to which student EI is associated with academic performance. We found an overall effect of $\rho=.20$ using robust variance estimation $(N=$ $42,529, k=1,246$ from 158 citations). The association is significantly stronger for ability EI $(\rho=.24, k=50)$ compared to self-rated $(\rho=.12, k=33)$ or mixed EI $(\rho=.19, k=90)$. Ability, self-rated and mixed EI explained an additional $1.7 \%, 0.7 \%$ and $2.3 \%$ of the variance respectively, after controlling for intelligence and big five personality. Understanding and management branches of ability EI explained an additional 3.9\% and 3.6\% respectively. Relative importance analysis suggests that EI is the third most important predictor for all three streams, after intelligence and conscientiousness. Moderators of the effect differed across the three EI streams. Ability EI was a stronger predictor of performance in humanities than science. Self-rated EI was a stronger predictor of grades than standardized test scores. We propose that three mechanisms underlie the EI/academic performance link: (a) regulating academic emotions, (b) building social relationships at school, and (c) academic content overlap with EI. Different streams of EI may affect performance through different mechanisms. We note some limitations, including the lack of evidence for a causal direction.
\end{abstract}




\section{Introduction}

Emotional intelligence (EI) has captured the public imagination, and rightly so. Recent meta-analyses clearly demonstrate that emotionally intelligent people perform better in their jobs (Joseph, Jin, Newman, \& O'Boyle, 2015; Joseph \& Newman, 2010; O'Boyle, Humphrey, Pollack, Hawver, \& Story, 2011), and have better health and wellbeing outcomes (Martins, Ramalho, \& Morin, 2010; Schutte, Malouff, Thorsteinsson, Bhullar, \& Rooke, 2007). In education, there is a growing consensus among educators, researchers, and policymakers that EI is an important skill for students to develop, both for their future wellbeing as well as their future workplace success. While there is evidence that social and emotional learning programs in school are effective (Durlak, Weissberg, Dymnicki, Taylor, \& Schellinger, 2011), and that non-cognitive constructs are powerful predictors of academic performance (Poropat, 2009; Richardson, Abraham, \& Bond, 2012), there is not yet a largescale meta-analysis examining the extent to which EI correlates with academic performance. The current manuscript provides the first comprehensive large-scale meta-analyses estimating the extent to which EI predicts academic performance. We consider all major conceptualizations of EI, all stages of education (from elementary school through to university), and the different facets of EI. We also examine the incremental validity of EI above and beyond the traditional psychological characteristics known to predict academic performance (intelligence and the five major personality domains).

\section{Emotional Intelligence}

Emotional intelligence (EI) is a relatively new construct compared to intelligence or personality, with the first academic article appearing in 1990 (Salovey \& Mayer, 1990). The concept was relatively unknown until it was popularized by science journalist Daniel Goleman in his 1995 book Emotional Intelligence: Why it Can Matter More than IQ. This book sparked massive interest from researchers and the general public in the late 1990s. One 
effect of this sudden widespread popularity was that research teams commenced their work in parallel, creating their own theories and assessments rather than building on existing research. For much of the 1990 s there was little agreement on how to define or measure EI, leading to many different theories and measures that were often quite dissimilar from each other (Davies, Stankov, \& Roberts, 1998). To bring some clarity to the field, researchers suggested that a distinction should be made between two kinds of measurement models - ability scales and rating scales (Mayer, Caruso, \& Salovey, 2000). Ability scales require test-takers to demonstrate knowledge or to process emotion-related information to provide a response. Rating scales require test-takers to rate their agreement with a series of statements about themselves (e.g., "I am able to handle most upsetting problems"; Brackett, Rivers, Shiffman, Lerner, \& Salovey, 2006). Evidence to date suggests that rating scales and ability scales of EI capture different constructs and are only weakly related to each other (Brackett \& Mayer, 2003; Brackett et al., 2006).

Paralleling the distinction between two measurement models is a similar distinction of two theoretical models - mixed model and ability model theories of EI. Mixed model conceptualizations of EI include a broad mix of constructs that lead to emotionally intelligent behaviour, including emotion-related abilities, character traits, and motivational elements (Bar-On, 2006; Petrides, Pita, \& Kokkinaki, 2007). In contrast, ability models of EI conceptualize EI as a cognitive ability of a similar type to verbal ability or quantitative ability, with the content domain as emotions rather than words or numbers (MacCann, Joseph, Newman, \& Roberts, 2014). Ashkanasy and Daus (2005) distinguished between rating scales based on ability theories and those based on mixed-model theories. They refer to three 'streams' of EI measures: (1) ability scales, (2) ratings of EI abilities (self-perceptions of EI, sometimes referred to as emotional self-efficacy; Qualter, Gardner, Pope, Hutchinson, \& Whiteley, 2012); and (3) ratings of mixed model EI (often referred to as trait EI, after the 
major mixed model conceptualization; Furnham \& Petrides, 2003; Petrides \& Furnham, 2000, 2003). In the current meta-analysis, we separately consider results for these three different types of assessments, based on theoretical and empirical evidence that these are three separate constructs (Joseph \& Newman, 2010; O'Boyle et al., 2011). We refer to these as ability EI, self-rated EI, and mixed EI. The paragraphs below describe the major ability model of EI (and the ability and self-rated EI assessments based on this model), and the major mixed models of EI (and the mixed model assessments based on these).

\section{Ability EI: A four-branch hierarchical model of emotional skills}

There is general agreement on a single theoretical model that describes the component abilities of EI. The hierarchical four-branch model was first described by Mayer and Salovey in 1997. This model outlines four key branches of emotion-related abilities that range in complexity from low-level information processing to strategic and deliberative use of emotional information to meet personal goals. These four branches are: (1) perceiving emotions accurately, (2) using emotions to facilitate decision-making, (3) understanding emotions, and (4) managing emotions to up-regulate positive emotions and down-regulate negative emotions. We describe these in detail below. The best-known assessment of these four branches is the ability-based Mayer-Salovey-Caruso Emotional Intelligence Test (MSCEIT, Mayer, Salovey, Caruso, \& Sitarenios, 2003), which has two subtests for each of the four branches. The MSCEIT is the only commercially-available ability EI measure and is the most commonly-used ability measure in research. Although there are several noncommercial alternative ability EI assessments, these tend to measure only one or two of the four branches (e.g., Freudenthaler \& Neubauer, 2007; MacCann \& Roberts, 2008; Matsumoto et al., 2000). Earlier research on the four-branch model also used the Multi-factor Emotional Intelligence Scale (MEIS), the precursor to the MSCEIT (Mayer, Caruso, \& Salovey, 1999). Youth versions of the MSCEIT and MEIS have often been used for research in schools 
(Rivers et al., 2012).

In addition to the ability-based assessments, there are several assessments that use rating-scales to assess self-rated ability EI. One of the earliest measures of this kind was the 33-item Assessing Emotions Scale (AES; Schutte et al., 1998). The AES was based on an earlier definition of EI that pre-dated the four-branch hierarchical model. The early definition included perceiving, using, and managing emotions, but did not include understanding emotions (Salovey \& Mayer, 1990). Because the AES was available early in the public domain, it was frequently used in EI research. Another EI measure that used this early definition is Wong's Emotional Intelligence Scale (WEIS), which contains four subscales that assess perceiving one's own emotions, perceiving others' emotions, using emotions, and managing emotions (i.e., it does not include emotion understanding, in line with the earlier definition of EI; Law, Wong, \& Song, 2004). A rating-scale instrument designed specifically after the four-branch model is the Self-Rated Emotional Intelligence Scale (SREIS; Brackett et al., 2006), which contains 19 items that assess five subscales (perceiving emotions, using emotions, understanding emotions, managing one's own emotions, and managing others' emotions). The four branches of EI are described in detail below.

Emotion perception is the ability to "identify emotional content in faces, voices, and designs and ability to accurately express emotions" (Mayer, Caruso, \& Salovey, 2016). Theoretically, this branch includes several related abilities, including: (a) the ability to identify emotions in external stimuli (b) the ability to identify one's own emotions (i.e., internal stimuli); (c) the ability to express one's own emotions accurately; (d) the ability to distinguish between genuine emotion expressions and deceptive or forced expressions; and (e) knowledge of display rules for emotion expression in different cultures and contexts (Mayer et al., 2016; Mayer \& Salovey, 1997b). However, this branch has been operationalized solely as the first of these - tests assess the capacity to identify the type and 
extent of emotion present in external stimuli such as facial expressions, micro-expressions, tone-of-voice, body postures, landscapes and evocative art (Matsumoto et al., 2000; Mayer et al., 2003; Nowicki \& Duke, 1994; Schlegel, Grandjean, \& Scherer, 2014). As such, the empirical basis for what is known about emotion perception is solely defined as individual differences in identifying emotions in others (and not the wider array of abilities that may theoretically be included). Once emotions are perceived, this emotion information acts as input for the cognitive system (Mayer, Salovey, Caruso, \& Sitarenios, 2001).

Emotion facilitation of thought involves the use of emotions and emotional information as input or guidance in cognitive tasks or decisions. It has been defined as the ability to "facilitate thinking by drawing on emotions as motivational and substantive inputs" (Mayer et al., 2016, p. 296). Both the theory and measurement of this branch involve two key elements: (1) using existing emotions to guide task selection or approaches to tasks, and (2) generating new emotions to aid performance on a specific task. When using existing emotions, a person uses their current emotional state as a critical task parameter to guide the strategies or processes used in problem solving in two ways. First, emotions can direct attention to critical information through the action tendencies associated with each emotion. For example, positive affect relates to a broad rather than narrow outlook and may lead to creative exploration whereas anxiety is associated with hypervigilance to threat (Bar-Haim, Lamy, Pergamin, Bakermans-Kranenburg, \& van IJzendoorn, 2007; Fredrickson, 2001). Second, tasks can be selected to take advantage of a mood state that might help performance. For example, one could choose to write an enthusiastic welcome email when in a happy mood but wait to counsel a disgruntled employee until one is feeling more serious (i.e., the emotion regulation strategy of situation selection). The MSCEIT contains two subtests assessing facilitation. The Sensations test assesses the generation of emotions-test-takers must generate an emotion and rate the similarity of their sensory experience to sensations 
such as hot, red, or quiet. The Facilitation test assesses knowledge of which mood states will be most helpful in different types of tasks.

The facilitation branch has been criticized on both empirical and theoretical grounds. Empirically, factor analyses have generally not supported the inclusion of a clear and distinct facilitation branch, possibly due to the dual nature of facilitation as both emotion generation and situation selection (Fan, Jackson, Yang, Tang, \& Zhang, 2010; Palmer, Gignac, Manocha, \& Stough, 2005; Rossen, Kranzler, \& Algina, 2008). Theoretically, emotion facilitation seems like a subset of emotion management (the fourth branch). Emotion generation is a core concept for emotion management, as managing emotions involves the ability to generate the desired emotion to match the task at hand (mostly, but not always, the up-regulation of positive emotions and down-regulation of negative emotions) (Joseph \& Newman, 2010; MacCann et al., 2014; Mestre, MacCann, Guil, \& Roberts, 2016). The other element of emotion facilitation — situation selection - is a well-known emotion regulation strategy (Gross \& Thompson, 2007; Werner \& Gross, 2010), and thus might also be considered a key element of emotion management (the emotion management branch is sometimes also referred to as 'emotion regulation'; e.g., Joseph \& Newman, 2010; Mayer \& Salovey, 1997a).

Emotion understanding encompasses one's knowledge base regarding emotions and emotion-related phenomena. It is the "central locus of abstract processing and reasoning about emotions and emotional information" (Mayer et al., 2001, p. 235). It includes the following types of emotion knowledge: the vocabulary of emotion terms; the antecedents and consequences of emotions; the way emotions may combine or change over time; and the likely effect of a specific situation on one's emotions now or in the future (Mayer, Caruso, \& Salovey, 2016, in press; Mayer \& Salovey, 1997a). Emotion understanding may be considered as domain-specific knowledge for the content domain of emotions. Emotion understanding shows the strongest links to conventional cognitive abilities of the four EI 
branches, with meta-analytic estimates ranging from $\rho=.39$ to .42 (Joseph \& Newman, 2010; MacCann, 2010; Olderbak, Semmler, \& Doebler, 2019; Roberts, Schulze, \& MacCann, 2008).

Emotion management is the ability to manage emotions in oneself and others by upregulating positive emotions and down-regulating negative emotions in order to achieve a desired outcome such as personal growth (Mayer et al., 2016; Mayer \& Salovey, 1997a; Mayer et al., 2001). There are four key elements to emotion management. First, this branch involves managing both one's own and others' emotions (termed intrinsic and extrinsic emotion regulation in the process model of emotion regulation; Gross, 2008; Gross \& Thompson, 2007). Second, this branch includes both: (a) knowledge of emotion management, and (b) meta-cognitive strategies pertaining to emotion management, such as the ability to "monitor emotional reactions" and to "evaluate strategies to maintain, reduce, or intensify an emotional response" (Mayer et al., 2016, p. 294). Third, emotions are managed with respect to personal goals. That is, up- or down-regulation of emotion is undertaken strategically to achieve goals such as personal growth. As such, emotion management represents not only the knowledge of how emotions are managed, but the motivational elements that determine when and why emotions are managed. That is, emotion management "interface(s) with personality and personal goals" (Mayer et al., 2001, p. 235). Of the four EI branches, emotion management shows the strongest relationships to personality traits, particularly agreeableness $(\rho=.29 ;$ Joseph \& Newman, 2010).

Given the known relationships of ability EI with both intelligence and personality, some researchers have argued that ability EI shows little incremental prediction of key outcomes above and beyond the effects of personality (e.g., Schulte, Ree, \& Carretta, 2004). For this reason, it is essential to provide evidence of incremental validity when considering whether EI predicts academic performance. We will therefore control for personality and 
intelligence in the prediction of academic performance from EI.

\section{Mixed Models of EI}

While there are many mixed models of EI, the three major conceptualizations are Goleman's emotional competence (Goleman, 1998), Bar-On's emotional and social competence (Bar-On, 2006) and Petrides and Furnham's trait emotional intelligence (Petrides, Perez-Gonzalez, \& Furnham, 2007; Petrides, Pita, et al., 2007). We describe these below.

Emotional competence. Goleman's model, first outlined in his 1998 book Working with Emotional Intelligence, consists of four major competencies: (1) self-awareness (being aware of one's emotions, accurate in one's self-assessments, and self-confident); (2) selfmanagement (being conscientious, trust-worthy, adaptable, achievement-oriented, and able to control one's emotions and behaviours); (3) social awareness (showing empathy to others, and having a service orientation and organizational awareness); and (4) social skills (being skilled in leadership, communication, influence, conflict management, building relationships, showing good teamwork and collaboration skills, as well as the ability to mentor others) (Boyatzis, Goleman, \& Rhee, 2000; Goleman, 1998). That is, the model distinguishes between awareness (the tendencies and abilities to detect essential emotional information in oneself and one's environment) and management (being able to change or regulate the social and emotional content of oneself and one's surroundings) as they are applied to the self and to others. This emotional competence model is the basis for the emotional competence inventory (ECI), a rating-scale inventory commercially available to assess EI. There is relatively little peer-reviewed empirical evidence evaluating the ECI, and it has been criticized based on a lack of content validity and predictive validity evidence (Landy, 2005; Matthews, Zeidner, \& Roberts, 2002). Nevertheless, the theoretical model has been very influential in both business and education settings. For instance, this model formed the basis 
for the social and emotional learning (SEL) competency model used by the Collaborative for Academic, Social, and Emotional Learning (CASEL, 2003; Durlak et al., 2011). CASEL's SEL model includes the four Goleman competencies as well as a fifth competency of responsible decision making (being able to make constructive choices about personal behaviour and social interactions). This model is widely used internationally to guide educational interventions designed to increase student, class and school-level socio-emotional competencies.

Social and emotional competence. Bar-On's model of social and emotional competence was developed to represent "key components of effective emotional and social functioning that lead to psychological well-being" (Bar-On, 2000, p. 364). There are five major domains of emotional and social competence-interpersonal competence, intrapersonal competence, stress management, adaptability, and general mood (Bar-On, 2006). The Emotional Quotient Inventory (EQ-i) instrument is based on this model, and contains 15 subscales that are unevenly distributed across these five domains: (1) intrapersonal competence (self-awareness and self-expression) contains five subscales-self-regard, emotional self-awareness, assertiveness, independence, and self-actualization; (2) interpersonal competence (social awareness and interpersonal relationships), contains three subscales - empathy, social responsibility, and interpersonal relationship; (3) stress management (emotion management and regulation) contains two subscales — stress tolerance and impulse control; (4) adaptability (change management) contains three subscales - reality testing, flexibility, and problem solving; and (5) general mood (self-motivation) contains two subscales — optimism and happiness (Bar-On, 2006). Exploratory and confirmatory factor analysis of the items provided support for only 10 of the 15 subscales. Both of the general mood subscales, two of the five intrapersonal competence subscales and the social responsibility subscale of interpersonal competence were not supported, but were retained in 
the instrument as 'facilitators' of social and emotional competence (Bar-On, 2000, 2006). A youth version of the EQ-i is also available, and the EQ-i has frequently been used in peerreviewed research linking EI to academic performance. EQ-i scores correlate very highly with personality traits. For example, EQ-i total scores correlate at -.62 to -.72 with neuroticism (Dawda \& Hart, 2000), .52 to .56 with extraversion and -.76 with anxiety (a facet of neuroticism) (Dawda \& Hart, 2000; O’Connor \& Little, 2003). Correlations of this magnitude have led some researchers to claim that EI (especially mixed-model conceptualizations) represents 'old wine in a new bottle' - that is, a re-branding of personality rather than a new and distinct construct (Matthews et al., 2002).

Trait Emotional Intelligence. Trait EI is the most comprehensive mixed model of EI, consisting of 15 facets taken from both the ability model of emotion as well as the two models of emotional competence described above (Petrides, Pita, et al., 2007; Petrides, 2009). The four ability facets in this model are: (1) accurately perceiving emotions in oneself and others; (2) expressing and communicating emotions clearly; (3) managing others' emotions; and (4) regulating one's own emotions. The non-ability facets include adaptability, assertiveness, low impulsivity, fulfilling personal relationships, self-esteem, self-motivation, social awareness, stress management, trait empathy, trait happiness, and trait optimism. The trait EI model is assessed with the Trait Emotional Intelligence Questionnaire (TEIQue; Petrides, Pita, et al., 2007), which also has a short form, adolescent form, child form, and adolescent and child short forms. The TEIQue is very frequently used in EI peer-reviewed research. TEIQue scores show very high correlations with the five major domains of personality (Matthews et al., 2002; Mayer, Roberts, \& Barsade, 2008). Some researchers have argued that this is a problem for the discriminant validity of trait EI- that trait EI is in fact indistinguishable from personality. A recent meta-analysis provides empirical justification for this idea, showing that trait EI correlates at .85 with a general personality 
factor derived from the five major domains of personality, suggesting that these two constructs are "very similar, perhaps even synonymous" (p. 36, van der Linden et al., 2017). Given that personality is known to predict academic performance, the question of whether trait EI can add anything to this prediction is therefore important. In the current manuscript, we thus examine whether trait EI predicts academic performance over and above the effects of personality.

\section{Emotional Intelligence and Academic Performance}

There is ample evidence to suggest that EI has a positive association with academic performance. Social and emotional learning programs (which are broadly based on Goleman's model of EI) are known to increase academic performance, with Durlak et al.'s (2011) meta-analysis showing that such programs result in an 11-percentile improvement in academic performance. Social and emotional learning focuses on developing five key competencies that overlap substantially with Goleman's emotional competencies (selfawareness, social awareness, self-management, relationship skills and responsible decision making; CASEL, 2003). Programs were more effective if they followed a sequenced, step-bystep approach, used active forms of learning, allowed adequate time for skill development, and had explicit learning goals (Durlak et al., 2011). The effect of SEL programs on academic performance was stronger when teachers ran the programs $(d=.34)$ compared to non-school personnel $(d=.12)$.

There is also some direct evidence that EI is positively associated with academic performance. Three meta-analyses to date have examined this question, and all have found a positive association. First, Van Rooy and Viswesvaran (2004) estimated a corrected correlation of .10 between EI and academic performance $(k=10)$. This analysis did not distinguish between the different streams of EI. Second, Perera and DiGiacomo (2013) examined rating scales of EI, finding a corrected correlation of .20 with academic 
performance $(k=48)$. Effects were stronger for younger students and at earlier levels of education. Other moderators were examined were not significant. These included: (a) the gender composition of the sample; (b) the instrument used; and (c) whether the sample was in a transition year (i.e., first year of high school or university). Perera and DiGiacomo did not include ability scales in their analysis nor distinguish between mixed EI and self-rated EI. They also did not assess the incremental prediction of EI above the known effects of personality and intelligence. Third, Richardson et al. (2012) examined the relationship between EI and academic performance as part of a wide-sweeping meta-analytic review of 42 non-cognitive correlates of academic performance. They reported a slightly smaller relationship between EI and academic performance $(\rho=.17)$ but included only 14 studies and did not differentiate between ability scales and rating scales.

The current comprehensive meta-analysis expands on previous work in five ways. First, we cover all relevant research whereas previous studies included only a small subset (i.e., we located 162 relevant citations, such that Richardson's $k$ of 14 studies represents less than $10 \%$ of the available data). Second, we include ability-based EI assessments as well as rating scales. The relation between ability EI and academic performance has never previously been reported in meta-analyses, despite being the most objective and arguably most valid assessments of EI (Matthews et al., 2002; Mayer et al., 2008). Third, we use the now-standard categorization of EI scales into ability EI, self-rated EI, and mixed EI to separately examine the effects of EI on academic performance across these three different constructs (cf. Ashkanasy \& Daus, 2005; Joseph \& Newman, 2010; O'Boyle et al., 2011). Fourth, we examine a range of moderators of the effects (described in more detail in the sections below), including EI stream, EI facet, sample age, gender composition, and publication type. Fifth, and perhaps most importantly, we examine the incremental validity of EI above and beyond the effects of personality and intelligence by constructing a correlation matrix of EI, 
intelligence, personality and academic performance. The correlations in this matrix are drawn from: (a) our original meta-analyses (EI/academic performance and intelligence/academic performance correlations); and (b) previously published meta-analyses (personality/EI, personality/performance, intelligence/performance, intelligence/peraonlity, and the relations among personality domains; Joseph \& Newman, 2010; van der Linden, Pekaar, Bakker, Schermer, Vernon, Dunkel, \& Petrides, 2016; Poropat, 2009; Judge, Jackson, Shaw, Scott, \& Rich, 2007; van der Linden, te Nijenhuis, \& Bakker, 2010). Moreover, we use relative importance analysis to compare the relative contribution of intelligence, personality, and EI to explaining differences in academic performance (Johnson, 2000; LeBreton \& Tonidandel, 2008). That is, we are building a more comprehensive picture of the extent to which EI predicts academic performance than ever before, including a consideration of the relative importance of EI compared to other well-known predictors of academic performance. Our major hypothesis is that $E I$ will be positively associated with academic performance

\section{(Hypothesis 1).}

\section{Moderators of the EI/Academic Performance Relationship}

EI Stream. While evidence suggests a positive association of EI with academic performance, it is not clear whether this relationship differs for ability versus self-rated versus mixed EI. Meta-analyses predicting workplace performance and wellbeing outcomes have found different effects for these three streams (Harms \& Credé, 2010; Joseph \& Newman, 2010; Martins et al., 2010; Miao, Humphrey, \& Qian, 2017; O’Boyle et al., 2011; SanchezAlvarez, Extremera, \& Fernandez-Berrocal, 2016; Schutte et al., 2007). These findings are summarized in Table 1, and cut across multiple outcomes: workplace performance, organizational citizenship behaviours, counter-productive workplace behaviours, leadership, subjective wellbeing and health outcomes. Across all major meta-analyses linking EI to positive life outcomes, there are two consistent findings. First, the relationship of EI to 
positive outcomes is uniformly positive, showing that high EI confers benefits to those who possess it. Second, ability EI consistently shows the lowest relationships with criteria of the three streams of EI. This difference among streams may relate to method effects. To date, the criteria examined in meta-analyses are dominated by rating scales. With little objective data for criteria such as job performance, health outcomes, or wellbeing, higher criterioncorrelation with rating scales of EI (both mixed models and self-rated EI) compared to ability scales is consistent with a mono-method bias in measurement. That is, rating scales correlate more highly with rating scales, irrespective of content. There is some support for this idea of a method-effect component to the EI/outcome associations in Harms and Credé's (2010) meta-analysis of EI and leadership. They found that effects were vastly stronger when EI and leadership were both rated by the same source (self, subordinate, peer or supervisor) compared to different sources $-\rho=.59$ versus $\rho=.12$. The pattern of correlations in Table 1 also supports this argument. Self-rated EI measures have much higher association with criteria as compared to ability EI measures. As both types of assessments are meant to measure the same underlying constructs, the difference must be due to method effects rather than construct effects.

Unlike the other outcomes in previous meta-analyses, academic performance is rarely assessed with rating scales (either self- or observer-rated) but rather is an objective composite composed of course-work, examination, and participation results (in the case of course grades) or objective performance on standardized assessments (in the case of standardized test results). While neither course grades nor standardized test scores are problem-free as valid measures of academic performance, their issues are qualitatively different to ratingscale measures of critical criteria. If some of the predictive superiority of EI rating scales over EI ability scales is due to method bias (rather than substantive differences), then ability EI would show a stronger prediction of an objective criteria such as course grades, as compared 
to self-rated EI or mixed EI. We thus propose a directional hypothesis that ability EI will show stronger prediction of performance as compared to self-rated or mixed EI

\section{(Hypothesis 2).}

Facet of EI. There are three possible mechanisms that may account for the relationship between EI and academic performance. First, emotionally intelligent students may be able to deal more easily with negative emotions elicited by academic settings. The prototypical academic emotion is test anxiety, but there are a variety of other emotions specific to academic settings (Pekrun, Elliot, \& Maier, 2009; Pekrun, Goetz, Titz, \& Perry, 2002). For example, students need to regulate the disappointment of lower-than-expected test scores or negative feedback, or the boredom involved in learning concepts and subject matter that are of instrumental rather than intrinsic interest (e.g., learning a tax code to pass an accountancy exam) (Pekrun, Goetz, Daniels, Stupnisky, \& Perry, 2010). Students with the emotion management skills to down-regulate their anxiety, disappointment or boredom will be able to achieve better exam results, and to learn more from negative feedback or boring subject matter. If this mechanism accounts for the EI/academic performance association, the emotion management branch should show the strongest association with academic performance.

Second, social demands are present at all stages of education, from sharing crayons in kindergarten, resisting peer pressure and managing group projects in high school, to adjusting to moving out of home when starting university. For learning and achievement to take place, students must first be able to manage their lives so that they show up to class in a fit state to concentrate on the subject matter. Students with higher EI may be better able to manage the social world around them, forming better relationships with teachers, peers, and family. This may directly influence grades (e.g., in subjective criteria such as participation marks, teachers may award better marks to students who have formed better relationships with them). This 
may also indirectly influence grades through providing the student with a social support network that protects them in times of stress. Developing social relationships would require emotion management (particularly managing social relationships-a subscale of the MSCEIT; Mayer et al., 2016). If this mechanism accounts for the EI/academic performance relationship, then we would again expect emotion management branch to show stronger effects than the other branches.

Third, there may be an overlap between emotional competencies and intellectual competencies. For example, knowing a lot of emotion words and being able to communicate one's feelings could be conceptualized as a subset of vocabulary/verbal ability. Teaching emotional competencies may in fact result in teaching academic competencies-learning the language of emotions increases vocabulary and spelling more generally, and interventions involving written text may also improve reading comprehension. That is, one possibility is that there is nothing particularly special about emotional skills - it is the overlap between emotional skills and other academic skills that mean students who are emotionally intelligent are also likely to be intelligent in other ways (e.g., good with language). MacCann et al. (2014) proposed that EI may in fact be one element of intelligence - a student can be smart with emotions in the same way that they can be good with numbers or good with words. Under this conceptualization, the overlap between EI and academic skills is the purported mechanism by which EI would affect academic performance. If this mechanism accounts for the relationship between EI and academic performance, we would expect the EI/academic performance association to: (a) be strongest for ability EI and weakest for mixed EI (providing further justification for Hypothesis 2); (b) decrease in size after controlling for intelligence; and (c) be strongest for the knowledge-based branch of EI (understanding emotions). In combination with the previously described mechanisms regarding regulating academic emotions and building social relationships, we thus hypothesize that effects will be 


\section{strongest for the understanding and management branches of EI than the perception and}

\section{facilitation branches (Hypothesis 3).}

Peer-reviewed journal article status. The recent 'replication crisis' in psychology and other sciences based on inferential statistics demonstrates that published articles may represent selective reporting, where effects reported in peer-reviewed publications are systematically higher than studies that remained unpublished (Collaboration for Open Science, 2015). Along with other questionable research practices (such as selective analysis), selective reporting may over-estimate effect sizes to such an extent that published estimates are up to twice as large as the real effects (Collaboration for Open Science, 2015). To assess whether there is a file-drawer problem where non-significant results remain unpublished, we will test for any differences between peer-reviewed publications and unpublished data (e.g., unpublished data sets, dissertation abstracts, conference proceedings). If published findings are biased towards significant results, we would expect a stronger association for peerreviewed journal articles than other sources of data. The fourth hypothesis is thus a test of the file-drawer problem, where we hypothesize that the EI/academic performance association will be significantly larger in published than unpublished sources (Hypothesis 4).

Student age. Perera and DiGiacomo (2013) reported a stronger effect of EI on academic performance in elementary school students than in university students $(r=.28$ versus $r=.18$ ) but did not examine ability-based EI. Similarly, Poropat (2008) found significantly stronger associations between conscientiousness and academic performance at earlier stages of education. This implies that self-regulatory processes (such as EI) may be a more critical determinant of educational outcomes at earlier ages and stages of education. We will therefore test whether the EI/academic performance relationship differs across different across age groups. Our expectation is that EI may prove more important at earlier ages. This is because when the average level of emotional skills is relatively low (as for 5 to 7 -year- 
olds), being below average constitutes a lower absolute level of skill that might prove more detrimental to performance overall. For example, a 5-year-old with lower-than-average emotion management skills may spend the day crying, hitting other children, and be completely unable to focus on the tasks at hand. A university student with lower-than-average emotion management skills may have a less satisfying a time at university (Brackett, Mayer, \& Warner, 2004; Brackett et al., 2006) but is nevertheless likely be able to self-regulate sufficiently well so as not to spend the day crying and hitting others. Moreover, there is likely to be selective attrition based on emotional skills, resulting in a restriction of range at university compared to elementary schools and high schools. Students with very low emotional skills are more likely to have anxiety-based school refusal, conduct problems leading to suspensions or expulsion, and/or more difficulties resisting peer pressure (resulting in early drug and alcohol use or unintended pregnancy), and are therefore less likely to obtain entrance to university. Thus, we hypothesize that the EI/academic performance association will be stronger at younger ages (Hypothesis 5).

Type of academic performance: Grades versus standardized test scores. Academic performance is commonly measured in two ways; as standardized test scores or as end-ofsemester grades. Standardized tests are usually developed and administered by state or national bodies (or even international bodies, as in the case of the OECD's Program for International Student Assessment [PISA]). They are often considered high-stakes either for the individual student or for their institution. School funding, reputation, or position within publicly-available league tables may depend on test score results, and students' entrance into selective secondary schools or university programs may depend on their individual test scores. Standardized tests would normally be administered in large groups with a set time limit for completion, and classroom teachers and school administrators have no direct input on the content of these tests. In contrast, end-of-semester grades are composite measures of 
multiple forms of assessment, which may include formal examinations, written assignments, regular home-work, contribution to class discussion, group projects or other assessment tasks. Classroom teachers and school or university administrators have much more control over the content of these assessments. That is, one of the primary ways in which EI could contribute to high scores on standardized tests is through the regulation of test anxiety. Grades (being a more diffuse criterion) would also be influenced via the ability to maintain relationships with one's instructors and other students, to manage group projects, and to manage the emotions that motivate procrastination as well as the ability to manage test anxiety. We therefore hypothesize that EI will show a stronger relationship to grades than to standardized test scores (Hypothesis 6).

Gender composition of the sample. While Perera and DiGiacomo (2013) found that gender composition of the sample did not moderate the effect of EI on academic performance, we revisit this moderator for two reasons. First, we examine ability EI (which Perera and DiGiacomo did not). Second, we have a much larger sample and therefore greater power to detect an effect.

There are two main ways in which the gender composition of the sample could moderate the EI/academic performance association. First, moderation could occur due to the gender effects at the individual level of analysis. To the extent that say males are more likely to benefit academically from higher levels of EI than females, having a greater proportion of males in the sample will result in a stronger relationship between EI and academic performance. In this regard, there is some evidence that the relationship of EI to social and emotional outcomes is stronger for males than females, suggesting that EI may confer greater benefit to males (Brackett et al., 2006; Brackett, Warner, \& Bosco, 2005). There is evidence that males and females experience different kinds of emotions-females experience greater internalising emotions such as anxiety whereas males experience greater externalising 
emotions such as anger (Chaplin, \& Aldao, 2013; Fischer, Rodriguez Mosquera, Van Vianen, $\&$ Manstead, 2004). To the extent that uncontrolled anger may be more damaging to school engagement and mastery goals as compared to anxiety (Pekrun, Elliot, \& Maier, 2009; Pekrun et al., 2002), this may mean that higher EI is more beneficial to males than females, as the consequences of failing to regulate are different for the different kinds of emotions.

Second, moderation could occur due to contextual effects. The gender composition of the sample defines the broader context in which academic performance takes place, which in turn could influence the beneficial value of high EI, regardless of whether an individual is male or female. As described above, the beneficial value of EI may be increased by contexts that place greater demands on dealing with social relationships, managing negative emotions, or learning academic material with emotional or social content. Co-educational schools place greater emphasis on affiliation and social relationships than same-sex schools (e.g., Schneider $\&$ Coutts, 1982). Furthermore, academic contexts with a greater proportion of males can create an intellectually threatening environment and heightened text anxiety among females, thus hampering their performance (see Inzlicht \& Ben-Zeev, 2000).

Taken together, the above arguments suggest that samples that are comprised of largely female participants will benefit less from the effects of EI than samples that are more mixed or male dominated. We thus hypothesize that samples with a higher proportion of females will show weaker effects of EI on academic performance (Hypothesis 7).

Student minority status. SEL programs are of interest to educators and policy-makers as a pathway to address issues of equity for students from traditionally disadvantaged backgrounds or at disadvantaged schools. For SEL programs to reduce achievement gaps between groups: (a) programs must be at least as effective for minority/disadvantaged populations, and (b) the EI/achievement association at least as large for minority/disadvantaged groups (because increasing EI will increase achievement only in so 
much as EI and achievement are related). Evidence is mixed for point (a). Taylor, Oberle, Durlak \& Weissberg's (2017) recent meta-analysis demonstrates that there are no significant differences in the effectiveness of SEL programs for different levels of SES or for majority versus minority groups. However, there is research to suggest that SEL programs are less effective in disadvantaged schools (Bierman et al., 2010). Such differences may be due to the challenges of implementing SEL programs in schools serving disadvantaged students (who are disproportionately ethnic minorities).

Our moderation analysis will test point (b). We hypothesize that samples with larger proportions of minorities may have a stronger EI/achievement association. Our logic is that low EI constitutes a greater barrier in a disadvantaged environment (where EI is required to deal with daily obstacles) than in more supportive environment. Ethnic minority status is bot associated with social and educational disadvantage. In addition, ethnic minority students face additional daily obstacles in the form of micro-aggressions and racism which produce negative emotions (such as anger and anxiety) that require emotion regulation.

As our arguments are partly based on advantaged versus disadvantaged environments, they would also hold for comparisons of high versus low socio-economic status (irrespective of ethnic minority status). We do not examine this directly because sample socio-economic status is rarely if ever reported in correlational research on EI. We use the sample percentage who are of a minority ethnicity (i.e., non-White) as a moderator of the EI/academic performance association. Because of the difficulty of defining 'minority' across different countries, we have restricted this analysis to samples from the USA (where sample ethnicity is commonly reported using consistent categories of White, Black, Asian, and/or Hispanic in most educational and psychological research). We hypothesize that the EI/academic performance association will be larger for samples with higher proportions of minority students (Hypothesis 8). 
Subject area: Mathematics/Science versus Humanities. Many of the arguments mentioned above assume that EI affects the learning process, where high EI students learn more and perform better by regulating their anxiety or boredom, or managing the social relationships of the classroom, playground or campus. However, it is also possible that the EI/academic performance association is due to the content of what is learned. Emotional content is self-evidently more relevant to a performing arts grade (where accurately portraying and evoking emotion form part of the assessable content) as compared to mathematics (where the content is unrelated to emotions). Similarly, analyzing the universal themes of a poem or canonical play requires an understanding of the emotions and motivations of the characters, such that emotions may be a required knowledge base for humanities-based but not science/mathematics-based content domains. Understanding human motivations and emotions may be a required skill for interpreting the meaning of some texts. This is true from the earliest levels of education (e.g., the dramatic tension of The Cat in the Hat derives from understanding both the protagonist's initial boredom and the anxiety caused by the cat's chaos) through to the higher ones (e.g., analyzing the role of charismatic leaders in creating a totalitarian state when studying modern history). To test whether the EI/performance association derives from process versus content, we will test whether the effect is stronger for humanities-based subjects versus mathematics and science-based subjects. We hypothesize that EI will show a stronger relationship to humanities performance as compared to mathematics/science performance (Hypothesis 9).

\section{The Incremental Validity and Relative Importance of EI for Academic Performance Other Predictors of Academic Performance: Intelligence}

The dominant view for much of the twentieth century was that intelligence is the critical ingredient for success at school. While different theorists have defined intelligence in slightly different ways, the American Psychological Association Taskforce defined it as the 
"ability to understand complex ideas, to adapt effectively to the environment, to learn from experience, [and] to engage in various forms of reasoning” (Neisser et al., 1996, p. 77).

Since the dawn of intelligence testing, one of the key tenets of intelligence tests is that scores should correspond to student's achievement at school. In fact, intelligence tests were originally devised by Alfred Binet to assess students' ability to succeed at school. Prominent economists and psychologists have tried to gauge the size of the intelligence/achievement association, with estimates ranging from around $r=.40$ to .70 (e.g., Deary, Strand, Smith, \& Fernandes, 2007; Jencks, 1979; Kaufman \& Lichtenberger, 2005). Early meta-analyses estimated this relationship as $.34, .43$, and .48 respectively, but were focused only on achievement in science in primary and secondary school (Boulanger, 1981; Fleming \& Malone, 1983; Steinkamp \& Maehr, 1983). Three recent meta-analyses have estimated the size of the intelligence/academic performance correlation more generally but have come to different conclusions on the size of this effect. Roth et al. (2015) found a corrected correlation of .54 across 240 studies of primary and secondary students. Poropat (2009) found a corrected correlation of .25 across 47 studies of primary, secondary and university students. Richardson (2012) found a corrected correlation of .21 across 35 studies of university students.

There are two possible reasons for this large discrepancy — stage of education and the time-period covered in the meta-analysis. Roth et al.'s (2015) samples were predominantly pre-adolescent children (no university students were included, and only 1/3 of the samples were from secondary school). In contrast, Poropat (2009) included primary, secondary, and tertiary students with $55 \%$ of studies from university samples, and less than $10 \%$ from primary school samples. Richardson et al. (2012) included university students only and had the lowest estimate of the three meta-analyses. Although no single meta-analysis has tested for moderation across tertiary versus earlier levels of education on the intelligence/academic 
performance relationship, this comparison of different meta-analyses suggests that effects may be smaller in tertiary education than they are in primary or secondary education. Jensen (1998) also believed that the importance of intelligence for academic achievement dropped from primary to secondary to tertiary to post-graduate education.

Second, more recent studies show smaller effects. Roth et al. (2015) reported that older studies (pre-1983) showed a significantly stronger relationship than newer studies. All studies included in Poropat's (2009) meta-analysis were published after 1990, all but four after 1995 , and the majority after 2000 . As such, discrepancies between Roth et al. and Poropat may be due to the time-periods examined. Roth et al. propose that the reduced effect of intelligence on academic performance over time is due to increasing grade inflation (which reduces the variance in academic performance in more recent studies, depressing correlations). There is abundant evidence of continued grade inflation since 1983 (Bachan, 2017; Nata, Pereira, \& Neves, 2014; Rojstaczer \& Healy, 2012). Given that conceptualizations and study of EI did not commence until the 1990s, and much of the research occurred only in the last 10 years, we believe it is important to control for intelligence/academic performance estimates obtained in the current era, ideally from similarly constituted samples (i.e., from tertiary samples as well as primary and secondary). For this reason, we conduct a secondary meta-analysis of studies in our EI/academic performance citations, examining the intelligence/academic performance relationship reported in these citations. This effectively controls for both the time period of the study, and the stage of education (i.e., estimates of the intelligence/academic performance association are then drawn from the same time period and same samples as the estimates of EI/academic performance). We will then use our intelligence/academic performance estimate (along with other meta-analytic correlations) to construct a correlation matrix to test for the incremental validity of EI on academic performance, over and above the effect of intelligence and the five 
major domains of personality.

\section{Other Predictors of Academic Performance: Non-cognitive constructs and}

\section{Personality}

A recent zeitgeist lead by behavioural economist James Heckman has focused on 'non-cognitive' factors such as personality traits as critical predictors of education and workplace outcomes (Heckman \& Rubinstein, 2001; Heckman, Stixrud, \& Urzua, 2006). While earlier canonical writings on the impact of intelligence stressed that non-cognitive, motivational, or conative factors were also likely to be impactful for life success (Jencks, 1979; Wechsler, 1943), these lacked an organizing framework.

One possible organizing framework for non-cognitive factors is the Big Five model of personality, which gained acceptance among psychologists from the 1990s onwards (Digman, 1986; Goldberg, 1981; John, 1989; Tupes \& Christal, 1961). Factor analysis of trait adjectives produced a five-factor solution (the Big Five) that was largely similar to the Five Factor Model (FFM) of personality that emerged from factor analysis of questionnaire data. These five personality factors are extraversion (positive affect, high energy levels, and sociability), agreeableness (sympathy, kindness, and submissiveness), conscientiousness (hard-working, detail-minded, and organized), neuroticism (easily and frequently feeling stress and negative affect) and openness to experience (open to new ideas, enjoyment of arts, culture, and aesthetics; referred to as 'Intellect' in the Big-Five and 'Openness' in the FiveFactor Model). These five major domains of personality provide a conceptual framework for grouping the multiple different non-cognitive constructs that have emerged from different sub-disciplines of psychology and education. For example, conscientiousness provides an overarching framework for the conceptually similar psychological constructs of delay of gratification, ego control, effortful control, self-control, self-regulation and grit (Heckman \& Kautz, 2012; Roberts, Lejuez, Krueger, Richards, \& Hill, 2014). 
A series of meta-analyses demonstrates that these five personality domains, and particularly conscientiousness, predict workplace performance independently from the effects of intelligence (Barrick \& Mount, 1991; Salgado, 1998; Schmidt \& Hunter, 1998). However, research on the importance of these personality traits for academic performance did not follow for another 20 years. Poropat (2009) provided the first large scale meta-analysis linking five domains of personality to academic performance. Across all levels of education, he found a conscientiousness/academic performance relationship of $\rho=.22$, which was of similar magnitude to his estimate of intelligence/performance relationship $(\rho=.25)$. Moreover, conscientiousness predicted academic performance independently of the effects of intelligence. Other recent meta-analyses found similar estimates of .23 and .24 for the conscientiousness/academic performance corrected correlation in tertiary academic performance (O’Connor \& Paunonen, 2007; Richardson et al., 2012). Across these three meta-analyses, agreeableness also showed a significant (but small) positive relationship with academic performance. As the five factors of personality are known to predict academic performance, we will examine whether EI provides incremental prediction above and beyond the effects of personality as well as intelligence.

\section{The combined effect of EI, intelligence and personality on academic performance}

Given that intelligence and personality (particularly conscientiousness) are wellestablished predictors of academic performance, it is important to examine the incremental validity of EI alongside the contribution of these traditional predictors. As reviewed in earlier sections, EI has known relationships with both intelligence and personality. This has led some researchers to argue that $\mathrm{EI}$ is redundant and has little incremental validity above and beyond the effects of intelligence and personality (Schulte et al., 2004). Indeed, in a few studies where EI has been related to positive outcomes, the positive effect of EI disappears after controlling for intelligence and personality (see Walter, Cole, \& Humphrey, 2011, for a 
review). Therefore, researchers have argued for the need to establish not only the main effect of EI, but also the incremental validity of EI relative to intelligence and personality (Antonakis, Ashkanasy, \& Dasborough, 2009; Miao et al., 2017). Moreover, as meta-analyses arguably provide the best estimates for effect sizes of the relationship between different variables, this manuscript is well-placed to determine the incremental validity of EI (ability EI, self-rated EI, and mixed EI) for academic performance. Given the high correlations between mixed EI and personality (e.g., van der Linden et al., 2017) and the high correlations between ability EI and conventional non-emotional measures of intelligence (e.g, MacCann et al., 2014), it is reasonable to expect that correlations of EI with academic performance will shrink after accounting for these variables. However, we hypothesize that overlap with personality and intelligence will not be entirely responsible for the effect of EI on academic performance, such that all three streams of EI will predict academic performance above and beyond the contributions of intelligence and personality (Hypothesis 10).

While incremental validity examines the prediction of a variable to a criterion above and beyond the contribution of other variables, relative importance refers to the contribution each predictor makes to the total criterion variance in combination with other predictors (Johnson \& LeBreton, 2004). The goal of relative weights analysis is to "partition explained variance among multiple predictors to better understand the role played by each predictor in a regression equation" (Tonidandel \& LeBreton, 2011, p. 1). This is a separate question to incremental prediction, as the order in which variables are entered into the analysis does not affect the relative weights. Relative weights can be expressed as a percentage of the $R$ squared value that each variable independently contributes. We will examine not only the incremental prediction of EI but also the relative importance of EI as a predictor when considered in conjunction with intelligence and personality. Previous meta-analyses have used relative weights analysis to compare the relative contribution of EI to the prediction of 
workplace outcomes (Miao, Humphrey, \& Qian 2017; O’Boyle et al., 2011). Many of the original claims in the 1990s popular science books on emotional intelligence proposed that EI was more important than intelligence - that "it can matter more than IQ" (Goleman, 1995, p. 1). A comparison of the relative contribution of EI and intelligence to the prediction of academic performance would thus test whether there is any merit to these original claims. Given the ubiquitous influence of intelligence and conscientiousness on academic performance, we hypothesised that EI will be among the top three predictors of academic performance, along with intelligence and conscientiousness (Hypothesis 11).

\section{Method}

\section{Search Strategy}

First, we searched the following nine databases for relevant studies on EI and academic performance: ERIC, Google Scholar, ISI Web of Science, Medline, ProQuest Dissertations and Theses, PSYCInfo, PubMed, ScienceDirect, and Scopus. For academic performance we used the search string "(academic OR education OR university OR school) AND (grade OR GPA OR performance OR achievement)" in line with Poropat (2009). For emotional intelligence we used the search string “(emotional intelligence) OR EI OR (emotion perception) OR (emotion understanding) OR (emotion facilitation) OR (emotion recognition) OR (emotion management) OR MSCEIT OR MEIS OR TEIQue OR SREIS OR WLEIS OR (Mayer-Salovey-Caruso Emotional Intelligence Test) OR (Multifactor Emotional Intelligence Scale) OR (Trait Emotional Intelligence Questionnaire) OR (Schutte Self Report Emotional Intelligence Test) OR (Wong and Law Emotional Intelligence Scale)". Combining these yielded an initial search result of 6139 citations. All citations up until 1 November 2016 were considered, with no lower limit to the publication year (unpublished data or studies were labelled with the year they were located). After removing duplicates, the title, abstract, 
and, where necessary, full-text, of the remaining citations were reviewed. Ancestry searches of the reference lists yielded an additional 14 citations. After reviewing the reference section of relevant existing meta-analytic reviews (Perera \& DiGiacomo, 2013; Richardson et al., 2012) an additional 10 relevant citations were added. We then conducted a search for unpublished data on this question by: (a) searching the American Education Research Association database (which resulted in no additional relevant citations); and (b) emailing 23 prolific emotional intelligence and putting out a call on the EMONET listserve to request unpublished data, and (c) contacting major testing companies and educational research companies which resulted an additional 7 citations. This search strategy is outlined in the PRISMA chart in Figure 1.

\section{Inclusion and Exclusion Criteria}

Citations were included in the meta-analyses if they met the following inclusion criteria: (1) written in English; (2) the measure of EI was published in either a test manual or journal article; (3) included academic performance indices appraised either directly (e.g., GPA, SAT results) or self-reported (self-reported GPA has been found to correlate at $r=.90$ with actual GPA for college students and $r=.82$ for high school students) (Kuncel, Crede, \& Thomas, 2005); (4) referred to original data not reported in any other citation; (5) reported an effect size between EI and academic performance, or reported data from which an unbiased estimate of effect size could be calculated; and (6) reported the sample size. Conversely, studies were excluded from the meta-analyses based on the following exclusion criteria: (1) measured clinical or work-related training performance; (2) used degree attainment as an index of academic performance (e.g., Kapp, 2000; Kashani, Azimi, \& Vaziri, 2012); (3) used an in vivo laboratory achievement test (e.g., Shao, Yu, \& Ji, 2013); (4) were publications based on the same data as another citation in the meta-analysis (e.g., Ahmad, 2010); or (5) the EI constructs were not based on established ability, trait, or mixed EI theory (e.g., social 
intelligence).

Most citations included multiple correlations estimating the EI/academic performance association (e.g., correlations for several different EI tests with both university and high school grade-point-average, for several different subscales of EI, or several different subject areas of achievement). We recorded all possible combinations of EI/achievement as withincitation effects. After exclusion criteria, there were $n=162$ different citations (188 samples), with $k=1,276$ correlations available for analysis. The final file for analysis is included as an excel sheet in the supplementary material, and a summary of citations is provided in Appendix A.

Citations represented 27 different countries, with most data from English-speaking countries $(76.5 \%, k=974)$ such as the USA $(43.9 \%, k=560)$, UK $(8.2 \%, k=105)$, or Australia $(7.8 \%, k=99)$. The largest number of observations from non-English speaking countries were from Iran $(k=74)$, Portugal $(k=54)$ and Spain $(k=35)$.

\section{Coding}

Each of the 1,276 effects was coded on the criteria described below. The first set of coding was conducted by the second and third authors, who both hold post-graduate degrees in psychology. A second coder (the fourth author, who holds an undergraduate psychology degree) coded 73 randomly-selected citations to test the reliability of coding. Errors were resolved by the first author going back to the original paper.

Effect size. Pearson's correlation ( $r$ ) was used as the metric of effect size. In the few samples where $r$ was not reported, the available statistic (e.g., chi-square, $t$ value, $F$ value) was transformed into $r$ using effect size calculators (Lenhard \& Lenhard, 2016; Lyons \& Morris, 2017). Coder agreement was 93\%.

Sample size. Sample size was ranged from 18 to 2,195 with a median of 180 and a mean of 256 (25\% of observations were based on 99 or fewer participants and $25 \%$ of 
observations were based on 291 or more participants). Coder agreement was $90 \%$.

Reliabilities of measures. The reliability of both EI and GPA were coded. For measures of EI, if a study did not provide reliability information, the average reliability from all studies that used the same measure in the current meta-analysis was imputed. If no other studies used the same measure, the reliability estimate was obtained from the test manual or original psychometric validation study. If either of these were not available, then a reliability estimate was obtained from a published, large sample study. Coder agreement for EI was $80 \%$. For academic performance indexes, very few studies reported reliabilities. Therefore, the reliability estimates were obtained from published studies on the reliability of different academic performance measures, as follows: GPA obtained from academic records (Westrick, 2017); self-reported GPA (Kuncel et al., 2005); self-reported SAT or other equivalent standardized tests scores (Kuncel et al., 2005); SAT (Ewing, Huff, Andrews, \& King, 2005); and American College Test (ACT, 2014).

Standard deviation of EI. Standard deviations were recorded for EI measures to correct for range restriction. Coding agreement was $80 \%$.

Gender. Gender was coded as a continuous variable using percentage (\%) of female participants in each citation. This value ranged from $0 \%$ to $100 \%$, with a median of $61 \%$. Coder agreement was $95 \%$.

Ethnicity. Ethnicity was coded as a continuous variable using percentage (\%) of White participants in each citation. This was only coded for samples from the USA, where ethnicity was commonly reported using the same categories. Most observations $(k=520$ of 558) reported this information. Percentage White ranged from $0 \%$ to $100 \%$ with a median of $52 \%$ and a mean of $51 \%$.

Age. Mean sample age of participants was coded as a continuous variable, and ranged from 7.68 to 40 years, with a median of 19.52. Coder agreement (to the nearest whole number 
of age in years) was $98 \%$. If the study did not report mean age, but gave an age range, the median age in the range was used. For studies that did not report an age mean or range, the mean age was imputed based on an average of the mean ages in other studies that included participants at a similar academic level (Poropat, 2009).

EI stream. EI stream was coded into three categories: Ability EI $(31 \%, k=399)$, Selfrated EI $(13 \%, k=161)$ and Mixed EI $(56 \%, k=716)$. Coder agreement was $100 \%$. The most commonly used tests were the EQ-i $(31.6 \%, k=403)$ and the MSCEIT $(24.1 \%, k=307)$.

EI facet. Effects were coded as representing one of the four ability facets (Perception, Facilitation, Understanding, and Management) five Bar-On-s EQ-i facets (Intrapersonal, Interpersonal, Stress Management, Adaptability, General Mood), or Overall EI. Other facets of EI were not coded. Coder agreement was 95\%.

Educational level. Educational level was coded as a categorical moderator with three levels: primary $(7.6 \%, k=97)$, secondary $(32.3 \%, k=412)$, or tertiary $(59.6 \%, k=761)$. One study (Alumran \& Punamaki, 2008) used a mixed sample of secondary and tertiary students, and so was excluded from the relevant moderator analyses. Coder agreement was $99 \%$.

Type of academic performance measure. This variable was coded as a categorical moderator with two levels: course grade (e.g., GPA, semester course grade, and school subject mark; 83.9\%, $k=1071)$ and standardized test score (e.g., SAT and GRE; $16.1 \%, k=$ 205). Coder agreement was $96 \%$.

Publication format. This variable was coded as a categorical moderator with 4 levels: peer-reviewed articles $(54.5 \%, k=696)$, conference proceedings $(3.7 \%, k=47)$, dissertations $(38.1 \% ; k=486)$, and unpublished data $(3.7 \%, k=47)$. Coder agreement was $100 \%$.

Subject area. The subject area was coded as general (for overall GPA or standardized test covering both numeracy and literacy areas) $(54.3 \%, k=694)$, as mathematics/science $(21.1 \%, k=267)$, or as humanities/arts $(23.4 \%, k=299)$. 


\section{Statistical analyses}

Prior to calculating mean sample-weighted correlations, effect sizes were corrected for: (a) unreliability in academic performance, (b) range restriction in EI, and (c) unreliability in EI. We used the formulae and processes outlined in Hunter, Schmidt, and Le (2006) for direct range restriction. This equation uses mu (the ratio of the sample to population standard deviation). For citations where mu could not be calculated (because sample or population standard deviation was not available), we imputed a value of mu equal to the mean mu for other studies in the same stream and stage of education.

Outliers for each meta-analysis were detected and removed using Hoaglin and Iglewicz's (1987) outlier labeling rule, using the more conservative multiplier of $g=2.2$. When interpreting the effect size, we used Cohen's $(1962,1988)$ benchmarks of $.10, .30$ and .50 for small, medium, and large.

We used Robust Variance Estimation (RVE) to control for dependencies between effect sizes (Hedges, Tipton, \& Johnson, 2010). Most citations we located report more than one effect size. Including multiple effect sizes from the one citation can be problematic due to the potential for dependencies caused by theoretically irrelevant variables, such as lab specific procedures, similar participants etc. RVE is a multilevel approach that calculates standard errors that are adjusted for clustering of effect sizes (i.e. citation level clustering). We use RVE with a correlated effects structure, which stipulates that effect sizes from the same citation are likely to be correlated with each other due to erroneous study characteristics. RVE has been shown to accurately estimate effect sizes even when the precise nature of the correlation between effects is unknown (Moeyaert et al., 2017). We specified a correlation rho of .80 as is typical when the correlation between effect sizes unknown (Hedges et al., 2010). However, we also performed a sensitivity analysis which suggested none of our findings different substantially as a function of the selected rho. The multi-level 
random effect meta-analysis with RVE estimation were performed using the 'robumeta' package (Fisher, Tipton \& Hou, 2017) in R version 3.4.3 (R Core team, 2017). The R-code is provided as supplementary material. To test for the effect of publication bias we looked at funnel plots and Egger's test.

To test hypotheses 2 to 9 (testing for moderators) we conducted meta-regressions using RVE. We conducted multiple regressions simultaneously controlling for publication type, stream, sample mean age, gender composition, subject area, and performance type (Table 3). Because there was a lot of missing data for EI facet (only available for a subset of Stream 1 studies) and ethnicity (only available for USA studies), these were conducted as separate simple meta-regressions (otherwise we would have a substantially reduced $k$ and reduced power for multiple regressions). For categorical moderators (EI Stream, EI facet, publication status, education stage, and subject area of achievement), we also conducted subgroup analyses so that the relative magnitude of the difference could be easily communicated. For categorical moderators, we used contrast coding in the meta-regressions (see table note, Table 3 for details). Because age and stage of education are dependent, we only entered age into the multiple regressions, to avoid collinearity.

To test hypothesis 10 (the incremental validity of EI in predicting academic performance controlling for cognitive ability and personality), we created a correlation matrix of meta-analytic correlations (Table 4). These were drawn from: (a) the current meta-analysis (EI/academic performance and intelligence/academic performance cells) and (b) other published meta-analyses. We used this matrix to test hierarchical regression models where intelligence was entered in Step 1, the big-five personality domains in Step 2, and EI in Step 3. The harmonic mean of the sample size across all cells in the matrix was the input sample size. Regression models were run separately for the three streams of EI, and for the four branches of ability EI. It was not possible to conduct a meta-analysis of beta-weights, as only 
4 citations had conducted regressions where academic performance was regressed on all three of intelligence, big five personality, and EI. SPSS syntax for inputting these matrices and running these analyses is provided as supplementary material.

To test hypothesis 11 (the relative importance of EI in predicting academic performance as compared to intelligence and personality), we conducted relative importance analysis using the R code provided by Tonidandel and LeBreton (2011). This was conducted for each regression described above. 


\section{Results}

\section{Hypothesis 1: Overall correlation between EI and Academic Performance}

An initial multi-level random effects meta-analysis with RVE was conducted on the measurement and range corrected correlations to estimate the mean true correlation between overall EI (across all EI streams) and academic performance. Prior to conducting the analysis, 30 effect sizes were removed using the outlier labeling rule (Hoaglin \& Iglewicz, 1987). All 30 of these effect sizes had corrected correlations in excess of $\rho=.73$ (such that their inclusion would have increased the overall size of the effect). There was a significant positive correlation between overall EI and academic performance, of small to moderate effect size $(\rho=.20,95 \%$ CI $[.17, .22])$, supporting hypothesis 1 . The test for heterogeneity of effect sizes was statistically significant, $Q(1245)=18050.20, p<.001$, indicating true differences in effect sizes across samples. Moreover, the very large $I^{2}$ value of $91.41 \%$ suggests that an overwhelming amount of observed variation between samples was due to systematic between-samples variability. As such, the planned subgroup analyses and meta-regressions using RVE were conducted, testing hypotheses 2 to 9 (possible moderators of the effect). Tables 2 and 3 present the results of the moderator analyses.

\section{Hypothesis 2: Moderating Effects of EI Stream}

Subgroup analyses and meta-regressions with RVE were used to examine the moderating effect of EI stream on the association between EI and academic performance (see Tables 2 and 3). Studies using ability EI measures obtained the largest average effect size $(\rho=.24 ;$ CI: .18, .30), followed by studies using mixed EI measures $(\rho=.19 ; \mathrm{CI} . .15, .22)$, and studies using self-rated EI measures $(\rho=.12$; CI: .07, .18). Meta-regressions showed that the ability EI showed a stronger effect than the other two streams $(b=.07, p=.006)$, supporting hypothesis 2. However, the significant heterogeneity Q statistics and high $I^{2}$ index (ranging from $85.28 \%$ to $92.39 \%$ ) suggest heterogeneity within each of the subgroups. Given 
the systematic variability between samples within each of the EI streams, and the differing theoretical meaning of the three streams, the remaining moderators were examined separately for each EI stream, as well as overall.

\section{Hypothesis 3: Moderating Effects of EI Facet}

For ability EI, there were moderate effect sizes for understanding emotions $(\rho=.35$; CI: $[.28, .43])$ and emotion management ( $\rho=.26$; CI: $[.16, .35])$, a small to moderate effect size for emotion facilitation ( $\rho=.18$; CI: $[.09, .27])$, and a small effect size for emotion perception ( $\rho=.09$; CI: $[.01, .18])$ (see Table 2$)$. Follow-up tests of moderation used multi-

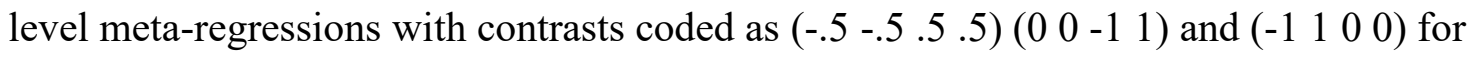
Perception, Facilitation, Understanding, and Management respectively. Because only a subset of studies reported branch-level effects, this analysis was run separately to the regression shown in Table 3 (so as not to reduce power). Results showed that the effect size was significantly larger for strategic EI (understanding and management), compared with experiential EI (perceiving and facilitation) $(b=.16, \mathrm{SE}=.04,95 \% \mathrm{CI}: .08$ to $.24, p<.001)$. This regression also controlled for publication type, age, gender composition, subject area, and performance type. This supports hypothesis 3 . The effect was not significantly different for understanding versus management branches $(b=-.03, \mathrm{SE}=.04,95 \% \mathrm{CI}:-.07$ to $.01, p=.157)$, nor for perception versus facilitation branches $(b=.03, \mathrm{SE}=.04,95 \% \mathrm{CI}$ : -.05 to $.12, p=.408)$.

\section{Hypothesis 4: Moderating Effect of Publication Status}

As can be seen in Tables 2 and 3, publication format (published versus unpublished) did not significantly moderate the effect of EI on academic performance. The effect size was larger for published than unpublished research in the case of ability and self-rated EI, the differences were mostly very small $(\Delta \rho=.01, .07, .03$, and .01 for overall EI, ability EI, selfrated EI and mixed EI respectively). The meta-regressions indicated no significant difference 
between published versus unpublished citations for all streams and for overall EI. That is, there is no evidence for the file drawer effect (selective publication) for included studies. In addition, we further explored the possibility of publication bias by inspecting funnel plot asymmetry (see Figure 2). No visual signs of asymmetry were noted, and an Eggers test suggested that there was no significant asymmetry $(z=-1.5788, p=0.11)^{1}$. Collectively, the results do not support Hypothesis 4 (that there would be selective publication such that published articles showed a higher effect size than unpublished studies).

\section{Hypothesis 5: Moderating Effect of Age}

As shown in Table 2, effect sizes tended to be smaller for tertiary samples as compared to primary or secondary samples. This was true for overall EI $(\rho=.16, .23$ and .22 for tertiary, secondary, and primary respectively), ability EI $(\rho=.18, .30$ and .29$)$ and mixed EI $(\rho=.17, .20$ and .20$)$ but not self-rated EI $(\rho=.10, .14$ and .07$)$, although confidence intervals overlapped in all cases. When we tested the effect of sample mean age using metaregressions, the effect of age was not significant for overall EI or for any of the three streams. Taken together, results do not support Hypothesis 5, showing no moderating effect of age.

\section{Hypothesis 6: Moderating Effect of Type of Achievement}

As shown in Table 3, the meta-regressions revealed showed that achievement type (course grade versus standardized test) was a significant moderator for overall EI $(b=-.07, p$ $=.045)$ and for self-rated EI $(b=-.22, p=.02)$, but not for ability EI or mixed EI. The effect was in the same direction mixed EI, but the difference was not significant. There were stronger effects for grades than standardized tests for overall EI ( $\rho=.20$ versus .17), selfrated EI $(\rho=.13$ versus -.03$)$, and mixed EI $(\rho=.20$ versus .10$)$ but not ability EI $(\rho=.24$ versus .24). Taken together, hypothesis 6 received partial support.

\footnotetext{
${ }^{1}$ As Egger's test has not been implemented with robust variance estimation, we therefore calculated Egger's test using a meta-regression with the standard error of the effect size as a predictor variable.
} 


\section{Hypothesis 7: Moderating Effect of Gender Composition}

Table 3 shows the results of moderator analyses using meta-regressions for gender composition. In interpreting results, we note that gender composition was not distributed evenly across the studies — studies tended to have more females than males. The median proportion of females was 0.61 , and only $17.6 \%$ of studies had more males than females. For overall EI, the simple meta-regression $(b=-.002, p=.026)$ showed a significant effect of gender, with a higher percentage of females associated with lower effect size. Gender composition was not significant moderator for any of the streams individually. This result provides partial support for hypothesis 7 , showing a small effect such that samples with larger proportions of females showed weaker effects than more gender-diverse samples when all streams were considered together.

\section{Hypothesis 8: Moderating Effect of Ethnic Composition}

A simple meta-regression $(k=522)$ suggested that the ethnic composition of the sample (percentage White) was not statistically significant, either for overall EI $(b=.001, p$ $=.219)$ ability EI $(b=-.001, p=.289)$; self-rated EI $(b=.002, p=.258)$ or mixed EI $(b$ $=.000 ; p=.863)$. Therefore, hypothesis 8 was not supported. The EI/academic performance association does not appear to be affected by the proportion of minority students in the sample.

\section{Hypothesis 9: Moderating Effect of Subject Area}

As shown in Tables 2 and 3, subject area (math/science versus humanities) is a significant moderator of the EI/performance relationship for ability EI only $(b=.08, p=.04)$, where effects are stronger for humanities $(\rho=.38)$ than for math/science $(\rho=.21)$. The effect was not significantly different for math/science versus humanities for overall EI, self-rated EI, or mixed EI. Results therefore provide partial support for Hypothesis 9. 


\section{Hypothesis 10: Incremental prediction of EI to academic performance The Relationship between IQ and EI}

In addition to the above meta-regressions, we examined the relationship between intelligence and academic performance from the studies included under the current search criteria, in order to draw comparisons with EI. For the intelligence/academic performance effect, there were 23 studies with 84 effect sizes and 4,801 participants. Intelligence showed a moderate to large association with academic performance $\left(\rho=.39\right.$, CI $[.31, .46], p<.001, I^{2}$ $=89.98 \%$ ). This value is larger than that reported by Poropat (2008) where there was no correction for range restriction, but smaller than that reported by Roth et al. (2015) where only primary and secondary education samples were included. We will use this value of $\rho$ $=.39$ to assess the incremental validity of EI over-and-above intelligence and big five personality in the analyses below.

\section{Incremental prediction of EI to academic performance}

Table 4 shows the meta-analytic correlation matrix we derived from our original meta-analyses and previously published estimates. We used this matrix to conduct multiple regressions predicting academic performance from intelligence, personality and EI for each of the three EI streams. We checked multi-collinearity using tolerance values in each case. Tolerance values were acceptable for all three streams, ranging from .70 to .91 for ability EI, .70 to .92 for self-rated EI, and .58 to .92 for mixed EI. Intelligence, personality and EI predicted $24.0 \%$ of the variation in academic performance for the ability EI analysis, $22.9 \%$ of the variance in academic performance for the self-rated EI analysis, and $24.6 \%$ of the variance in academic performance for the mixed EI analysis (see Table 5). Ability EI and mixed EI showed modest incremental prediction $\left(\Delta R^{2}=.017\right.$ and .023 respectively $)$ and selfrated EI showed negligible incremental prediction $\left(\Delta R^{2}=.007\right)$. Partial correlations of EI with academic performance were significant at $p<.001$ in all cases, and were .148 for ability 
EI, .092 for self-rated EI, and .248 for mixed EI. These results provide support for hypothesis 10 , although the size of the incremental prediction was very small.

We conducted these regressions separately for each of the four branches of ability EI. Results of these analyses are shown in Table 6. The understanding emotions branch showed the strongest incremental prediction $\left(\Delta R^{2}=.039\right)$, followed by emotion management $\left(\Delta R^{2}\right.$ $=.036$ ). Both emotion perception and emotion facilitation showed negligible incremental prediction of academic performance $\left(\Delta R^{2}=.000\right.$ for emotion perception and .009 for emotion facilitation). Partial correlations of the ability EI branches with academic performance were significant for facilitation $(r=.108, p<.001)$, understanding $(r=.223, p<.001)$, and management $(r=.216, p<.001)$, but not for perception $(r=-.017, p=.074)$. These results demonstrate that the active ingredients of EI for academic performance are emotion understanding and emotion management. They also demonstrate that the strong effect of emotion understanding on academic performance cannot be explained solely by its overlap with intelligence.

\section{Hypothesis 11: The most important predictors of academic performance will be intelligence, conscientiousness, and EI}

Tables 5 and 6 show the relative weights and the corresponding percentage of $R^{2}$ explained by each variable in the regressions, as determined by relative weights analysis. For all three streams: (a) intelligence was the most important variable (accounting for between $58 \%$ and $69 \%$ of the explained variance); (b) conscientiousness the second-most important (accounting for between $20 \%$ and $21 \%$ of the explained variance); and (c) EI the third-most important variable. The relative importance of EI was greater for mixed EI (RW\% $=15 \%)$ than self-rated $(\mathrm{RW} \%=10 \%)$ than ability EI $(\mathrm{RW} \%=4 \%)$.

However, results were very different across the four branches of ability EI. While intelligence remained the most important predictor in all cases, EI was the second most 
important predictor for both emotion understanding (RW\% $=31 \%$ for EI versus $19 \%$ for conscientiousness) and emotion management (RW\% $=20 \%$ for EI versus $19 \%$ for conscientiousness). Relative importance was lower for emotion facilitation (RW\% $=9 \%$ ) and negligible for emotion perception $(\mathrm{RW} \%=1 \%)$. It is clear that the strategic branches of EI (emotion understanding and management) are more important than the experiential branches (perception and facilitation).

Taken together, these results provide support for hypothesis 11, showing that EI is among the top 3 most important predictors of academic performance. However, this analysis also highlights that results are quite different for different streams and different branches of EI. 


\section{Discussion}

Results from these meta-analyses demonstrate that EI shows a small to moderate relationship with academic performance, of similar effect size to well-known non-cognitive predictors (e.g., $\rho=.20$ for EI versus $\rho=.22$ for conscientiousness, based on the current meta-analysis and Poropat [2009]). Ability EI was a significantly stronger predictor than selfreport or mixed EI, as hypothesized. Within ability EI, understanding and management branches had a stronger effect than perception or facilitation branches. There is no evidence for selective publication of larger effects, for stronger effects in younger students, nor that effects differ depending on the proportion of ethnic minority students in the sample. For the other moderators, effects were mixed or limited. There is limited evidence that the effect is stronger: (a) for less female-dominated samples (this effect was significant for total EI, but not for any of the three streams); (b) for grades than standardized test scores (this was significant for total EI and Stream 2 only); and (c) for humanities versus mathematics/science performance (this was significant for ability EI only).

There was evidence of incremental validity of EI over intelligence and personality, but this was largely restricted to mixed EI (which explained an additional $2.3 \%$ of the variance) and the understanding and management branches of ability EI (which explained an additional $3.9 \%$ and $3.6 \%$ of the variance respectively). That is, self-rated EI, total ability EI, and the lower two branches of ability EI (emotion perception and facilitation) provide little to no explanatory power for academic performance over intelligence and personality. These differences across the three streams suggest that the underlying mechanisms accounting for the EI/performance relationship may differ for ability EI, self-rated EI, and mixed EI.

\section{Why does EI predict academic performance? Insights based on moderators}

In our introduction, we suggested there were three reasons why EI may predict academic performance. First, students with higher EI may be more able to regulate the 
negative emotions such as anxiety, boredom and disappointment involved in academic performance. If this is true, emotion management would be responsible for the effects. Second, students with higher EI may be better able to manage the social world around them, forming better relationships with teachers, peers, and family. If this was the case, emotion management would again be responsible for the effect, and the effect would be stronger for grades than for standardized tests. Third, EI competencies may overlap with the academic competencies required for humanities subjects like history and language arts (e.g., understanding human motivations and emotions). In this case: (a) understanding - the knowledge base of EI—would show the strongest effect and (b) the effect would be bigger for humanities than sciences. Based on the significant moderations, there is some support for each of these effects, with slightly different results for different streams of EI. We discuss the significance moderations below, with respect to these three proposed mechanisms.

Evidence for Mechanism 1: Is 'emotion management' the key ingredient in EI? Joseph and Newman (2010) proposed a "key conceptual role" of emotion management for predicting job performance (p. 69), proposing emotion management as the proximal predictor of performance. The facet-level moderation for ability EI provides partial support for this assumption, finding that management and understanding are jointly the strongest predictors of academic performance. Both these branches (management and understanding) showed significantly stronger effects than the two other branches. The effect was larger for understanding than management, but not significantly so ( $\rho=.35$ versus $\rho$ $=.26$ ) and was equal after accounting for the effects of intelligence and personality (partial $\rho$ $=.22$ in both cases). That is, both emotion understanding and emotion management are active ingredients in the prediction of academic performance. We believe this is consistent with an interpretation that EI affects academic performance through the regulation of academic emotions, but also due to the relevance of emotion content knowledge for academic 
performance in the humanities.

The critical role of emotion understanding for academic performance has implications for comparing ability EI with self-rated EI. For self-rated EI, many of the effects in our metaanalysis used instruments that did not include emotion understanding content (because they were based on an older definition of EI that did not have emotion understanding in the definition). Specifically, 50\% of the Stream 2 citations used the Schutte Self-Report Scale, Trait Meta-Mood Scale or the Wong-Law Emotional Intelligence Scale, which do not include a subscale assessing emotion understanding. Given that ability EI shows the strongest relationship for emotion understanding, the difference in effect size between ability EI and self-rated EI measures may in fact represent a difference in content (i.e., prediction is greater for tests that include emotion understanding content) rather than a difference in method (ability scales versus rating-scales). Many of the more recent self-rated EI tests $d o$ include an emotion understanding component (e.g., Anguiano-Carrasco, MacCann, Geiger, Seybert, \& Roberts, 2015; Brackett et al., 2006).

\section{Evidence for Mechanism 2: Are EI competencies required for academic content?}

Moderation analyses largely support the idea that performance on academic tasks require some EI competencies. First, academic performance related significantly more strongly to ability EI than to the other two streams. This finding differs from meta-analyses predicting job performance, where ability EI is consistently the weakest predictor of the three streams (Joseph \& Newman, 2010; Miao et al., 2017; O'Boyle et al., 2011). This difference may relate to assessment methods. Academic performance is mainly assessed with objective tasks (i.e., evaluations of a product, such as an essay, lab report, speech, worksheet or test), whereas job performance is most often assessed via supervisor ratings. Similarly, ability EI is assessed with objective tasks and self-rated and mixed EI are assessed with rating scales. We would expect stronger predictor-criterion relationships when predictor and criterion have the 
same method. As such, a higher relationship for ability EI (as compared to the other streams) may represent method bias rather than content overlap of academic and emotional knowledge.

However, ability EI (but not self-rated or mixed EI) relates more strongly to performance in humanities than sciences. This is one of the larger differences we found, where the effect was nearly twice as large for humanities as sciences $(\rho=.38$ versus .21$)$. Objective measurement of performance is similar across humanities and sciences. The academic processes (social context and the student's emotions and emotion regulation in the classroom) are also similar for different sub-disciplines. While sub-disciplines differ in the degree of social interaction involved, the degree of social interaction does not align with the humanities versus science categorization (e.g., science frequently involves lab partners or group work, while this is rare for mathematics). As such, we interpret this difference in subject areas to be largely due to a difference in academic content, and specifically the relevance of emotion knowledge to subjects requiring an understanding of people and their interactions, motivations and emotions (i.e., literature, history, geography, drama and other humanities subjects). The first standard of The Standards for the English Language Arts (1996), as put forward by the National Council of Teachers of English, states that the purpose of reading texts is to "build an understanding of ... themselves and the cultures of the United States and the world" and the second standard states that the purpose is "to build an understanding of the many dimensions (e.g., philosophical, ethical, aesthetic) of human experience" (p. 19). That is, broad statements of content for achievement in language arts inherently involve an understanding of oneself and of others in terms of the intangible nature of being human — which we would argue is essentially emotions and social interactions. That is, understanding human emotions and the social and situational causes appear to be an underlying component of achievement in language arts. 
In addition, the fact that the emotion understanding showed the strongest relationship to academic performance (as compared to the other four branches) supports the interpretation mentioned above, where understanding emotional content is a key part of the content of language arts education. It is possible to view emotion understanding as a kind of domainspecific knowledge, where the content domain is emotions. Content knowledge of emotion words, as well as the causes and consequences of emotions, appear highly relevant for understanding character motivations in literature as well as other academic subject matter relating to people and how they shape societies, countries and history (i.e., history, geography, psychology, sociology).

One possible interpretation is that the ability EI/academic performance association may be due to a third variable — reading comprehension. Because ability EI tests involve interpreting written text, reading comprehension ability may constitute construct-irrelevant variance on such tests (AERA, APA, \& NCME, 2014) that may partially explain the relationship between EI and academic performance. This particularly affects understanding and management tests, which involve more and more complex text (e.g., most management tests involve a paragraph of text in each item stem). However, the fact that emotion understanding and management predicted academic performance over-and-above the effect of intelligence suggests that this confound does not account for the entirety of the relationship between ability EI and academic performance. Nevertheless, the relationship was greatly reduced, particularly for emotion understanding. Because the partial correlations remained of small to moderate size after accounting for intelligence, our interpretation is that the bulk of the content overlap represents more than a reading comprehension method effect, particularly for emotion management. Taken together, results support the suggested mechanism whereby EI predicts academic performance due to the emotional content required in academic subjects. 


\section{Evidence for Mechanism 3: Does EI affect academic performance through}

\section{interpersonal processes?}

If EI exerts an influence on academic performance via the ability to develop social relationships in the educational context, then EI should have a stronger effect on grades than standardized tests (as the social networking and relationship building with other students and teachers should have a stronger effect on grades than on standardized tests). This difference was significant only for self-rated EI and the three streams combined (not for ability or mixed EI). Self-rated EI did not relate to standardized test scores at all $(\rho=-.03)$. In contrast, ability EI and mixed EI related to both grades and standardized tests. This suggests that academic performance relates to self-rated EI through relationship building only. In contrast, academic performance relates to ability EI and mixed EI through both relationship building and mechanisms related to regulating academic emotions.

For all three streams of EI, there is evidence that higher EI relates to building social relationships in a school environment. Ability EI relates to peer-nominations of reciprocal friendship in college students and to higher-quality of social interactions with others (Lopes, Brackett, Nezlek, Schütz, Sellin, \& Salovey, 2004; Lopes, Salovey, Côté, Beers, \& Pett, 2005). Self-rated EI predicts greater social support in both high school and university students (Ciarrochi, Chan, \& Bajgar, 2001; Kong, Zhao, \& You, 2012). Mixed EI is associated with peer reports of cooperative behavior (Mavroveli, Petrides, Rieffe, \& Bakker, 2007; Petrides, Sangareau, Furnham, \& Frederickson, 2006). There is also evidence that both ability EI and mixed EI relate to using more effective strategies to regulate negative emotions (Peña-Sarrionandia, Mikolajczak, \& Gross, 2015).

Taken together with these findings, we propose that differences between the three streams of EI relate to the number of mechanisms that underlie the EI/performance relationship. Specifically: (a) self-rated EI predicts academic performance only through a 
relationship building pathway (students with higher emotional self-efficacy can build better relationships with teachers and peers); (b) mixed EI predicts academic performance through both relationship building and the regulation of academic emotions; and (c) ability EI predicts academic performance through relationship building, regulation of academic emotions, and also through emotion content knowledge requirements of some academic areas. This explanation accounts for the relatively greater prediction of academic performance by ability EI than mixed EI than self-rated EI and is consistent with the pattern of moderators we found.

\section{The Relative Importance of EI to Academic Achievement}

One of the critical drivers of EI's early popularity was the idea that emotional skills are more important than intelligence in predicting life success. Indeed, the title of Daniel Goleman's first book, the catalyst for EI's snowballing popularity, was "Emotional intelligence: Why it can matter more than IQ". The 1995 cover story of TIME magazine made similar claims, stating that "emotions, not IQ, may be the true measure of human intelligence" (Gibbs, 1995, p. 60). These early claims were generally not borne out by research on job performance. Although EI predicts better job performance (Joseph \& Newman, 2010; O’Boyle et al., 2011), a critical mass of research indicates that intelligence is a much stronger predictor and is in fact the single best predictor of job performance (Ree \& Earles, 1992; Salgado et al., 2003; Schmidt \& Hunter, 1998). We found largely similar results for academic performance. Although EI predicts academic performance, intelligence was a much stronger predictor, with relative importance analysis indicating that cognitive ability was the single most important predictor of academic performance.

While the popular press hype about EI was not substantiated, we nevertheless believe that demonstrating a small to moderate effect size is informative for research and practice. Moreover, some of the recent changes occuring in education and assessment practices may increase the importance of noncognitive qualities, including EI. 
The first such change to modern assessment and learning practice is the increasing use of group activities, including collaborative group assessments (Ahles \& Bosworth, 2004). Managing the social relationships and interpersonal conflicts of the group may thus become more and more reflected in students' end of semester grades. A second change to education practices is the extent to which graduate attributes (also referred to as 'twenty-first century skills' or 'non-cognitive constructs') are emphasized by schools and universities (e.g., Clarke, Double, \& MacCann, 2017). Graduate attributes often include social-emotional skills such as leadership, communication, teamwork and inter-cultural competencies, with some institutions explicitly including EI as a graduate attribute. For example, Australia uses Goleman's model of EI as the basis for its national K-10 curriculum of personal and social competencies that students should be developing as they progress through primary and secondary education (ACARA, 2017). Schools and universities are increasingly attempting to embed these graduate qualities within the content that is taught and assessed. As such, high grades might increasingly reflect skill development in these areas.

A third change to the classroom is the extent to which computers and technology are now an integral part of education. In tertiary education, there are a large and increasing number of online only courses or courses that have at least some online-only content (most famously, the Massive Open Online Courses [MOOCs]). There are two main differences between traditional face-to-face learning and online learning. First, in a traditional face-toface university course, the schedule of learning is set by the schedule of the face-to-face lectures. In contrast, an online only course requires the learner to manage their own schedule of accessing online content, such that students with poor time management will not succeed (MacCann, Fogarty, \& Roberts, 2012). Second, in a traditional face-to-face course, communication with teachers and other students occurs through in-person conversation, with access to multiple channels of information (e.g., facial and vocal expression, body language, 
and real-time clarification of misunderstandings). Online communication is more often based on text (e.g., discussion boards, emails, or computer chat). Most neurotypical people find it more difficult to detect another person's emotions and social needs from text rather than faceto-face contact. As such, greater emotional skills are required to build relationships with the instructor or other students in an online environment. Thus, social and emotional skills (both self-regulation and interpersonal skills) may become increasingly important as tertiary education involves a greater amount of online content.

\section{Practical Implications}

One of the major findings of this meta-analysis is that different parts of EI are differentially important for academic performance. Any applied uses of EI in education seem limited to the three parts of EI with non-trivial incremental validity: mixed EI, emotion management ability, and emotion understanding ability. There are three broad applications that might be considered: (a) identifying students at risk for failure, attrition, or underperformance; (b) selection decisions for high-stakes educational opportunities; and (c) policy decisions about the relative cost versus benefit of implementing SEL or EI training programs in schools.

The first two applications (identifying at risk students, and high-stakes selection) require careful consideration of response distortion issues. Particularly in a high-stakes selection context, test-takers are motivated to gain high scores and will distort their responses on rating scales to 'fake high' (Birkeland, Manson, Kisamore, Brannick, \& Smith, 2006; Viswesvaran \& Ones, 1999). Faking is a consequential issue with personality scales, which use self-report or observer-report ratings that test takers can fake. Observer-reports do not necessarily solve this problem, as the observers are often not impartial, but may be school staff with a vested interest in their students gaining entrance to prestigious colleges or programs. Faking is a problem for rating-scale measures of EI, but not for ability scales (Day 
\& Carroll, 2008; Grubb \& McDaniel, 2007; Tett, Freund, Christiansen, Fox, \& Coaster, 2012). The current meta-analysis is the first to demonstrate that the relationship between EI and academic performance holds for ability-based tests as well as rating scales (in fact, the relationship is actually higher for ability-based EI tests as compared to rating scales). As such, we demonstrate a pathway that might provide modest increments in high-stakes education selection decisions_- using ability-based EI assessments of understanding and managing emotions (based on current results, other parts of ability EI are not important). Ability-based EI tests are already used for selection into medical schools in several countries, and evidence supports their use for selecting better candidates (Libbrecht, Lievens, Carette, \& Cote, 2014; Lievens \& Sackett, 2006). However, such tests are rarely used in other broader education selection contexts. If EI is considered as a selection procedure (perhaps as an addon to intelligence and personality assessment), we suggest that ability tests of understanding and managing emotions be preferred over rating scales (due to response distortion) or tests of facilitation or management (due to low incremental prediction over intelligence and personality).

A national and international focus on standardized tests to measure academic performance and milestones has lead schools, districts, states and countries to focus on achievement in the narrow range of academic content that such tests focus on. Alongside this, classroom teachers face increasing challenges to their workload, including adapting the curriculum to individual students' needs, the mainstreaming of students with special educational requirements, and adapting to rapidly changing curriculum and policy (Skaalvik \& Skaalvik, 2007). Against this background, devoting resources to teaching children EI skills can be seen as taking teacher resources and classroom time away from more critical activities that will increase test scores and achievement. What our meta-analysis shows is that EI skills are in fact associated with higher academic performance. This implies that time spent 
teaching EI skills may not necessarily detract from student achievement, given that higher EI students also show higher achievement. Again, we highlight different importance of the four EI abilities as a guide for where to focus skills training - a focus on perceiving emotions is likely to be less useful than a focus on understanding and managing emotions.

Our meta-analysis also has implications for the effects of the such training programs (or a focus on EI more generally) on the known achievement gaps between ethnic groups and between males and females. While there is evidence that the Black-White achievement gap is slowly closing, differences in the achievement for minority students compared to White students remain substantial, at around 0.75 standard deviations for Black students and around 0.60 standard deviations for Hispanic students (Hansen, Mann Levesque, Quintero, \& Valant, 2018). There is also increasing evidence that males are falling behind females in terms of the grades they receive and their participation in higher education (Fortin, Oreopoulos, \& Phipps, 2015). Against this background, it is important to note that the effect of EI on academic performance does not appear to differ for minority students versus White students, and that gender differences are negligible and when significant favor males (who currently show lower achievement). These results imply, at the very least, that efforts to improve EI are unlikely to widen the achievement gaps.

The key role of emotion understanding and management is also important to consider in terms of EI training programs. Three recent meta-analyses on the effectiveness of EI training have reported significant increases in EI, with effect sizes of $.45, .46, .51$, and .61 (Hodzic, Scharfen, Ripoll, Holling, \& Zenasni, 2018; Mattingly \& Kraiger, 2018; Schutte, Malouff, \& Thorsteinsson, 2013). Hodzic et al. found that programs based on the ability model were significantly more effective than those based on mixed models $(g=.60$ versus .31), and that emotion understanding showed the largest increase of all the ability EI branches - significantly more than emotion facilitation $(g=.69$ versus .42$)$. That is, it seems 
that programs are effective for increasing ability EI, and particularly its emotion understanding facet. This is highly relevant for our own meta-analysis, where ability EI (and specifically emotion understanding) showed the highest association with academic performance. That is, EI training seems to produce the strongest increases in exactly those competencies that are most relevant for academic performance.

Although Hodzic et al. did not distinguish between EI training programs for workplace applications and EI training programs for schools and universities, several studies conducted in schools and universities report similar findings regarding the largest increases for emotion understanding. For example, Pool and Qualter (2012) conducted a training study in university students and found the largest increase in ability EI was for emotion understanding (and the second-largest for emotion management). Moreover, evidence from the RULER Feeling Words curriculum (an EI development program for secondary school students) shows that EI training programs increase grades as well as social and emotional competencies. Specifically, students completing the RULER showed improved school grades as well as improved teacher ratings of social and emotional competencies compared to control groups (Brackett, Rivers, Reyes, \& Salovey, 2012). In fact, the relative increase in school grades was a larger effect than the relative increase in social and emotional competencies. That is, EI training programs are likely to increase academic performance as well as social and emotional outcomes, such that education decision-makers and policymakers are not faced with a decision of whether to invest in social/emotional wellbeing at the expense of student achievement — evidence suggests that these programs likely do both. This is a critical piece of information for schools deciding where to best allocate their resources.

\section{Limitations}

Our results demonstrated only that EI and academic performance are significantly associated, but not that higher EI causes higher achievement. Only three of the citations 
reported a longitudinal design, such that the empirical evidence for EI causing later achievement is very weak (Costa \& Faria, 2015; Qualter et al., 2012; Stewart \& Chrisholm, 2012). This association could occur because: (a) higher EI causes increased academic performance; (b) higher achievement causes increased EI; or (c) there are one or more variables that influence both EI and academic performance. In the introduction, we outlined the reasons we believe theoretically that EI could cause later achievement. However, there are also feasible pathways by which greater academic performance could cause higher EI. Greater academic performance could feasibly result in increased self-esteem, greater opportunities for social and emotional development, and higher expectations for social skills and emotion regulation. High academic performance may act as a gateway for gifted and talented programs, streaming into enrichment activities, and a culture of high expectations from teachers, parents, and communities that permeate social and emotional behaviors as well as academic ones via the halo effect (Nisbett, \& Wilson, 1977). Conversely, low academic performance may act as a barrier to opportunities to develop social and emotional skills through loss of privileges for academic failures (e.g., losing recess playtime or evening socialization to complete work or denied extra-curricular activity participation due to course failure), the development of strong negative emotions surrounding school and schoolwork, and the correspondingly low expectations for social and emotional behaviors. It seems likely that the reality is complex, with bidirectional effects of academic and emotional development, particularly in the earlier years of school.

One further limitation of the current manuscript concerns the use of the meta-analytic correlation matrix (used to test hypotheses 10 and 11). This was composed of estimates taken from different journal articles from different research teams, and therefore did not use the same methods for estimation nor the same samples. While we used RVE in the current study, all other sources for effect sizes were obtained by aggregating multiple effect sizes from the 
same study. All studies except for Poropat (2009) corrected for unreliability as well as range restriction. The personality/academic performance estimation was not corrected for range restriction of measurement in either the predictor or criterion (Poropat, 2009). The possible effect of this would be to under-estimate the prediction and relative importance of personality traits such as conscientiousness.

\section{Future research and recommendations}

One obvious future direction for further research is to test our three proposed mechanisms of the EI/performance relationship: (a) social relationship building, (b) regulation of academic emotions, and (c) content overlap between EI and academic subject matter. For point a, an analysis of content overlap between the competencies of EI and the different processes required for success in different disciplines could be undertaken by a panel of educators. Longitudinal research involving all three streams could test whether all three mediate ability EI, (a) and (b) mediate mixed EI, and (a) along mediates self-rated EI, as we proposed. As we mention above, there is a paucity of long-term longitudinal research on EI and academic performance. As such, examining mediators of the link as well as conducing lagged panel models to tease apart the direction of causation is important.

While there is ample evidence that training EI works (e.g., Hodzic, Scharfen, Ripoll, Holling, \& Zenasni, 2018; Mattingly \& Kraiger, 2018; Schutte, Malouff, \& Thorsteinsson, 2013), we are not aware of experimental studies on EI training that examine the effects of training different branches of EI. Such designs would isolate which facets of EI are most relevant for the improvement of which types of outcomes and would also provide stronger evidence for the causal direction from EI to academic performance.

\section{Conclusion}

While we know that intelligence and conscientiousness are collectively the most important psychological characteristics needed for academic performance, this manuscript 
highlights that there is a third broad psychological characteristic that may help students succeed-EI. The different varieties of EI most likely predict academic performance via different pathways. Emotional self-efficacy (the self-beliefs about one's emotional skills captured by self-rated EI) is the least important. Knowledge about the causes and consequences of emotions and a vocabulary of emotions words, along with knowing how to manage emotional situations are potentially the most important parts of EI for academic performance. It is not enough to be smart and hard-working - to have the added edge for success, students must also be able to understand and manage emotions to succeed at school. 


\section{References}

* References included in the meta-analysis are marked with an asterisk

*Abdo, N. (2012). Academic performance and social/emotional competence in adolescence. (Unpublished doctoral dissertation). Yeshiva University, New York City, NY.

*Abdullah, M. C., Elias, H., Mahyuddin, R., \& Uli, J. (2004). Emotional intelligence and academic achievement among Malaysian secondary students. Pakistan Journal of Psychological Research, 19(3-4), 105-121. Retrieved from http://www.pjprnip.edu.pk/pjpr/index.php/pjpr

*Abel, N. R. (2014). Trait emotional intelligence, perceived discrimination, and academic achievement among African American and Latina/o high school students: A study of academic resilience. (Unpublished doctoral dissertation). Minnesota State University, Mankato, MN.

ACARA. (2017). Australian curriculum: Personal and social capability learning continuum: Retrieved 6 December 2017, from http://docs.acara.edu.au/resources/General_capabilities_PSC_learning continuum.pdf

ACT. (2014). American College Test (ACT). Iowa City: Research Services, ACT.

*Adeyemo, D. A. (2007). Moderating influence of emotional intelligence on the link between academic self-efficacy and achievement of university students. Psychology and Developing Societies, 19, 199-213. https://doi.org/10.1177/097133360701900204

AERA, APA, \& NCME. (2014). Standards for Educational and Psychological Testing. Washington, DC: AERA.

*Afolabi, O. A., Ogunmwonyi, E., \& Okediji, A. (2009). Influence of emotional intelligence and need for achievement on interpersonal relations and academic achievement of undergraduates. Educational Research Quarterly, 33(2), 60-72. Retrieved from http://erquarterly.org/

*Agnoli, S., Mancini, G., Pozzoli, T., Baldaro, B., Russo, P. M., \& Surcinelli, P. (2012). The interaction between emotional intelligence and cognitive ability in predicting scholastic performance in school-aged children. Personality and Individual Differences, 53, 660-665. https://doi.org/10.1016/j.paid.2012.05.020

*Ahammed, S., Abdullah, A. S., \& Hassane, S. H. (2011). The role of emotional intelligence in the academic success of United Arab Emirates university students. International Education, 41, 7-25. Retrieved from http://www.proquest.com/

Ahles, C. B., \& Bosworth, C. C. (2004). The perception and reality of student and workplace teams. Journalism \& Mass Communication Educator, 59, 42-59. https://doi.org/10.1177/107769580405900108

Ahmad, I. (2010). Trait-emotional intelligence as predictor of academic performance. Pakistan Journal of Social and Clinical Psychology, 8, 54-65. Retrieved from http://www.gcu.edu.pk/Soc\&ClinPsyJour.htm

*Ahmad, I. (2011). Psychological predictors of college students' performance. Pakistan Journal of Psychological Research, 26, 87-103. Retrieved from http://www.pjprnip.edu.pk/pjpr/index.php/pjpr

*Ahmad, I., \& Rana, S. (2012). Affectivity, achievement motivation, and academic performance in college students. Pakistan Journal of Psychological Research, 27, 107-120. Retrieved from http://www.pjprnip.edu.pk/pjpr/index.php/pjpr 
*Alhashemi, S. E. (2014). Measuring emotional intelligence of university students: A comparison between China and Bahrain. International Journal of Social and Organizational Dynamics in IT, 3(4), 59-76. https://doi.org/10.4018/ijsodit.2013100104

*Alumran, J. I., \& Punamaki, R.-L. (2008). Relationship between gender, age, academic achievement, emotional intelligence, and coping styles among Bahraini adolescents. Individual Differences Research, 6(2), 104-119. Retrieved from https://www.ncbi.nlm.nih.gov/labs/journals/individ-differ-res/

*Amdurer, E., Boyatzis, R. E., Saatcioglu, A., Smith, M. L., \& Taylor, S. N. (2014). Long term impact of emotional, social and cognitive intelligence competencies and GMAT on career and life satisfaction and career success. Frontiers in Psychology, 5, 1447. https://doi.org/10.3389/fpsyg.2014.01447

*Anand, A. F. J., Ramgopal, C. N., \& Swaminathan, V. D. (2016). Emotional intelligence and academic performance of graduate engineering students. Research Journal of Pharmaceutical, Biological and Chemical Sciences, 7(3), 2540-2551. Retrieved from https://www.rjpbcs.com/

Anguiano-Carrasco, C., MacCann, C., Geiger, M., Seybert, J. M., \& Roberts, R. D. (2015). Development of a forced-choice measure of typical-performance emotional intelligence. Journal of Psychoeducational Assessment, 33, 83-97. http://dx.doi.org/10.1177/0734282914550387

Antonakis, J., Ashkanasy, N. M., \& Dasborough, M. T. (2009). Does leadership need emotional intelligence? The Leadership Quarterly, 20, 247-261. http://dx.doi.org/10.1016/j.leaqua.2009.01.006

*Arbabisarjou, A., Maede-Sadat, R., Narges, M., \& Shekoofeh-Sadat, R. (2013). Relationship between different types of intelligence and student achievement. Life Science Journal, 10(7s), 128-133. https://doi.org/10.13140/2.1.4974.5927

*Aremu, O. A., Tella, A., \& Tella, A. (2006). Relationship among emotional intelligence, parental involvement and academic achievement of secondary school students in Ibadan, Nigeria. Electronic Journal of Research in Educational Psychology, 5, 163180. Retrieved from http://www.investigacionpsicopedagogica.org/revista/new/english/index.php

Ashkanasy, N. M., \& Daus, C. S. (2005). Rumors of the death of emotional intelligence in organizational behavior are vastly exaggerated. Journal of Organizational Behavior, 26(4), 441-452. http://dx.doi.org/10.1002/job.320

Bachan, R. (2017). Grade inflation in UK higher education. Studies in Higher Education, 42, 1580-1600. http://dx.doi.org/10.1080/03075079.2015.1019450

Bar-Haim, Y., Lamy, D., Pergamin, L., Bakermans-Kranenburg, M. J., \& van IJzendoorn, M. H. (2007). Threat-related attentional bias in anxious and nonanxious individuals: A meta-analytic study. Psychological Bulletin, 133, 1-24. http://dx.doi.org/10.1037/0033-2909.133.1.1

Bar-On, R. (2000). Emotional and social intelligence: Insights from the Emotional Quotient Inventory. In R. Bar-On \& J. D. A. (Eds.) The handbook of emotional intelligence: Theory, development, assessment, and application at home, school, and in the workplace (pp. 363-388). San Francisco, CA: Jossey-Bass; US.

Bar-On, R. (2006). The Bar-On model of emotional-social intelligence (ESI). Psicothema, 18(Suppl), 13-25.

*Barchard, K. A. (2003). Does emotional intelligence assist in the prediction of academic success? Educational and Psychological Measurement, 63, 840-858. https://doi.org/10.1177/0013164403251333

*Barisonek, E. S. (2005). The relationship between emotional intelligence, academic 
achievement and academic production among third-and sixth-grade students. (Unpublished master's thesis). State University of New York at Buffalo, New York, NY.

Barrick, M. R., \& Mount, M. K. (1991). The Big 5 Personality Dimensions and JobPerformance - a Metaanalysis. Personnel Psychology, 44, 1-26. http://dx.doi.org/10.1111/j.1744-6570.1991.tb00688.x

*Bastian, V. A., Burns, N. R., \& Nettelbeck, T. (2005). Emotional intelligence predicts life skills, but not as well as personality and cognitive abilities. Personality and Individual Differences, 39, 1135-1145. https://doi.org/10.1016/j.paid.2005.04.006

*Berenson, R., Boyles, G., \& Weaver, A. (2008). Emotional Intelligence as a predictor for success in online learning. International Review of Research in Open and Distance Learning, 9(2), 1-17. https://doi.org/10.19173/irrodl.v9i2.385

Bierman, K. L., Coie, J. D., Dodge, K. A., Greenberg, M. T., Lochman, J. E., McMahon, R. J., \& Pinderhughes, E. (2010). The effects of a multiyear universal social-emotional learning program: The role of student and school characteristics. Journal of Consulting and Clinical Psychology, 78, 156-168. https://doi.org/10.1037/a0018607

*Billings, C. E. W., Downey, L. A., Lomas, J. E., Lloyd, J., \& Stough, C. (2014). Emotional Intelligence and scholastic achievement in pre-adolescent children. Personality and Individual Differences, 65, 14-18. https://doi.org/10.1016/j.paid.2014.01.017

Birkeland, S. A., Manson, T. M., Kisamore, J. L., Brannick, M. T., \& Smith, M. A. (2006). A meta-analytic investigation of job applicant faking on personality measures. International Journal of Selection and Assessment, 14, 317-335. doi: http://dx.doi.org/10.1111/j.1468-2389.2006.00354.x

*Borin, E. B. (2013). The relationship between emotional intelligence and college success for students with learning disabilities. (Unpublished doctoral dissertation). Capella University, Minneapolis, MN.

Boulanger, F. D. (1981). Ability and science learning: A quantitative synthesis. Journal of Research in Science Teaching, 18, 113-121. http://dx.doi.org/10.1002/tea.3660180203

*Bowman, J. K. (2007). The utility of emotional intelligence as a predictor of school psychologists' clinical competence. (Unpublished doctoral dissertation), St John's University, New York Ciry, NY.

Boyatzis, R. E., Goleman, D., \& Rhee, K. S. (2000). Clustering competence in emotional intelligence: Insights from the Emotional Competence Inventory. In R. Bar-On \& J. D. A., Parker (Eds.) The handbook of emotional intelligence: Theory, development, assessment, and application at home, school, and in the workplace (pp. 343-362). San Francisco, CA: Jossey-Bass; US.

*Boyce, D. A. (2002). The correlation of emotional intelligence, academic success, and cognitive ability in master's level physical therapy students. (Unpublished doctoral dissertation). Spalding University, Louisville, KY.

*Brackett, M. A., \& Mayer, J. D. (2003). Convergent, discriminant, and incremental validity of competing measures of emotional intelligence. Personality and Social Psychology Bulletin, 29, 1157-1158. https://doi.org/10.1177/0146167203254596

*Brackett, M. A., Mayer, J. D., \& Warner, R. M. (2004). Emotional intelligence and its relation to everyday behaviour. Personality and Individual Differences, 36, 13871402. https://doi.org/10.1016/S0191-8869\%2803\%2900236-8

Brackett, M. A., Rivers, S. E., Reyes, M. R., \& Salovey, P. (2012). Enhancing academic performance and social and emotional competence with the RULER Feeling Words Curriculum. Learning and Individual Differences, 22, 218-224. http://dx.doi.org/10.1016/j.lindif.2010.10.002

Brackett, M. A., Rivers, S. E., Shiffman, S., Lerner, N., \& Salovey, P. (2006). Relating 
emotional abilities to social functioning: A comparison of self-report and performance measures of emotional intelligence. Journal of Personality and Social Psychology, 91, 780-795. http://dx.doi.org/10.1037/0022-3514.91.4.780

Brackett, M. A., Warner, R. M., \& Bosco, J. S. (2005). Emotional intelligence and relationship quality among couples. Personal Relationships, 12, 197-212. http://dx.doi.org/10.1111/j.1350-4126.2005.00111.x

*Bradshaw, F. B. (2008). Exploring the relationship between emotional intelligence and academic achievement in African American female college students. (Unpublished doctoral dissertation). College of Notre Dame of Maryland, Baltimore, MD.

Bramley, T., \& Dhawan, V. (2011). Estimates of reliability of qualifications. Coventry, UK: Office of Qualifications and Examinations Regulation.

*Brouzos, A., Misailidi, P., \& Hadjimattheou, A. (2014). Associations between emotional intelligence, socio-emotional adjustment, and academic achievement in childhood: The influence of age. Canadian Journal of School Psychology, 29, 83-99. https://doi.org/10.1177/0829573514521976

*Carrothers, R. M., Gregory, S. W., Jr., \& Gallagher, T. J. (2000). Measuring emotional intelligence of medical school applicants. Academic Medicine, 75, 456-463. https://doi.org/10.1097/00001888-200005000-00016

CASEL. (2003). Safe and Sound: An Educational Leader's Guide to Evidence-Based Social and Emotional Learning (SEL) Programs. Chicago, IL: CASEL in collaboration with the Mid-Atlantic Regional Educational Laboratory The Laboratory for Student Success. Retrieved from https://eric.ed.gov/?id=ED505372

*Castro-Johnson, M., \& Wang, A. Y. (2003). Emotional intelligence and academic performance of college honors and non-honors freshmen. Journal of the National Collegiate Honors Council, 4(2), 105-115. Retrieved from http://digitalcommons.unl.edu/nchcjournal/

*Catalina, C. C., Stanescu, D. F., \& Mohorea, L. (2012). Academic self-efficacy, emotional intelligence and academic achievement of Romanian students: Results from an exploratory study. Journal of Educational Sciences and Psychology, 2(1), 41-52. Retrieved from http://jesp.upg-ploiesti.ro/

*Cavins, B. J. (2006). The relationship between emotional-social intelligence and leadership practices among college student leaders. (Unpublished doctoral dissertation). Bowling Green State University, Bowling Green, OH.

Chaplin, T. M., \& Aldao, A. (2013). Gender differences in emotion expression in children: A meta-analytic review. Psychological Bulletin, 139, 735- 765. http://dx.doi.org/10.1037/a0030737

*Chapman, B. P., \& Hayslip, B., Jr. (2005). Incremental validity of a measure of emotional intelligence. Journal of Personality Assessment, 85, 154-169. https://doi.org/10.1207/s15327752jpa8502_08

*Cheshire, M. H., Strickland, H. P., \& Carter, M. R. (2015). Comparing traditional measures of academic success with emotional intelligence scores in nursing students. AsiaPacific Journal of Oncology Nursing, 2, 99-106. https://doi.org/10.4103/2347$\underline{5625.154090}$

*Chew, B. H., Zain, A. M., \& Hassan, F. (2013). Emotional intelligence and academic performance in first and final year medical students: A cross-sectional study. BMC Medical Education, 13, 44-54. https://doi.org/10.1186/1472-6920-13-44

Ciarrochi, J., Chan, A. Y., \& Bajgar, J. (2001). Measuring emotional intelligence in adolescents. Personality and Individual Differences, 31, 1105-1119. https://doi.org/10.1016/S0191-8869(00)00207-5

*Clark, P. R. (2004). An analysis of emotional intelligence: Its relationship to student 
performance and the implications for education. (Unpublished doctoral dissertation). Arkansas State University, Jonesboro, AR.

Clarke, I. E., Double, K., \& MacCann, C. (2017). Rethinking how we prepare students for the workforce. In J. Burrus, K. Mattern, B. Naemi \& R. Roberts (Eds.), Building Better Students: Preparation for the Workforce (pp. 229-243). New York: Oxford University Press.

*Codier, E., \& Odell, E. (2014). Measured emotional intelligence ability and grade point average in nursing students. Nurse Education Today, 34, 608-612. https://doi.org/10.1016/j.nedt.2013.06.007

Cohen, J. (1962). The statistical power of abnormal-social psychological research: A review. The Journal of Abnormal and Social Psychology, 65, 145-153. http://dx.doi.org/10.1037/h0045186

Cohen, J. (1988). Statistical power analysis for the behavioral sciences (2nd ed.). Hillsdale, NJ: Erlbaum.

* Collins, S. B. (2012). The emotional intelligence profiles and cognitive measures of nurse anaesthesia students in the South-Eastern United States (Unpublished doctoral dissertation). Andrews University, Berrien Springs, MI.

*Colston, R. (2008). The relationship between emotional intelligence and academic achievement: Implications of birth order based on social rank for nontraditional adult learners. (Unpublished doctoral dissertation). Capella University, Minneapolis, MN.

*Costa, A., \& Faria, L. (2015). The impact of emotional intelligence on academic achievement: A longitudinal study in Portuguese secondary school. Learning and Individual Differences, 37, 38-47. https://doi.org/10.1016/j.lindif.2014.11.011

*Cyr, J. (2007). Emotional intelligence as a predictor of performance in college courses. (Unpublished doctoral dissertation). Rutgers, The State University of New Jersey, New Brunswick, NJ.

Davies, M., Stankov, L., \& Roberts, R. D. (1998). Emotional intelligence: In search of an elusive construct. Journal of Personality and Social Psychology, 75, 989-1015. http://dx.doi.org/10.1037//0022-3514.75.4.989

Dawda, D., \& Hart, S. D. (2000). Assessing emotional intelligence: Reliability and validity of the Bar-On Emotional Quotient Inventory (EQ-i) in university students. Personality and Individual Differences, 28, 797-812. http://dx.doi.org/10.1016/S01918869(99)00139-7

Day, A. L., \& Carroll, S. A. (2008). Faking emotional intelligence (EI): Comparing response distortion on ability and trait-based EI measures. Journal of Organizational Behavior, 29, 761-784. http://dx.doi.org/10.1002/job.485

Deary, I. J., Strand, S., Smith, P., \& Fernandes, C. (2007). Intelligence and educational achievement. Intelligence, 35, 13-21. http://dx.doi.org/10.1016/j.intell.2006.02.001

*Di Fabio, A., \& Palazzeschi, L. (2009). An in-depth look at scholastic success: Fluid intelligence, personality traits or emotional intelligence? Personality and Individual Differences, 46, 581-585. https://doi.org/10.1016/j.paid.2008.12.012

*Di Fabio, A., \& Palazzeschi, L. (2015). Beyond fluid intelligence and personality traits in scholastic success: Trait emotional intelligence. Learning and Individual Differences, 40, 121-126. https://doi.org/10.1016/j.lindif.2015.04.001

Digman, J. M., \& Inouye, J. (1986). Further specification of the five robust factors of personality. Journal of Personality and Social Psychology, 50, 116-123. http://dx.doi.org/10.1037/0022-3514.50.1.116

*Ditterline, J. W. (2012). The predictive validity of self-reported emotional intelligence in children. (Unpublished doctoral dissertation). University of Florida, Gainesville, FL.

*Doring, D. P. (2006). Social and academic predictors of success for gifted children. 
(Unpublished doctoral dissertation). St. John's University, New York City, NY.

*Downey, L. A., Lomas, J., Billings, C., Hansen, K., \& Stough, C. (2014). Scholastic success: Fluid intelligence, personality, and emotional intelligence. Canadian Journal of School Psychology, 29, 40-53. https://doi.org/10.1177/0829573513505411

*Downey, L. A., Mountstephen, J., Lloyd, J., Hansen, K., \& Stough, C. (2008). Emotional intelligence and scholastic achievement in Australian adolescents. Australian Journal of Psychology, 60, 10-17. https://doi.org/10.1080/00049530701449505

*Drago, J. M. (2005). The relationship between emotional intelligence and academic achievement in nontraditional college students. (Unpublished doctoral dissertation). Walden University, Minneapolis, MN, United States.

*Drati, B. A. (2010). Closing the achievement gap: The relationship between emotional intelligence, race identity attitudes, and academic achievement with African American adolescents. (Unpublished doctoral dissertation). California State University, Long Beach, CA.

Durlak, J. A., Weissberg, R. P., Dymnicki, A. B., Taylor, R. D., \& Schellinger, K. B. (2011). The Impact of Enhancing Students' Social and Emotional Learning: A Meta-Analysis of School-Based Universal Interventions. Child Development, 82, 405-432. http://dx.doi.org/10.1111/j.1467-8624.2010.01564.x

*Edison, B. R. (2003). Emotional intelligence as a mediating variable in Astin's I-E-O model of higher education. (Unpublished doctoral dissertation). The College of William and Mary, Williamsburg, VA.

*Evenson, E. A. (2008). Examining the relationship between emotional intelligence and college success. (Unpublished doctoral dissertation). Capella University, Minnesota, $\mathrm{MN}$.

Ewing, M., Huff, K., Andrews, M., \& King, K. (2005). Assessing the Reliability of Skills Measured by the SAT Research Notes (Vol. RN-24): College Board.

*Fahim, M., \& Pishghadam, R. (2007). On the role of emotional, verbal, and psychometric intelligences in the academic achievement of students majoring in language learning. Asian EFL Journal, 9, 240-253. Retrieved from https://www.asian-efl-journal.com/

*Fallahzadeh, H. (2011). The relationship between emotional intelligence and academic achievement in medical science students in Iran. Procedia - Social and Behavioral Sciences, 30, 1461-1466. https://doi.org/10.1016/j.sbspro.2011.10.283

Fan, H. Y., Jackson, T., Yang, X. G., Tang, W. Q., \& Zhang, J. F. (2010). The factor structure of the Mayer-Salovey-Caruso Emotional Intelligence Test V 2.0 (MSCEIT): A metaanalytic structural equation modeling approach. Personality and Individual Differences, 48, 781-785. http://dx.doi.org/10.1016/j.paid.2010.02.004

*Fannin, B. E. (2002). The contributions of emotional intelligence to academic achievement and production. (Unpublished doctoral dissertation). Walden University, Minnesota, $\mathrm{MN}$.

*Fatum, B. A. (2008). The relationship between emotional intelligence and academic achievement in elementary-school children. (Unpublished doctoral dissertation). University of San Francisco, San Francisco, CA.

*Fayombo, G. A. (2012). Relating emotional intelligence to academic achievement among university students in Barbados. The International Journal of Emotional Education, 4(2), 43-54. https://doi.org/10.1037/e734362011-095

*Feldman, J. M. (2004). The relationship among college freshmen's cognitive risk tolerance, academic hardiness, and emotional intelligence and their usefulness in predicting academic outcomes. (Unpublished doctoral dissertation). Temple University, Philadelphia, PA.

Fischer, A. H., Rodriguez Mosquera, P. M., Van Vianen, A. E., \& Manstead, A. S. (2004). 
Gender and culture differences in emotion. Emotion, 4, 87. http://dx.doi.org/10.1037/1528-3542.4.1.87

Fisher, Z., Tipton, E., \& Hou, Z. (2016). Robumeta: Robust variance meta-regression. R package (Version 2.0)[Computer software].

Fleming, M. L., \& Malone, M. R. (1983). The relationship of student characteristics and student performance in science as viewed by meta-analysis research. Journal of Research in Science Teaching, 20, 481-495. http://dx.doi.org/10.1002/tea.3660200510

Fortin, N. M., Oreopoulos, P., \& Phipps, S. (2015). Leaving boys behind: Gender disparities in high academic achievement. Journal of Human Resources, 50, 549-579. http://dx.doi.org/10.3368/Jhr.50.3.549

Fredrickson, B. L. (2001). The role of positive emotions in positive psychology - The broaden-and-build theory of positive emotions. American Psychologist, 56, 218-226. http://dx.doi.org/10.1037//0003-066x.56.3.218

Freudenthaler, H., \& Neubauer, A. C. (2007). Measuring emotional management abilities: Further evidence of the importance to distinguish between typical and maximum performance. Personality and Individual Differences, 42, 1561-1572. http://dx.doi.org/10.1016/j.paid.2006.10.031

Furnham, A., \& Petrides, K. V. (2003). Trait emotional intelligence and happiness. Social Behavior and Personality, 31, 815-823. http://dx.doi.org/10.2224/sbp.2003.31.8.815

*Garg, R., Levin, E., \& Tremblay, L. (2016). Emotional intelligence: Impact on postsecondary academic achievement. Social Psychology of Education, 19, 627-642. http://dx.doi.org/10.1007/s11218-016-9338-X

Gibbs, N. (1995). The EQ factor. TIME, 146(14), 60-67.

*Gibson, G. J. (2005). Emotional intelligence and performance in a graduate school counseling program. (Unpublished doctoral dissertation). University of North Dakota, Grand Forks, ND.

* Gilbert, T. (2003). Emotional perception as a component of emotional intelligence: Its role in academic achievement, social interaction, and focus of attention. (Unpublished doctoral dissertation). Middlesex University, London, UK.

*Glickman-Rogers, A. (2010). How do social and emotional competencies influences the grades that male students receive? (Unpublished doctoral dissertation). Hofstra University, Hempstead, NY.

Goldberg, L. R. (1981). Language and individual differences: The search for universals in personality lexicons. Review of personality and social psychology, 2, 141-165.

Goleman, D. (1995). Emotional intelligence: Why it can matter more than IQ. London: Bloomsbury.

Goleman, D. (1998). Working with emotional intelligence. London: Bloomsbury.

*Goodwin, W. N. (2016). Assessing the link between emotional intelligence and online student achievement. (Unpublished doctoral dissertation). Texas A\&M University, Corpus Christi, TX, United States.

Gross, J. J. (2008). Emotion regulation. In M. Lewis, J. M. Haviland-Jones \& L. F. Barrett (Eds.), Handbook of emotions (3rd Edition ed., pp. 497-513). New York: The Guilford Press.

Gross, J. J., \& Thompson, R. A. (2007). Emotion regulation: Conceptual foundations. In J. J. Gross (Ed.), Handbook of emotion regulation. New York: Guilford Press.

Grubb, W., \& McDaniel, M. A. (2007). The fakability of Bar-On's Emotional Quotient Inventory Short Form: Catch me if you can. Human Performance, 20, 43-59. http://dx.doi.org/10.1207/s15327043hup2001_3

*Hall, C. P., \& West, J. H. (2011). Potential predictors of student teaching performance: Considering Emotional Intelligence. Issues in Educational Research, 21, 145-161. 
Retrieved from http://www.iier.org.au/iier.html

Hansen, M., Mann Levesque, E., Quintero, D., \& Valant, J. (2018). Have we made progress on achievement gaps? Looking at evidence from the new NAEP results. Retrieved from https://www.brookings.edu/blog/brown-center-chalkboard/2018/04/17/have-wemade-progress-on-achievement-gaps-looking-at-evidence-from-the-new-naep-results

Harms, P., \& Credé, M. (2010). Emotional intelligence and transformational and transactional leadership: A meta-analysis. Journal of Leadership \& Organizational Studies, 17, 5 17. http://dx.doi.org/10.1177/1548051809350894

*Hassan, A., Sulaiman, T., \& Ishak, R. (2009). Philosophy underlying emotional intelligence in relation to level of curiosity and academic achievement of rural area students. Journal of Social Sciences, 5, 95-103. http://dx.doi.org/10.3844/jssp.2009.95.103

Heckman, J. J., \& Kautz, T. (2012). Hard evidence on soft skills. Labour Economics, 19, 451464. http://dx.doi.org/10.1016/j.labeco.2012.05.014

Heckman, J. J., \& Rubinstein, Y. (2001). The importance of noncognitive skills: Lessons from the GED testing program. American Economic Review, 91(2), 145-149. http://dx.doi.org/10.1257/Aer.91.2.145

Heckman, J. J., Stixrud, J., \& Urzua, S. (2006). The effects of cognitive and noncognitive abilities on labor market outcomes and social behavior. Journal of Labor Economics, 24, 411-482. http://dx.doi.org/10.1086/504455

Hedges, L. V., Tipton, E., \& Johnson, M. C. (2010). Robust variance estimation in metaregression with dependent effect size estimates. Research synthesis methods, 1, 39-65. http://dx.doi.org/10.1002/jrsm.5

Hoaglin, D. C., \& Iglewicz, B. (1987). Fine-tuning some resistant rules for outlier labeling. Journal of the American Statistical Association, 82(400), 1147-1149.

Hodzic, S., Scharfen, J., Ripoll, P., Holling, H., \& Zenasni, F. (2018). How efficient are emotional intelligence trainings: a meta-analysis. Emotion Review, 10, 138-148. https://doi.org/10.1177/1754073917708613

*Hogan, M. J. (2003). Prediction of grade point average and retention in first-year students by social and emotional competencies. (Unpublished master's thesis). Trent University, Peterborough, Ontario, Canada.

*Hogan, M. J., Parker, J. D. A., Wiener, J., Watters, C., Wood, L. M., \& Oke, A. (2010). Academic success in adolescence: Relationships among verbal IQ, social support and emotional intelligence. Australian Journal of Psychology, 62, 30-41. https://doi.org/10.1080/00049530903312881

*Holt, S. (2007). Emotional intelligence and academic achievement in higher education. (Unpublished doctoral dissertation). Pepperdine University, Malibu, CA.

*Humphrey-Murto, S., Leddy, J. J., Wood, T. J., Puddester, D., \& Moineau, G. (2014). Does emotional intelligence at medical school admission predict future academic performance? Academic Medicine, 89, 638-643. https://dx.doi.org/10.1097/ACM.0000000000000165

Hunter, J. E., Schmidt, F. L., \& Le, H. (2006). Implications of direct and indirect range restriction for meta-analysis methods and findings. Journal of Applied Psychology, 91, 594-612.

Inzlicht, M., \& Ben-Zeev, T. (2000). A threatening intellectual environment: Why females are susceptible to experiencing problem-solving deficits in the presence of males. Psychological Science, 11, 365-371. http://dx.doi.org/10.1111/1467-9280.00272

*Izaguirre, R. (2008). The relationship among emotional intelligence, academic achievement, and demographic characteristics in first-year community college students. (Unpublished doctoral dissertation). University of the Incarnate Word, San Antonio, TX. 
*Jaeger, A. J. (2003). Job competencies and the curriculum: An inquiry into emotional intelligence in graduate professional education. Research in Higher Education, 44, 615-639. https://doi.org/10.1023/a:1026119724265

Jencks, C. (1979). Who gets ahead? The determinants of economic success in America. New York: Basic Books.

Jensen, A. R. (1998). The g factor: The science of mental ability (Vol. 648). Westport, CT: Praeger.

John, O. P. (1989). Towards a taxonomy of personality descriptors, In D. M. Buss \& N. Cantor (Eds.) Personality Psychology (pp. 261-271). New York, US: Springer.

*Johnson, G. D. K. (2008). Learning styles and emotional intelligence of the adult learner. (Unpublished doctoral dissertation). Auburn University, Auburn, AL.

Johnson, J. W. (2000). A heuristic method for estimating the relative weight of predictor variables in multiple regression. Multivariate Behavioral Research, 35, 1-19. http://dx.doi.org/10.1207/S15327906mbr3501_1

Johnson, J. W., \& LeBreton, J. M. (2004). History and use of relative importance indices in organizational research. Organizational Research Methods, 7, 238-257. http://dx.doi.org/10.1177/1094428104266510

*Jones, D. P. (2013). The relationship between emotional intelligence and literacy achievement of secondary students. (Unpublished doctoral dissertation). Walden University, Minneapolis, MN.

*Jordan, J. A., McRorie, M., \& Ewing, C. (2010). Gender differences in the role of emotional intelligence during the primary-secondary school transition. Emotional and Behavioural Difficulties, 15, 37-47. https://doi.org/10.1080/13632750903512415

Joseph, D. L., \& Newman, D. A. (2010). Emotional intelligence: An integrative meta-analysis and cascading model. Journal of Applied Psychology, 95(1), 54-78. http://dx.doi.org/10.1037/a0017286

Joseph, D. L., Jin, J., Newman, D. A., \& O'Boyle, E. H. (2015). Why does self-reported emotional intelligence predict job performance? A meta-analytic investigation of mixed ei. Journal of Applied Psychology, 100(2), 298-342. http://dx.doi.org/10.1037/a0037681

Judge, T. A., Jackson, C. L., Shaw, J. C., Scott, B. A., \& Rich, B. L. (2007). Self-efficacy and work-related performance: The integral role of individual differences. Journal of Applied Psychology, 92, 107. http://doi.org/10.1037/0021-9010.92.1.107

*Kaliská, L. (2015). Three types of intelligences and their relationship to students' school performance. New Educational Review, 41, 275-286. https://doi.org/10.15804/tner.2015.41.3.22

Kapp, C. A. (2000). Emotional intelligence (EQ) and success in post-graduate studies: A pilot study. South African Journal of Higher Education, 14, 151-160. http://dx.doi.org/10.4314/sajhe.v14i3.50182

Kashani, F. L., Azimi, A. L., \& Vaziri, S. (2012). Relationship between emotional intelligence and educational achievement. Procedia-Social and Behavioral Sciences, 69, 12701275. http://dx.doi.org/10.1016/j.sbspro.2012.12.061

Kaufman, A. S., \& Lichtenberger, E. O. (2005). Assessing adolescent and adult intelligence (3rd ed.). Boston: Allyn \& bacon.

*Khajehpour, M. (2011). Relationship between emotional intelligence, parental involvement and academic performance of high school students. Procedia - Social and Behavioral Sciences, 15, 1081-1086. https://doi.org/10.1016/j.sbspro.2011.03.242

*Killen, M. A. (2016). The relationship between parents' perceptions of their child's emotional intelligence and academic performance among students with autism spectrum disorder. (Unpublished doctoral dissertation). Capella University, 
Minneapolis, MN, United States.

Kong, F., Zhao, J., \& You, X. (2012). Emotional intelligence and life satisfaction in Chinese university students: The mediating role of self-esteem and social support. Personality and Individual Differences, 53, 1039-1043. https://doi.org/10.1016/j.paid.2012.07.032

*Kracher, C. M. (2009). Academic and non-academic factors associated with retention of undergraduate college students. (Unpublished doctoral dissertation). Lynn University, Boca Raton, FL, United States.

*Kumar, A., Puranik, M. P., \& Sowmya, K. R. (2016). Association between dental students' emotional intelligence and academic performance: A study at six dental colleges in India. Journal of Dental Education, 80, 526-532. Retrieved from http://www.jdentaled.org/

*Kumar, V. V., Mehta, M., \& Maheshwari, N. (2013). Effect of emotional intelligence on the achievement motivation, psychological adjustment and scholastic performance of secondary school students. Journal of the Indian Academy of Applied Psychology, 39, 60-67. Retrieved from http://jiaap.org/

Kuncel, N. R., Crede, M., \& Thomas, L. L. (2005). The validity of self-reported grade point averages, class ranks, and test scores: A meta-analysis and review of the literature. Review of Educational Research, 75, 63-82. http://dx.doi.org/10.3102/00346543075001063

*Kvapil, L. (2007). The impact of emotional intelligence on the academic performance of atrisk high school students. (Unpublished doctoral dissertation). University of the Incarnate Word, San Antonio, TX.

*Laborde, S., Dosseville, F., \& Scelles, N. (2010). Trait emotional intelligence and preference for intuition and deliberation: Respective influence on academic performance.

Personality and Individual Differences, 49, 784-788. https://doi.org/10.1016/j.paid.2010.06.031

*Lanciano, T., \& Curci, A. (2014). Incremental validity of emotional intelligence ability in predicting academic achievement. The American Journal of Psychology, 127, 447461. https://doi.org/10.5406/amerjpsyc.127.4.0447

Landy, F. J. (2005). Some historical and scientific issues related to research on emotional intelligence. Journal of Organizational Behavior, 26, 411-424. http://dx.doi.org/10.1002/job.317

*Lasser, M. H. (1997). A study of possible correlates of emotional intelligence: Gender and grade point average. (Unpublished master's thesis). Kean University, Union, NJ.

Law, K. S., Wong, C. S., \& Song, L. J. (2004). The construct and criterion validity of emotional intelligence and its potential utility for management studies. Journal of Applied Psychology, 89, 483-496. http://dx.doi.org/10.1037/0021-9010.89.3.483

*Lawrence, S. A., \& Deepa, T. (2013). Emotional intelligence and academic achievement of high school students in Kanyakumari district. International Journal of Physical and Social Sciences, 3(2), 101-107. Retrieved from https://www.ijmra.us/physical journal.php

LeBreton, J. M., \& Tonidandel, S. (2008). Multivariate relative importance: Extending relative weight analysis to multivariate criterion spaces. Journal of Applied Psychology, 93, 329-345. http://dx.doi.org/10.1037/0021-9010.93.2.329

*Leddy, J. J., Moineau, G., Puddester, D., Wood, T. J., \& Humphrey-Murto, S. (2011). Does an emotional intelligence test correlate with traditional measures used to determine medical school admission? Academic Medicine, 86, S40-S42. https://doi.org/10.1097/ACM.0b013e31822a6df6

Lenhard, W., \& Lenhard, A. (2016). Calculation of Effect Sizes, Retrieved from https://www.psychometrica.de/effect_size.html 
*Lewis, E. S. (2004). A study of emotional intelligence, cognitive intelligence and clinical performance of physical therapy students. (Unpublished doctoral dissertation). University of Massachusetts Lowell, Lowell, MA.

*Libbrecht, N., Lievens, F., Carette, B., \& Côté, S. (2014). Emotional intelligence predicts success in medical school. Emotion, 14, 64-73. https://doi.org/10.1037/a0034392

Lievens, F., \& Sackett, P. R. (2006). Video-based versus written situational judgment tests: A comparison in terms of predictive validity. Journal of Applied Psychology, 91, 11811188. http://dx.doi.org/10.1037/0021-9010.91.5.1181

*Lochner, J. L. (2016). The relationship of emotional intelligence, self-efficacy and gender in predicting grade point average for visual arts students. (Unpublished doctoral dissertation). Capella University, Minneapolis, MN.

*Loera, D. L. (2013). Emotional intelligence and student success among White and first- and second-generation Latina/o college students. (Unpublished doctoral dissertation). University of La Verne, La Verne, CA.

Lopes, P. N., Brackett, M. A., Nezlek, J. B., Schütz, A., Sellin, I., \& Salovey, P. (2004). Emotional intelligence and social interaction. Personality and Social Psychology Bulletin, 30, 1018-1034. https://doi.org/10.1177/0146167204264762

Lopes, P. N., Salovey, P., Côté, S., Beers, M., \& Petty, R. E. (2005). Emotion regulation abilities and the quality of social interaction. Emotion, 5, 113-118. http://dx.doi.org/10.1037/1528-3542.5.1.113

*Lu, S.-C. (2010). Validation of a measure of emotional intelligence for first year college students in a Hispanic serving institution. (Unpublished doctoral dissertation). Texas A\&M University - Corpus Christi, Corpus Christi, TX.

*Lui, M. M. (2009). Can I succeed as an adolescent mother? Examining the role of emotional intelligence in predicting self-efficacy, academic achievement, and school attendance. (Unpublished doctoral dissertation). Temple University, Philadelphia, PA.

Lyons, L. C., \& Morris, W. A. (2017). The Meta-Analysis Calculator, Retrieved from http://www.lyonsmorris.com/ma1/

MacCann, C. (2010). Further examination of emotional intelligence as a standard intelligence: A latent variable analysis of fluid intelligence, crystallized intelligence, and emotional intelligence. Personality and Individual Differences, 49, 490-496. http://dx.doi.org/10.1016/j.paid.2010.05.010

*MacCann, C., \& Roberts, R. D. (2008). New paradigms for assessing emotional intelligence: Theory and data. Emotion, 8, 540-551. http://dx.doi.org/10.1037/a0012746

MacCann, C., Fogarty, G. J., \& Roberts, R. D. (2012). Strategies for success in education: Time management is more important for part-time than full-time community college students. Learning and Individual Differences, 22, 618-623. http://dx.doi.org/10.1016/j.lindif.2011.09.015

*MacCann, C., Fogarty, G. J., Zeidner, M., \& Roberts, R. D. (2011). Coping mediates the relationship between emotional intelligence (EI) and academic achievement. Contemporary Educational Psychology, 36, 60-70. https://doi.org/10.1016/j.cedpsych.2010.11.002

MacCann, C., Joseph, D. L., Newman, D. A., \& Roberts, R. D. (2014). Emotional intelligence is a second-stratum factor of intelligence: Evidence from hierarchical and bifactor models. Emotion, 14, 358-374. http://dx.doi.org/10.1037/a0034755

*Malik, F., \& Shujja, S. (2013). Emotional intelligence and academic achievement: Implications for children's performance in schools. Journal of the Indian Academy of Applied Psychology, 39, 51-59. http://jiaap.org/

*Margavio, T. M., Margavio, G. W., Hignite, M. A., \& Moses, D. R. (2012). A comparative 
analysis of the emotional intelligence levels of American and Chinese business students. College Student Journal, 46(4), 776-787. Retrieved from http://www.projectinnovation.biz/college student journal

*Marquez, P. G.-O., Martin, R. P., \& Brackett, M. A. (2006). Relating emotional intelligence to social competence and academic achievement in high school students. Psicothema, 18(Suppl), 118-123. Retrieved from http://www.psicothema.com/

*Martin, T. R. (2011). The relationship between emotional intelligence and academic success of 6th grade students. (Unpublished doctoral dissertation). Wilmington University, New Castle, DE.

Martins, A., Ramalho, N., \& Morin, E. (2010). A comprehensive meta-analysis of the relationship between emotional intelligence and health. Personality and Individual Differences, 49, 554-564. http://dx.doi.org/10.1016/j.paid.2010.05.029

*Matešić, K. (2015). The relationship between cognitive and emotional intelligence and high school academic achievement. Collegium antropologicum, 39, 371-375. Retrieved from http://www.collantropol.hr/antropo

Mattingly, V., \& Kraiger, K. (2019). Can emotional intelligence be trained? A meta-analytical investigation. Human Resource Management Review, 29, 140-155.

https://doi.org/10.1016/j.hrmr.2018.03.002

Matsumoto, D., LeRoux, J., Wilson-Cohn, C., Raroque, J., Kooken, K., Ekman, P., . . Goh, A. (2000). A new test to measure emotion recognition ability: Matsumoto and Ekman's Japanese and Caucasian Brief Affect Recognition Test (JACBART). Journal of Nonverbal Behavior, 24, 179-209. http://dx.doi.org/10.1023/A:1006668120583

Matthews, G., Zeidner, M., \& Roberts, R. D. (2002). Emotional intelligence: Science and myth. Cambridge, Massachusetts, US: MIT Press.

*Mavroveli, S., \& Sánchez-Ruiz, M. J. (2011). Trait emotional intelligence influences on academic achievement and school behaviour. British Journal of Educational Psychology, 81, 112-134. https://doi.org/10.1348/2044-8279.002009

*Mavroveli, S., Petrides, K. V., Sangareau, Y., \& Furnham, A. (2009). Exploring the relationships between trait emotional intelligence and objective socio-emotional outcomes in childhood. British Journal of Educational Psychology, 79, 259-272. https://doi.org/10.1348/000709908x368848

Mavroveli, S., Petrides, K. V., Rieffe, C., \& Bakker, F. (2007). Trait emotional intelligence, psychological well-being and peer-rated social competence in adolescence. British Journal of Developmental Psychology, 25, 263-275. https://doi.org/10.1348/026151006x118577

*Mavroveli, S., Petrides, K. V., Shove, C., \& Whitehead, A. (2008). Investigation of the construct of trait emotional intelligence in children. European Child and Adolescent Psychiatry, 17, 516-526. https://doi.org/10.1007/s00787-008-0696-6

Mayer, J. D., \& Salovey, P. (1997). What is emotional intelligence? In P. Salovey \& D. Sluyter (Eds.), Emotional development and emotional intelligence: Educational implications (pp. 3-31). New York, US: Basic Books.

Mayer, J. D., Caruso, D. R., \& Salovey, P. (1999). Emotional intelligence meets traditional standards for an intelligence. Intelligence, 27, 267-298. http://dx.doi.org/10.1016/S0160-2896\%2899\%2900016-1

Mayer, J. D., Caruso, D. R., \& Salovey, P. (2000). Selecting a measure of emotional intelligence: the case for ability scales. In R. Bar-On \& J. D. A. Parker (Eds.), Handbook of Emotional Intelligence (pp. 320-342). San Fransisco: Jossey-Bass.

Mayer, J. D., Caruso, D. R., \& Salovey, P. (2016). The ability model of emotional intelligence: Principles and updates. Emotion Review, 8, 290-300. 
http://dx.doi.org/10.1177/1754073916639667

Mayer, J. D., Roberts, R. D., \& Barsade, S. G. (2008). Human abilities: Emotional intelligence. Annual Review of Psychology, 59, 507-536. http://dx.doi.org/10.1146/annurev.psych.59.103006.093646

Mayer, J. D., Salovey, P., Caruso, D. R., \& Sitarenios, G. (2001). Emotional Intelligence as a Standard Intelligence. Emotion, 1, 232-242. http://dx.doi.org/10.1037//15283542.1.3.232

Mayer, J. D., Salovey, P., Caruso, D. R., \& Sitarenios, G. (2003). Measuring emotional intelligence with the MSCEIT V2.0. Emotion, 3, 97-105. http://dx.doi.org/10.1037/1528-3542.3.1.97

*McClain, E. K. (2009). The relationship of emotional intelligence to academic performance and perceived stress in first year medical students. (Unpublished doctoral dissertation). University of Kansas, Lawrence, KU.

McGrew, K. S. (2009). CHC theory and the human cognitive abilities project: Standing on the shoulders of the giants of psychometric intelligence research. Intelligence, 37, 110. http://dx.doi.org/10.1016/j.intell.2008.08.004

*Menzie, T. A. (2005). Emotional intelligence and social and academic competence in middle school youth. (Unpublished doctoral dissertation). Rutgers The State University of New Jersey, New Brunswci, NJ.

*Mestre, J. M., Guil, R., Lopes, P. N., Salovey, P., \& Gil-Olarte, P. (2006). Emotional intelligence and social and academic adaptation to school. Psicothema, 18s, 112-117. https://doi.org/10.15405/epsbs.2017.05.02.227

Mestre, J. M., MacCann, C., Guil, R., \& Roberts, R. D. (2016). Models of cognitive ability and emotion can better inform contemporary emotional intelligence frameworks. Emotion Review, 8, 322-330. http://dx.doi.org/10.1177/1754073916650497

Miao, C., Humphrey, R. H., \& Qian, S. (2017). Are the emotionally intelligent good citizens or counterproductive? A meta-analysis of emotional intelligence and its relationships with organizational citizenship behavior and counterproductive work behavior.

Personality and Individual Differences, 116, 114-156. http://dx.doi.org/10.1016/j.paid.2017.04.015

*Mitrofan, N., \& Cioricaru, M.-F. (2014). Emotional intelligence and school performancecorrelational Study. Procedia - Social and Behavioral Sciences, 127, 769-775. https://doi.org/10.1016/j.sbspro.2014.03.352

Moeyaert, M., Ugille, M., Natasha Beretvas, S., Ferron, J., Bunuan, R., \& Van den Noortgate, W. (2017). Methods for dealing with multiple outcomes in meta-analysis: a comparison between averaging effect sizes, robust variance estimation and multilevel meta-analysis. International Journal of Social Research Methodology, 20, 559-572. https://doi.org/10.1080/13645579.2016.1252189

*Naeem, N., van der Vleuten, C., Muijtjens, A. M. M., Violato, C., Ali, S. M., Al-Faris, E. A., .. . Naeem, N. (2014). Correlates of emotional intelligence: Results from a multiinstitutional study among undergraduate medical students. Medical Teacher, 36, S30S35. https://doi.org/10.3109/0142159x.2014.886008

Nata, G., Pereira, M. J., \& Neves, T. (2014). Unfairness in access to higher education: An 11 year comparison of grade inflation by private and public secondary schools in Portugal. Higher Education, 68, 851-874. http://dx.doi.org/10.1007/s10734-014-9748$\underline{7}$

National Council of the Teachers of English (1996). Standard for the English Language Arts. Retrieved from http://www.ncte.org/library/NCTEFiles/Resources/Books/Sample/StandardsDoc.pdf? $\mathrm{ga}=2.146967543 .198597852 .1548738430-683684206.1548738430$ 
Neisser, U., Boodoo, G., Bouchard, T. J., Boykin, A. W., Brody, N., Ceci, S. J., . . Urbina, S. (1996). Intelligence: Knowns and unknowns. American Psychologist, 51, 77-101. http://dx.doi.org/10.1037/0003-066x.51.2.77

*Nelson, P. D. (2010). Emotional intelligence and academic achievement in 11th grade atrisk students. (Unpublished doctoral dissertation). Walden University, Minneapolis, MN.

*Nesari, A. J., Karimi, L., \& Filinezhad, N. (2011). On the relationship between emotional intelligence and vocabulary learning of Iranian EFL learners at the intermediate level. Procedia - Social and Behavioral Sciences, 28, 900-903. https://doi.org/10.1016/j.sbspro.2011.11.165

*Newsome, S., Day, A. L., \& Catano, V. M. (2000). Assessing the predictive validity of emotional intelligence. Personality and Individual Differences, 29, 1005-1016. https://doi.org/10.1016/S0191-8869\%2899\%2900250-0

Nisbett, R. E., \& Wilson, T. D. (1977). The halo effect: Evidence for unconscious alteration of judgments. Journal of Personality and Social Psychology, 35, 250-256. http://dx.doi.org/10.1037/0022-3514.35.4.250

Nowicki, S., \& Duke, M. P. (1994). Individual differences in the nonverbal communication of affect - the Diagnostic-Analysis of Nonverbal Accuracy Scale. Journal of Nonverbal Behavior, 18, 9-35. http://dx.doi.org/10.1007/Bf02169077

*Nwabuebo, E. (2013). Emotional intelligence and academic achievement among senior Black students enrolled in Baccalaureate nursing programs: Implications for nursing education. (Unpublished doctoral dissertation). Capella University, Minneapolis, MN.

O’Boyle, E. H., Jr., Humphrey, R. H., Pollack, J. M., Hawver, T. H., \& Story, P. A. (2011). The relation between emotional intelligence and job performance: A meta-analysis. Journal of Organizational Behavior, 32, 788-818. http://dx.doi.org/10.1002/job.714

O’Connor, M. C., \& Paunonen, S. V. (2007). Big five personality predictors of postsecondary academic performance. Personality and Individual Differences, 43, 971990. http://dx.doi.org/10.1016/j.paid.2007.03.017

*O'Connor, R. M., Jr., \& Little, I. S. (2003). Revisiting the predictive validity of emotional intelligence: Self-report versus ability-based measures. Personality and Individual Differences, 35, 1893-1902. https://doi.org/10.1016/S0191-8869\%2803\%2900038-2

*Ogundokun, M. O., \& Adeyemo, D. A. (2010). Emotional intelligence and academic achievement: The moderating influence of age, intrinsic and extrinsic motivation. The African Symposium: An online journal of the African Educational Research Network, 10, 127-141. Retrieved from https://projects.ncsu.edu/aern/symposium main.htm

*Olatoye, A. R., Akintunde, O. S., \& Yakasai, I. M. (2010). Emotional Intelligence, Creativity and Academic Achievement of Business Administration Students. Electronic Journal of Research in Educational Psychology, 8(2), 763-786.

Olderbak, S., Semmler, M., \& Doebler, P. (2017). Four-branch model of emotional intelligence with fluid and crystallized intelligence: A meta-analysis of relations. Emotion Review, 11, 166-181. http://dx.doi.org/10.1177/1754073918776776

*Olson, L. G. (2008). An investigation of factors that influence academic achievement in Christian higher education: Emotional intelligence, self-esteem and spiritual wellbeing. (Unpublished doctoral dissertation). Capella University, Minneapolis, MN.

*Opateye, J. A. (2014). The relationship between emotional intelligence, test anxiety, stress, academic success and attitudes of high school students towards electrochemistry. lfe Psychologia, 22, 239-249.

Open Science Collaboration (2015). Estimating the reproducibility of psychological science. Science, 349(6251), 1-8. Retrieved from http://science.sciencemag.org/

Palmer, B. R., Gignac, G., Manocha, R., \& Stough, C. (2005). A psychometric evaluation of 
the Mayer-Salovey-Caruso emotional intelligence test version 2.0. Intelligence, 33, 285-305. http://dx.doi.org/10.1016/j.intell.2004.11.003

*Parker, J. D., Creque, R. E., Sr., Barnhart, D. L., Harris, J. I., Majeski, S. A., Wood, L. M., . . Hogan, M. J. (2004). Academic achievement in high school: Does emotional intelligence matter? Personality and Individual Differences, 37, 1321-1330. https://doi.org/10.1016/j.paid.2004.01.002

*Parker, J. D., Duffy, J. M., Wood, L. M., Bond, B. J., \& Hogan, M. J. (2005). Academic achievement and emotional intelligence: Predicting the successful transition from high school to university. Journal of The First-Year Experience \& Students in Transition, 17(1), 67-78.

*Parker, J. D., Summerfeldt, L. J., Hogan, M. J., \& Majeski, S. A. (2004). Emotional intelligence and academic success: examining the transition from high school to university. Personality and Individual Differences, 36, 163-172. https://doi.org/10.1016/S0191-8869\%2803\%2900076-X

Pekrun, R., Elliot, A. J., \& Maier, M. A. (2009). Achievement goals and achievement emotions: Testing a model of their joint relations with academic performance. Journal of Educational Psychology, 101, 115-135. http://dx.doi.org/10.1037/a0013383

Pekrun, R., Goetz, T., Daniels, L. M., Stupnisky, R. H., \& Perry, R. P. (2010). Boredom in achievement settings: Exploring control-value antecedents and performance outcomes of a neglected emotion. Journal of Educational Psychology, 102, 531-549. http://dx.doi.org/10.1037/a0019243

Pekrun, R., Goetz, T., Titz, W., \& Perry, R. P. (2002). Academic emotions in students' selfregulated learning and achievement: A program of qualitative and quantitative research. Educational Psychologist, 37, 91-105. http://dx.doi.org/10.1207/S15326985ep3702 4

Peña-Sarrionandia, A., Mikolajczak, M., \& Gross, J. J. (2015). Integrating emotion regulation and emotional intelligence traditions: a meta-analysis. Frontiers in Psychology, 6, 160. https://doi.org/10.3389/fpsyg.2015.00160

Perera, H. N., \& DiGiacomo, M. (2013). The relationship of trait emotional intelligence with academic performance: A meta-analytic review. Learning and Individual Differences, 28, 20-33. http://dx.doi.org/10.1016/j.lindif.2013.08.002

*Petersen, V. C. (2010). The relationship between emotional intelligence and middle school students with learning disabilities. (Unpublished doctoral dissertation). Fairleigh Dickinson University, Madison, NJ.

Petrides, K. V. (2009). Psychometric properties of the Trait Emotional Intelligence Questionnaire (TEIQue). In C. Stough, D.H. Saklofske, \& J. D. A. Parker (Eds.) Assessing emotional intelligence: Theory, research, and applications (pp. 85-101). New York, US: Springer Science + Business Media.

Petrides, K. V., \& Furnham, A. (2000). On the dimensional structure of emotional intelligence. Personality and Individual Differences, 29, 313-320. http://dx.doi.org/10.1016/S0191-8869(99)00195-6

Petrides, K. V., \& Furnham, A. (2003). Trait emotional intelligence: Behavioural validation in two studies of emotion recognition and reactivity to mood induction. European Journal of Personality, 17, 39-57. http://dx.doi.org/10.1002/Per.466

Petrides, K. V., Perez-Gonzalez, J. C., \& Furnham, A. (2007). On the criterion and incremental validity of trait emotional intelligence. Cognition and Emotion, 21(1), 2655. http://dx.doi.org/10.1080/02699930601038912

Petrides, K. V., Pita, R., \& Kokkinaki, F. (2007). The location of trait emotional intelligence in personality factor space. British Journal of Psychology, 98, 273-289. http://dx.doi.org/10.1348/000712606X120618 
Petrides, K. V., Sangareau, Y., Furnham, A., \& Frederickson, N. (2006). Trait emotional intelligence and children's peer relations at school. Social Development, 15, 537-547. http://dx.doi.org/10.1111/j.1467-9507.2006.00355.x

*Pishghadam, R. (2009). A quantitative analysis of the relationship between emotional intelligence and foreign language learning. Electronic Journal of Foreign Language Teaching, 6, 31-41. Retrieved from e-flt.nus.edu.sg/

Pool, L. D., \& Qualter, P. (2012). Improving emotional intelligence and emotional selfefficacy through a teaching intervention for university students. Learning and Individual Differences, 22, 306-312. http://dx.doi.org/10.1016/j.lindif.2012.01.010

*Por, J., Barriball, L., Fitzpatrick, J., \& Roberts, J. (2011). Emotional intelligence: Its relationship to stress, coping, well-being and professional performance in nursing students. Nurse Education Today, 31, 855-860. https:/doi.org/10.1016/j.nedt.2010.12.023

Poropat, A. E. (2009). A meta-analysis of the five-factor model of personality and academic performance. Psychological Bulletin, 135, 322-338.

http://dx.doi.org/10.1037/a0014996

*Qualter, P., Gardner, K. J., Pope, D. J., Hutchinson, J. M., \& Whiteley, H. E. (2012). Ability emotional intelligence, trait emotional intelligence, and academic success in British secondary schools: A 5-year longitudinal study. Learning and Individual Differences, 22, 83-91. https://doi.org/10.1016/j.lindif.2011.11.007

R Core Team (2017). R: A language and environment for statistical computing. R Foundation for Statistical Computing, Vienna, Austria. URL https://www.R-project.org/.

*Radford, M. (2011). Emotional intelligence as a predictor of nursing student success. (Unpublished doctoral dissertation). Union University, Jackson, TN.

*Rankin, B. (2013). Emotional intelligence: Enhancing values-based practice and compassionate care in nursing. Journal of Advanced Nursing, 69, 2717-2725. https://doi.org/10.1111/jan.12161

*Rastegar, M., \& Karami, M. (2013). On the relationships among emotional intelligence, affective and social strategy use, and academic achievement of Iranian EFL learners. Theory and Practice in Language Studies, 3, 389-396. https://doi.org/10.4304/tpls.3.2.389-396

Ree, M. J., \& Earles, J. A. (1992). Intelligence is the best predictor of job performance. Current Directions in Psychological Science, 1, 86-89. http://dx.doi.org/10.1111/1467-8721.ep10768746

*Rice, D. M. (2007). An examination of emotional intelligence: Its relationship to academic achievement in Army JROTC and the implications for education. (Unpublished doctoral dissertation). Capella University, Minneapolis, MN.

Richardson, M., Abraham, C., \& Bond, R. (2012). Psychological correlates of university students' academic performance: A systematic review and meta-analysis. Psychological Bulletin, 138, 353-387. http://dx.doi.org/10.1037/a0026838

*Richardson, T. L. (2000). Emotional intelligence as a mediator of transition trauma in students progressing from elementary to middle school. (Unpublished doctoral dissertation). The Florida State University, Tallahassee, FL.

*Rivers, S. E., Brackett, M. A., Reyes, M. R., Mayer, J. D., Caruso, D. R., \& Salovey, P. (2012). Measuring emotional intelligence in early adolescence with the MSCEIT-YV: Psychometric properties and relationship with academic performance and psychosocial functioning. Journal of Psychoeducational Assessment, 30, 344-366. https://doi.org/10.1177/0734282912449443

Roberts, B. W., Lejuez, C., Krueger, R. F., Richards, J. M., \& Hill, P. L. (2014). What is conscientiousness and how can it be assessed? Developmental Psychology, 50, 1315- 
1330. http://dx.doi.org/10.1037/a0031109

Roberts, R. D., Schulze, R., \& MacCann, C. (2008). The measurement of emotional intelligence: A decade of progress? In G. Boyle, G. Matthews \& D. Saklofske (Eds.), The Sage handbook of personality theory and assessment (pp. 461-482). New York: Sage.

*Rode, J. C., Mooney, C. H., Arthaud-Day, M. L., Near, J. P., Baldwin, T. T., Rubin, R. S., \& Bommer, W. H. (2007). Emotional intelligence and individual performance: Evidence of direct and moderated effects. Journal of Organizational Behavior, 28, 399-421. https://doi.org/10.1002/job.429

*Rodeiro, C. L. V., Emery, J. L., \& Bell, J. F. (2012). Emotional intelligence and academic attainment of British secondary school children: A cross-sectional survey. Educational Studies, 38, 521-539. https://doi.org/10.1080/03055698.2011.643115

Rojstaczer, S., \& Healy, C. (2012). Where A is ordinary: The evolution of American college and university grading. Teachers College Record, 114, 1940-2009. Retrieved from http://www.tcrecord.org/

Rossen, E., Kranzler, J. H., \& Algina, J. (2008). Confirmatory factor analysis of the MayerSalovey-Caruso Emotional Intelligence Test V 2.0 (MSCEIT). Personality and Individual Differences, 44, 1258-1269. http://dx.doi.org/10.1016/j.paid.2007.11.020

Roth, B., Becker, N., Romeyke, S., Schafer, S., Domnick, F., \& Spinath, F. M. (2015). Intelligence and school grades: A meta-analysis. Intelligence, 53, 118-137. http://dx.doi.org/10.1016/j.intell.2015.09.002

*Saklofske, D. H., Austin, E. J., Mastoras, S. M., Beaton, L., \& Osborne, S. E. (2012). Relationships of personality, affect, emotional intelligence and coping with student stress and academic success: Different patterns of association for stress and success. Learning and Individual Differences, 22, 251-257. https://doi.org/10.1016/j.lindif.2011.02.010

Salgado, J. F. (1998). Big Five personality dimensions and job performance in army and civil occupations: A European perspective. Human Performance, 11, 271-288. http://dx.doi.org/10.1207/s15327043hup1102\&3 8

Salgado, J. F., Anderson, N., Moscoso, S., Bertua, C., de Fruyt, F., \& Rolland, J. P. (2003). A meta-analytic study of general mental ability validity for different occupations in the European community. Journal of Applied Psychology, 88, 1068-1081. http://dx.doi.org/10.1037/0021-9010.88.6.1068

Salovey, P., \& Mayer, J. D. (1990). Emotional intelligence. Imagination, Cognition and Personality, 9(3), 185-211. http://dx.doi.org/10.2190/DUGG-P24E-52WK-6CDG

*Samples, G. M. (2010). Emotional intelligence and academic success among Bible college students. (Unpublished doctoral dissertation). Regent University, Virginia Beach, VA.

Sanchez-Alvarez, N., Extremera, N., \& Fernandez-Berrocal, P. (2016). The relation between emotional intelligence and subjective well-being: A meta-analytic investigation. The Journal of Positive Psychology, 11, 276-285. http://dx.doi.org/10.1080/17439760.2015.1058968

*Sanchez-Ruiz, M.-J., Mavroveli, S., \& Poullis, J. (2013). Trait emotional intelligence and its links to university performance: An examination. Personality and Individual Differences, 54, 658-662. https://doi.org/10.1016/j.paid.2012.11.013

Schlegel, K., Grandjean, D., \& Scherer, K. R. (2014). Introducing the Geneva Emotion Recognition Test: An example of Rasch-based test development. Psychological Assessment, 26, 666-672. http://dx.doi.org/10.1037/a0035246

Schmidt, F. L., \& Hunter, J. E. (1998). The validity and utility of selection methods in personnel psychology: Practical and theoretical implications of 85 years of research findings. Psychological Bulletin, 124, 262-274. http://dx.doi.org/10.1037/0033- 
2909.124.2.262

Schneider, F. W., \& Coutts, L. M. (1982). The high school environment: A comparison of coeducational and single-sex schools. Journal of Educational Psychology, 74, 898906. http://dx.doi.org/10.1037/0022-0663.74.6.898

Schulte, M. J., Ree, M. J., \& Carretta, T. R. (2004). Emotional intelligence: Not much more than $g$ and personality. Personality and Individual Differences, 37, 1059-1068. http://dx.doi.org/10.1016/j.paid.2003.11.014

*Schutte, N. S., Malouff, J. M., Hall, L. E., Haggerty, D. J., Cooper, J. T., Golden, C. J., \& Liane, D. (1998). Development and validation of a measure of emotional intelligence. Personality and Individual Differences, 25, 167-177. https://doi.org/10.1016/S01918869(98)00001-4

Schutte, N. S., Malouff, J. M., \& Thorsteinsson, E. B. (2013). Increasing emotional intelligence through training: Current status and future directions. International Journal of Emotional Education, 5, 56.

Schutte, N. S., Malouff, J. M., Thorsteinsson, E. B., Bhullar, N., \& Rooke, S. E. (2007). A meta-analytic investigation of the relationship between emotional intelligence and health. Personality and Individual Differences, 42, 921-933. http://dx.doi.org/10.1016/j.paid.2006.09.003

Shao, K., Yu, W., \& Ji, Z. (2013). The relationship between EFL students' emotional intelligence and writing achievement. Innovation in Language Learning and Teaching, 7, 107-124. http://dx.doi.org/10.1080/17501229.2012.725730

*Shipley, N. L., Jackson, M. J., \& Segrest, S. L. (2010). The effects of emotional intelligence, age, work experience, and academic performance. Research in Higher Education Journal, 9, 1-8. Retrieved from https://link.springer.com/journal/11162

*Sierra, M. D. V., Borges del Rosal, M. A., Romero, N. R., Villegas, K., \& Lorenzo, M. (2013). Emotional intelligence and its relationship with gender, academic performance and intellectual abilities of undergraduates. Electronic Journal of Research in Educational Psychology, 11, 395-412. https://doi.org/10.14204/ejrep.30.12204

*Singh, B., Singh, M., \& Singh, K. (2009). The influence of emotional intelligence and learning style on student's academic achievement. Paper presented at the Conference on Scientific and Social Research. Retrieved from https://www.scribd.com/doc/13414285/The-Influence-of-Emotional-Intelligence-andLearning-Style-on-Student-s-Academic-Achievement

Skaalvik, E. M., \& Skaalvik, S. (2007). Dimensions of teacher self-efficacy and relations with strain factors, perceived collective teacher efficacy, and teacher burnout. Journal of Educational Psychology, 99, 611-625. http://dx.doi.org/10.1037/0022$\underline{0663.99 .3 .611}$

*Skipper, C. O., \& Brandenburg, S. (2013). Emotional intelligence and academic performance of engineering students. Engineering Project Organization Journal, 3, 13-21. https://doi.org/10.1080/21573727.2012.738669

*Song, L. J., Huang, G.-H., Peng, K. Z., Law, K. S., Wong, C.-S., \& Chen, Z. (2010). The differential effects of general mental ability and emotional intelligence on academic performance and social interactions. Intelligence, 38, 137-143. https://doi.org/10.1016/j.intell.2009.09.003

Steinkamp, M. W., \& Maehr, M. L. (1983). Affect, ability, and science achievement - a quantitative synthesis of correlational research. Review of Educational Research, 53, 369-396. http://dx.doi.org/10.3102/00346543053003369

*Stewart, M. F., \& Chisholm, C. U. (2012). Assessment of the impact of emotional competencies on academic achievement within engineering and other student cohorts. 
World Transactions on Engineering and Technology Education, 10, 110-115.

Retrieved from http://www.wiete.com.au/

*Stottlemyer, B. G. (2002). An examination of emotional intelligence: Its relationship to achievement and the implications for education. (Unpublished doctoral dissertation). Texas A\&M University - Corpus Christi, Corpus Christi, TX.

*Suliman, V. (2010). The relationship between learning styles, emotional social intelligence, and academic success of undergraduate nursing students. Journal of Nursing Research, 18, 136-143. https://doi.org/10.1097/jnr.0b013e3181dda797

*Sunbul, A. M. (2007). The relationship between emotional intelligence and achievement among 1 st and 4th grade faculty students. Paper presented at the First European SEBCD Conference, Malta.

*Szuberla, A. L. (2005). Emotional intelligence and school success. (Unpublished doctoral dissertation). Walden University, Minneapolis, MN.

Taylor, R. D., Oberle, E., Durlak, J. A., \& Weissberg, R. P. (2017). Promoting positive youth development through school-based social and emotional learning interventions: A meta-analysis of follow-up effects. Child Development, 88, 1156-1171. http://dx.doi.org/10.1111/cdev.12864

Tett, R. P., Freund, K. A., Christiansen, N. D., Fox, K. E., \& Coaster, J. (2012). Faking on self-report emotional intelligence and personality tests: Effects of faking opportunity, cognitive ability, and job type. Personality and Individual Differences, 52, 195-201. http://dx.doi.org/10.1016/j.paid.2011.10.017

*Tok, S., \& Morali, S. L. (2009). Trait emotional intelligence, the Big Five personality dimensions and academic success in physical education teacher candidates. Social Behavior and Personality, 37, 921-932. https://doi.org/10.2224/sbp.2009.37.7.921

Tonidandel, S., \& LeBreton, J. M. (2011). Relative importance analysis: A useful supplement to regression analysis. Journal of Business and Psychology, 26, 1-9. http://dx.doi.org/10.1007/s10869-010-9204-3

*Trapp, C. S. (2011). The association among emotional intelligence, resilience, and academic performance of preservice teachers. (Unpublished doctoral dissertation). University of Phoenix, Phoenix, AZ.

Tupes, E. C., \& Christal, R. E. (1961). Recurrent personality factors based on trait ratings. Journal of Personality, 60, 225-251. http://dx.doi.org/10.1111/j.14676494.1992.tb00973.x

van der Linden, D., Pekaar, K. A., Bakker, A. B., Schermer, J. A., Vernon, P. A., Dunkel, C. S., \& Petrides, K. (2017). Overlap between the general factor of personality and emotional intelligence: A meta-analysis. Psychological Bulletin, 143, 36-52. http://dx.doi.org/10.1037/bul0000078

Van der Linden, D., te Nijenhuis, J., \& Bakker, A. B. (2010). The general factor of personality: A meta-analysis of Big Five intercorrelations and a criterion-related validity study. Journal of research in personality, 44, 315-327. https://doi.org/10.1016/j.jrp.2010.03.003

Van Rooy, D. L., \& Viswesvaran, C. (2004). Emotional intelligence: A meta-analytic investigation of predictive validity and nomological net. Journal of Vocational Behavior, 65, 71-95. http://dx.doi.org/10.1016/S0001-8791\%2803\%2900076-9

*Vargas, G. A. (2014). The role of emotional intelligence skills in the academic achievement of students pursuing associate degrees at a South Texas college. (Unpublished doctoral dissertation). Texas A\&M University - Kingsville, Kingsville, TX.

*Veitch, B. L. (2011). Developmental education and emotional intelligence in three rural East Texas community colleges. (Unpublished doctoral dissertation). Texas A\&M University - Corpus Christi, Corpus Christi, TX. 
*Vela, R. H., Jr. (2004). The role of emotional intelligence in the academic achievement of first year college students. (Unpublished doctoral dissertation). Texas A\&M University - Kingsville, Kingsville, TX.

*Victoroff, K. Z., \& Boyatzis, R. E. (2013). What is the relationship between emotional intelligence and dental student clinical performance? Journal of Dental Education, 77, 416-426. Retrieved from http://www.jdentaled.org/

Viswesvaran, C., \& Ones, D. S. (1999). Meta-analyses of fakability estimates: Implications for personality measurement. Educational and Psychological Measurement, 59, 197 210. doi: http://dx.doi.org/10.1177/00131649921969802

*Walker, M. E. B. (2006). Emotional intelligence and academic success in college. (Unpublished doctoral dissertation). The University of Southern Mississippi, Hattiesburg, MS.

*Walsh-Portillo, J. (2011). The role of emotional intelligence in college students' success. (Unpublished doctoral dissertation). Florida International University, Greater Miami, FL.

Walter, F., Cole, M. S., \& Humphrey, R. H. (2011). Emotional intelligence: Sine qua non of leadership or folderol? Academy of Management Perspectives, 25, 45-59. http://dx.doi.org/10.5465/amp.2011.59198449

Wechsler, D. (1943). Non-intellective factors in general intelligence. Journal of Abnormal and Social Psychology, 38(1), 101-103. http://dx.doi.org/10.1037/H0060613

Werner, K., \& Gross, J. J. (2009). Emotion regulation and psychopathology: A conceptual framework. In A. M. Kring \& D. M. Sloan (Eds.) Emotion regulation and psychopathology: A transdiagnostic approach to etiology and treatment (pp. 13-37). New York, US: Guilford Press.

Westrick, P. A. (2017). Reliability estimates for undergraduate grade point average. Educational Assessment, 22, 231-252. http://dx.doi.org/10.1080/10627197.2017.1381554

*Willis, M. L. (2015). Emotional intelligence as a predictor of college student retention and success. (Unpublished doctoral dissertation). University of Nebraska, Lincoln, NE.

*Woitaszewski, S. A., \& Aalsma, M. C. (2004). The contribution of emotional intelligence to the social and academic success of gifted adolescents as measured by the Multifactor Emotional Intelligence Scale - Adolescent Version. Roeper Review: A Journal on Gifted Education, 27, 25-30. https://doi.org/10.1080/02783190409554285

*Wraight, M. E. (2008). The impact of trait emotional intelligence and cognitive style on the academic achievement and life satisfaction of college students. (Unpublished doctoral dissertation). The State University of New York at Buffalo, Buffalo, NY.

*Wurf, G., \& Croft-Piggin, L. (2015). Predicting the academic achievement of first-year, preservice teachers: The role of engagement, motivation, ATAR, and emotional intelligence. Asia-Pacific Journal of Teacher Education, 43, 75-91. https://doi.org/10.1080/1359866X.2014.932328

*Xu, J. (2018). Emotion regulation in mathematics homework: An empirical study. Journal of Educational Research, 111, 1-11. https://doi.org/10.1080/00220671.2016.1175409

*Yahaya, A., Ee, N. S., Bachock, J., Yahaya, N., Boon, Y., Hashim, S., \& Lee, G. M. (2012). The impact of emotional intelligence element on academic achievement. Archives Des Sciences, 65(4), 1-17. Retrieved from https://core.ac.uk/download/pdf/11798725.pdf

*Zandi, M. (2012). The role of emotional intelligence in French language learning and academic success of the female students. Procedia - Social and Behavioral Sciences, 46, 4986-4989. https://doi.org/10.1016/j.sbspro.2012.06.372

*Zarezadeh, T. (2013). The effect of emotional intelligence in English language learning. Procedia - Social and Behavioral Sciences, 84, 1286-1289. 
https://doi.org/10.1016/j.sbspro.2013.06.745

*Zirak, M., \& Ahmadian, E. (2015). Relationship between emotional intelligence \& academic achievement emphasizing on creative thinking. Mediterranean Journal of Social Sciences, 6(5S2), 561-570. https://doi.org/10.5901/mjss.2015.v6n5s2p561

*Zysberg, L., Levy, A., \& Zisberg, A. (2011). Emotional intelligence in applicant selection for care-related academic programs. Journal of Psychoeducational Assessment, 29, 27-38. https://doi.org/10.1177/0734282910365059 


\section{Table 1.}

Meta-analytic correlations of EI with positive life outcomes, by EI stream

Ability Self-Rated Mixed

\begin{tabular}{lccr} 
& EI & EI & EI \\
\hline Workplace performance (Joseph \& Newman, 2010) & .18 & .23 & .47 \\
Workplace Performance (O’Boyle et al., 2011) & .24 & .30 & .28 \\
Organizational Citizenship behaviours (Miao et al., 2017) & .17 & .57 & .48 \\
Counter-productive workplace behaviours (Miao et al., 2017) & .01 & -.38 & -.42 \\
Transformational Leadership (Harms \& Credé, 2010) & .24 & $.66^{\mathrm{a}}$ \\
Subjective well-being (Sanchez-Alvarez, et al., 2016) & .22 & .32 & .38 \\
Health (Schutte et al., 2007) & .11 & $.32^{\mathrm{a}}$ \\
Health (Martins et al., 2010) & .17 & $.34^{\mathrm{a}}$
\end{tabular}

$\overline{{ }^{a}}$ These analyses did not distinguish between rating scales based on mixed models and rating scales representing self-ratings of ability EI. 
Table 2.

Meta-analytic Results of the Overall Link between EI and Academic Performance and Subgroup Analyses-Overall EI, and by Streams 1, 2 and 3

\begin{tabular}{|c|c|c|c|c|c|c|c|c|c|}
\hline \multirow[t]{2}{*}{ Sub-group } & \multirow[t]{2}{*}{$n$} & \multirow[t]{2}{*}{$\boldsymbol{k}$} & \multirow[t]{2}{*}{$N$} & \multirow[t]{2}{*}{$r$} & \multirow[t]{2}{*}{ rho } & \multicolumn{2}{|c|}{$95 \%$ CI } & \multirow[t]{2}{*}{$I^{2}$} & \multirow[t]{2}{*}{$p$} \\
\hline & & & & & & Low & Upp & & \\
\hline Overall & 158 & 1,246 & 42,529 & .14 & .20 & .17 & .22 & $91.41 \%$ & $<.001$ \\
\hline \multicolumn{10}{|l|}{ Stream } \\
\hline Stream 1 & 50 & 383 & 8,826 & .16 & .24 & .18 & .30 & $92.39 \%$ & $<.001$ \\
\hline Stream 2 & 33 & 160 & 8,492 & .10 & .12 & .07 & .18 & $85.28 \%$ & $<.001$ \\
\hline Stream 3 & 90 & 703 & 27,939 & .13 & .19 & .15 & .22 & $91.49 \%$ & $<.001$ \\
\hline \multicolumn{10}{|l|}{ Education level } \\
\hline Primary & 13 & 91 & 2,329 & .14 & .22 & .10 & .34 & $91.81 \%$ & .001 \\
\hline Secondary & 60 & 507 & 16,139 & .16 & .23 & .18 & .28 & $91.93 \%$ & $<.001$ \\
\hline Tertiary & 103 & 643 & 28,596 & .11 & .16 & .13 & .20 & $90.64 \%$ & $<.001$ \\
\hline \multicolumn{10}{|c|}{ Achievement measure } \\
\hline Course grade & 141 & 1,050 & 38,759 & .14 & .20 & .17 & .23 & $91.24 \%$ & $<.001$ \\
\hline Stand. test & 37 & 196 & 8,178 & .12 & .17 & .10 & .23 & $93.53 \%$ & $<.001$ \\
\hline \multicolumn{10}{|l|}{ Publication Type } \\
\hline Journal Article & 82 & 684 & 23,798 & .14 & .19 & .15 & .23 & $91.35 \%$ & $<.001$ \\
\hline Unpublished & 76 & 562 & 18,731 & .14 & .20 & .16 & .24 & $91.57 \%$ & $<.001$ \\
\hline \multicolumn{10}{|l|}{ Subject Area } \\
\hline General & 125 & 687 & 33,941 & .13 & .19 & .16 & .22 & $89.60 \%$ & $<.001$ \\
\hline Humanities & 35 & 285 & 7,231 & .17 & .24 & .18 & .29 & $91.94 \%$ & $<.001$ \\
\hline Math/Science & 40 & 258 & 9,750 & .11 & .16 & .10 & .22 & $92.27 \%$ & $<.001$ \\
\hline Stream 1 (Ability) & 50 & 383 & 8,826 & .16 & .24 & .18 & .30 & $92.39 \%$ & $<.001$ \\
\hline \multicolumn{10}{|l|}{ Facet } \\
\hline Perception & 29 & 68 & 3,919 & .07 & .09 & .01 & .18 & $87.86 \%$ & .025 \\
\hline Facilitation & 25 & 53 & 3,234 & .12 & .18 & .09 & .27 & $90.52 \%$ & .001 \\
\hline Understanding & 29 & 85 & 4,815 & .22 & .35 & .28 & .43 & $94.01 \%$ & $<.001$ \\
\hline Management & 31 & 67 & 4,898 & .16 & .26 & .16 & .35 & $93.54 \%$ & $<.001$ \\
\hline \multicolumn{10}{|l|}{ Education level } \\
\hline Primary & 3 & 11 & 199 & .15 & .29 & -.86 & 1.43 & $96.92 \%$ & .394 \\
\hline Secondary & 25 & 176 & 5,177 & .20 & .30 & .22 & .38 & $90.99 \%$ & $<.001$ \\
\hline Tertiary & 35 & 196 & 5,515 & .11 & .18 & .11 & .24 & $89.13 \%$ & $<.001$ \\
\hline \multicolumn{10}{|c|}{ Achievement measure } \\
\hline Course grade & 46 & 291 & 8,406 & .15 & .24 & .17 & .30 & $92.07 \%$ & $<.001$ \\
\hline Stand. test & 19 & 92 & 3,135 & .17 & .24 & .12 & .36 & $94.84 \%$ & .001 \\
\hline \multicolumn{10}{|l|}{ Publication Type } \\
\hline Journal article & 25 & 183 & 5,443 & .17 & .28 & .20 & .36 & $92.52 \%$ & $<.001$ \\
\hline Unpublished & 25 & 200 & 3,383 & .14 & .21 & .11 & .30 & $92.45 \%$ & $<.001$ \\
\hline \multicolumn{10}{|l|}{ Subject Area } \\
\hline General & 40 & 207 & 6,608 & .14 & .22 & .16 & .28 & $90.25 \%$ & $<.001$ \\
\hline Humanities & 14 & 71 & 3,221 & .26 & .38 & .28 & .49 & $93.34 \%$ & $<.001$ \\
\hline Math/Science & 15 & 98 & 3,205 & .13 & .21 & .05 & .38 & $96.00 \%$ & .014 \\
\hline
\end{tabular}


Table 2 (continued)

\begin{tabular}{|c|c|c|c|c|c|c|c|c|c|}
\hline \multirow[t]{2}{*}{ Sub-group } & \multirow[t]{2}{*}{$n$} & \multirow[t]{2}{*}{$\boldsymbol{k}$} & \multirow[t]{2}{*}{$N$} & \multirow[t]{2}{*}{$\boldsymbol{r}$} & \multirow[t]{2}{*}{ rho } & \multicolumn{2}{|c|}{$95 \% \mathrm{CI}$} & \multirow[t]{2}{*}{$I^{2}$} & \multirow[t]{2}{*}{$p$} \\
\hline & & & & & & Lower & Upper & & \\
\hline Stream 2 (Self-rated) & 33 & 160 & 8,492 & .10 & .12 & .07 & .18 & $85.28 \%$ & $<.001$ \\
\hline \multicolumn{10}{|c|}{ Education level } \\
\hline Primary & 2 & 10 & 479 & .05 & .07 & .03 & .12 & $90.35 \%$ & .033 \\
\hline Secondary & 10 & 92 & 3,777 & .12 & .14 & .03 & .26 & $88.35 \%$ & .022 \\
\hline Tertiary & 24 & 58 & 4,676 & .08 & .10 & .03 & .18 & $83.32 \%$ & .006 \\
\hline \multicolumn{10}{|c|}{ Achievement measure } \\
\hline Course grade & 31 & 146 & 8,013 & .11 & .13 & .07 & .19 & $83.89 \%$ & $<.001$ \\
\hline Stand. test & 5 & 14 & 1,087 & -.03 & -.03 & -.18 & .13 & $84.29 \%$ & .67 \\
\hline \multicolumn{10}{|l|}{ Publication Type } \\
\hline Journal article & 24 & 134 & 6,757 & .10 & .13 & .06 & .20 & $84.50 \%$ & $<.001$ \\
\hline Unpublished & 9 & 26 & 1,735 & .08 & .10 & -.04 & .24 & $88.27 \%$ & .135 \\
\hline \multicolumn{10}{|l|}{ Subject Area } \\
\hline General & 27 & 73 & 5,337 & .10 & .13 & .06 & .19 & $82.01 \%$ & $<.001$ \\
\hline Humanities & 7 & 45 & 1,683 & .07 & .10 & .00 & .20 & $83.51 \%$ & .056 \\
\hline Math/Science & 9 & 37 & 3,722 & .05 & .07 & -.08 & .21 & $90.92 \%$ & .324 \\
\hline Stream 3 (Mixed) & 90 & 703 & 27,939 & .13 & .19 & .15 & .22 & $91.49 \%$ & $<.001$ \\
\hline \multicolumn{10}{|l|}{ Education level } \\
\hline Primary & 9 & 70 & 1,723 & .15 & .20 & .14 & .27 & $79.50 \%$ & $<.001$ \\
\hline Secondary & 33 & 239 & 9,035 & .15 & .20 & .13 & .27 & $90.64 \%$ & $<.001$ \\
\hline Tertiary & 53 & 389 & 19,715 & .11 & .17 & .12 & .21 & $92.67 \%$ & $<.001$ \\
\hline \multicolumn{10}{|c|}{ Achievement measure } \\
\hline Course grade & 78 & 613 & 24,996 & .14 & .20 & .16 & .24 & $91.58 \%$ & $<.001$ \\
\hline Stand. test & 19 & 90 & 5,088 & .08 & .10 & .04 & .16 & $88.18 \%$ & 0.004 \\
\hline \multicolumn{10}{|l|}{ Publication Type } \\
\hline Journal article & 48 & 336 & 14,585 & .13 & .19 & .14 & .24 & $91.76 \%$ & $<.001$ \\
\hline Unpublished & 42 & 367 & 13,354 & .13 & .18 & .13 & .23 & $91.25 \%$ & $<.001$ \\
\hline \multicolumn{10}{|l|}{ Subject Area } \\
\hline General & 68 & 407 & 23,439 & .13 & .19 & .15 & .23 & $90.29 \%$ & $<.001$ \\
\hline Humanities & 22 & 169 & 4,406 & .12 & .17 & .11 & .22 & $79.62 \%$ & $<.001$ \\
\hline Math/Science & 22 & 123 & 4,488 & .10 & .13 & .07 & .19 & $89.16 \%$ & $<.001$ \\
\hline
\end{tabular}


Table 3.

Meta-Regressions testing Moderators of EI/Academic Performance Link (multiple regressions with all moderators in same equation)

\begin{tabular}{|c|c|c|c|c|c|}
\hline \multirow[t]{2}{*}{ Moderator } & \multirow[t]{2}{*}{$b$} & \multirow[t]{2}{*}{ SE } & \multicolumn{2}{|c|}{$95 \%$ CI } & \multirow[t]{2}{*}{$p$} \\
\hline & & & Lower & Upper & \\
\hline \multicolumn{6}{|l|}{ Overall EI $(k=1,057)$} \\
\hline Publication type & -.013 & .031 & -.073 & .048 & .680 \\
\hline Age & -.004 & .003 & -.009 & .002 & .191 \\
\hline Gender ( $\%$ female $)$ & -.002 & .001 & -.003 & .000 & .026 \\
\hline \multicolumn{6}{|l|}{ Stream ${ }^{a}$} \\
\hline Ability vs Others & .070 & .024 & .021 & .118 & .006 \\
\hline Self-rated vs. mixed & -.017 & .019 & -.054 & .021 & .372 \\
\hline \multicolumn{6}{|l|}{ Subject area ${ }^{b}$} \\
\hline General vs others & .016 & .019 & -.022 & .055 & .401 \\
\hline Math/science vs. humanities ${ }^{b}$ & .034 & .017 & -.001 & .068 & .057 \\
\hline Performance type & -.071 & .034 & -.140 & -.002 & .045 \\
\hline \multicolumn{6}{|l|}{ Stream 1: Ability $(k=331)$} \\
\hline Publication type & .062 & .058 & -.057 & .180 & .296 \\
\hline Age & -.006 & .008 & -.023 & .010 & .428 \\
\hline Gender ( $\%$ female $)$ & .000 & .002 & -.004 & .004 & .852 \\
\hline \multicolumn{6}{|l|}{ Subject area ${ }^{b}$} \\
\hline General vs others & .090 & .036 & .013 & .167 & .025 \\
\hline Math/science vs. humanities & .082 & .037 & .003 & .162 & .043 \\
\hline Performance type & -.086 & .065 & -.221 & .050 & .202 \\
\hline \multicolumn{6}{|l|}{ Stream 2: Self-rated $(k=140)$} \\
\hline Publication type & .008 & .078 & -.165 & .181 & .918 \\
\hline Age & -.010 & .007 & -.025 & .006 & .188 \\
\hline Gender ( $\%$ female $)$ & -.003 & .001 & -.006 & .001 & .088 \\
\hline \multicolumn{6}{|l|}{ Subject area ${ }^{b}$} \\
\hline General vs others & .003 & .046 & -.104 & .110 & .950 \\
\hline Math/science vs. humanities & -.005 & .038 & -.094 & .084 & .896 \\
\hline Performance type & -.219 & .070 & -.384 & -.053 & .017 \\
\hline \multicolumn{6}{|l|}{ Stream 3: Mixed $(k=586)$} \\
\hline Publication type & -.015 & .039 & -.094 & .064 & .702 \\
\hline Age & -.002 & .003 & -.009 & .005 & .530 \\
\hline Gender ( $\%$ female $)$ & -.002 & .001 & -.004 & .001 & .161 \\
\hline \multicolumn{6}{|l|}{ Subject area } \\
\hline General vs others & -.015 & .024 & -.065 & .034 & .527 \\
\hline Math/science vs. humanities & .020 & .016 & -.013 & .052 & .222 \\
\hline Performance type & -.072 & .044 & -.163 & .019 & .115 \\
\hline
\end{tabular}




\section{Table 4.}

Meta-analytic Correlation Matrix of EI (Stream 1 Total and Four Branches, Stream 2, and Stream 3), Academic Performance, Cognitive Ability, and Big Five Personality (EI/Academic Performance and Intelligence/Academic Performance Cells from Current Meta-analysis)

\begin{tabular}{|c|c|c|c|c|c|c|c|c|c|c|c|c|c|}
\hline & & & $\begin{array}{c}\text { Stream } 1 \\
\text { EI }\end{array}$ & & & $\begin{array}{c}\text { Stream } 2 \\
\text { EI }\end{array}$ & $\begin{array}{c}\text { Stream } 3 \\
\text { EI }\end{array}$ & Perf & $g$ & $\mathrm{O}$ & $\mathrm{C}$ & $\mathrm{E}$ & A \\
\hline & Total & Perc & Fac & Und & Man & & & & & & & & \\
\hline \multirow[t]{2}{*}{ Perf } & $.24^{\mathrm{a}}$ & $.09^{\mathrm{a}}$ & $.18^{\mathrm{a}}$ & $.35^{\mathrm{a}}$ & $.26^{\mathrm{a}}$ & $.12^{\mathrm{a}}$ & $.19^{\mathrm{a}}$ & & & & & & \\
\hline & $50 / 8,826$ & $29 / 3,919$ & $25 / 3,234$ & $29 / 4,815$ & $31 / 4,898$ & $33 / 8,492$ & $90 / 27,939$ & & & & & & \\
\hline \multirow[t]{2}{*}{$g$} & $.25^{\mathrm{b}}$ & $.10^{\mathrm{b}}$ & $.18^{\mathrm{b}}$ & $.39^{\mathrm{b}}$ & $.16^{\mathrm{b}}$ & $.00^{\mathrm{b}}$ & $.11^{\mathrm{b}}$ & $.39^{\mathrm{a}}$ & & & & & \\
\hline & $28 / 5,383$ & $21 / 4,710$ & $18 / 3,971$ & $20 / 4,581$ & $19 / 4,277$ & $16 / 2,158$ & $19 / 2,880$ & $27 / 4,801$ & & & & & \\
\hline \multirow[t]{2}{*}{$\mathrm{O}$} & $.14^{\mathrm{c}}$ & $.07^{\mathrm{c}}$ & $.10^{\mathrm{c}}$ & $.18^{\mathrm{c}}$ & $.16^{\mathrm{c}}$ & $.29^{b}$ & $.29^{\mathrm{b}}$ & $.12^{\mathrm{d}}$ & $.22^{\mathrm{e}}$ & & & & \\
\hline & $47 / 10,258$ & $23 / 3,582$ & $23 / 3,582$ & $22 / 3,374$ & $22 / 3,374$ & $26 / 8,479$ & $30 / 5,386$ & $113 / 60,442$ & $46 / 13,182$ & & & & \\
\hline \multirow[t]{2}{*}{$\mathrm{C}$} & $.09^{\mathrm{c}}$ & $.28^{\mathrm{c}}$ & $.11^{\mathrm{c}}$ & $.09^{\mathrm{c}}$ & $.16^{\mathrm{c}}$ & $.38^{b}$ & $.38^{\mathrm{b}}$ & $.22^{\mathrm{d}}$ & $-.04^{\mathrm{e}}$ & $.24^{\mathrm{f}}$ & & & \\
\hline & $47 / 10,258$ & $23 / 3,582$ & $23 / 3,582$ & $22 / 3,374$ & $22 / 3,374$ & $27 / 8,566$ & $31 / 5,591$ & $138 / 70,926$ & $56 / 15,429$ & n.r./39,595 & & & \\
\hline \multirow[t]{2}{*}{$\mathrm{E}$} & $.05^{\mathrm{c}}$ & $.09^{\mathrm{c}}$ & $.10^{\mathrm{c}}$ & $.07^{\mathrm{c}}$ & $.18^{c}$ & $.32^{b}$ & $.46^{\mathrm{b}}$ & $-.01^{\mathrm{d}}$ & $.02^{\mathrm{e}}$ & $.39^{\mathrm{f}}$ & $.27^{\mathrm{f}}$ & & \\
\hline & $47 / 10,258$ & $24 / 3,696$ & $23 / 3,582$ & $22 / 3,374$ & $22 / 3,374$ & $26 / 8,479$ & $30 / 5,552$ & $113 / 59,986$ & $61 / 21,602$ & n.r./39,595 & n.r./39,595 & & \\
\hline \multirow[t]{2}{*}{ A } & $.16^{\mathrm{c}}$ & $.15^{\mathrm{c}}$ & $.17^{\mathrm{c}}$ & $.12^{\mathrm{c}}$ & $.30^{c}$ & $.31^{\mathrm{b}}$ & $.43^{\mathrm{b}}$ & $.07^{\mathrm{d}}$ & $.00^{\mathrm{e}}$ & $.30^{\mathrm{f}}$ & $.46^{\mathrm{f}}$ & $.33^{\mathrm{f}}$ & \\
\hline & $47 / 10,258$ & $23 / 3,582$ & $23 / 3,582$ & $22 / 3,374$ & $22 / 3,374$ & $23 / 8,479$ & $30 / 5,386$ & $109 / 58,552$ & $38 / 11,190$ & n.r./39,595 & n.r./39,595 & n.r./39,595 & \\
\hline \multirow[t]{2}{*}{$\mathrm{N}$} & $-.09^{c}$ & $-.12^{c}$ & $-.11^{\mathrm{c}}$ & $-.09^{c}$ & $-.17^{\mathrm{c}}$ & $-.04^{b}$ & $-.53^{b}$ & $-.02^{\mathrm{d}}$ & $-.09^{\mathrm{e}}$ & $-.18^{f}$ & $-.36^{f}$ & $-.37^{f}$ & $-.34^{\mathrm{f}}$ \\
\hline & $47 / 10,258$ & $24 / 3,696$ & $23 / 3,582$ & $22 / 3,374$ & $22 / 3,374$ & $26 / 8479$ & $30 / 5,386$ & $114 / 59,554$ & $61 / 21,404$ & n.r./39,595 & n.r./39,595 & n.r./39,595 & n.r./39,595 \\
\hline
\end{tabular}

Note. $\mathrm{g}=$ intelligence; Perf = academic performance; $\mathrm{O}=$ Openness to experience; $\mathrm{C}=$ Conscientiousness; $\mathrm{E}=\mathrm{Extraversion}$; $\mathrm{A}=\mathrm{Agreeableness}$; $\mathrm{N}=$ Neuroticism; Perc $=$ Emotion Perception; $\mathrm{Fac}=$ Emotion Facilitation; Und = Understanding Emotions; Man = Managing Emotions.

${ }^{a}$ Original meta-analysis; ${ }^{b}$ Joseph and Newman (2010); ${ }^{c}$ van der Linden, Pekaar, Bakker, Schermer, Vernon, Dunkel, \& Petrides (2016); ${ }^{\mathrm{d}}$ Poropat (2009); ' Judge, Jackson, Shaw, Scott, \& Rich (2007); fvan der Linden, te Nijenhuis, \& Bakker (2010), university student population. 
Table 5.

Regressions Predicting Academic Performance from Intelligence (Step 1), Personality (Step 2), and EI (Step 3) based on the Correlation Matrix shown in Table 3: Ability EI versus Self-rated EI versus Mixed EI

\begin{tabular}{|c|c|c|c|c|c|c|c|c|c|c|c|c|}
\hline & \multicolumn{4}{|c|}{$\begin{array}{l}\text { Stream 1: Ability EI } \\
\left(N_{\text {harmonic }}=18,367\right)\end{array}$} & \multicolumn{4}{|c|}{$\begin{array}{l}\text { Stream 2: Self-rated of EI } \\
\qquad\left(N_{\text {harmonic }}=14,647\right)\end{array}$} & \multicolumn{4}{|c|}{$\begin{array}{l}\text { Stream 3: Mixed EI } \\
\left(N_{\text {harmonic }}=12,939\right)\end{array}$} \\
\hline & $\beta$ & $\Delta R^{2}$ & RW & RW\% & $\beta$ & $\Delta R^{2}$ & RW & RW\% & $\beta$ & $\Delta R^{2}$ & RW & RW\% \\
\hline Step 1 & & $.152^{* *}$ & & & & $.152^{*}$ & & & & $.152^{*}$ & & \\
\hline Intelligence & $.38^{* *}$ & & .152 & $69.42 \%$ & $.42^{* *}$ & & .143 & $62.01 \%$ & $.40^{* *}$ & & .135 & $58.01 \%$ \\
\hline Step 2 & & $.071^{* *}$ & & & & $.071^{*}$ & & & & $.071^{*}$ & & \\
\hline Openness & .00 & & .005 & $2.49 \%$ & -.01 & & .006 & $2.42 \%$ & -.01 & & .005 & $2.29 \%$ \\
\hline Conscientiousness & $.29^{* *}$ & & .044 & $20.20 \%$ & $.27^{* *}$ & & .045 & $19.52 \%$ & $.27^{* *}$ & & .049 & $21.05 \%$ \\
\hline Extraversion & $-.05^{* *}$ & & .004 & $1.87 \%$ & $-.07^{* *}$ & & .006 & $2.75 \%$ & $-.10^{* *}$ & & .003 & $1.32 \%$ \\
\hline Agreeableness & $-.03^{* *}$ & & .003 & $1.17 \%$ & $-.02^{*}$ & & .003 & $1.36 \%$ & $-.05^{* *}$ & & .003 & $1.24 \%$ \\
\hline Neuroticism & $.10^{* *}$ & & .002 & $0.88 \%$ & $.12^{* *}$ & & .004 & $1.65 \%$ & $.16^{* *}$ & & .002 & $0.81 \%$ \\
\hline Step 3 & & $.017^{* *}$ & & & & $.007^{*}$ & & & & $.023^{*}$ & & \\
\hline EI & $.14^{* *}$ & & .009 & $3.96 \%$ & $.09^{* *}$ & & .024 & $10.28 \%$ & $.20^{* *}$ & & .036 & $15.28 \%$ \\
\hline Total $R^{2}$ & & $.240^{* *}$ & & & & $.230^{*}$ & & & & $.248^{*}$ & & \\
\hline
\end{tabular}

${ }^{*} p<.05,{ }^{* *} p<.01$ 
Table 6.

Regressions Predicting Academic Performance from Intelligence (Step 1), Personality (Step 2), and EI (Step 3) based on the Correlation Matrix shown in Table 3 for the four branches of Ability EI

\begin{tabular}{|c|c|c|c|c|c|c|c|c|c|c|c|c|c|c|c|c|}
\hline & \multicolumn{4}{|c|}{$\begin{array}{l}\text { Emotion Perception } \\
\left(N_{\text {harmonic }}=11,049\right)\end{array}$} & \multicolumn{4}{|c|}{$\begin{array}{l}\text { Emotion Facilitation } \\
\left(N_{\text {harmonic }}=10,586\right)\end{array}$} & \multicolumn{4}{|c|}{$\begin{array}{l}\text { Emotion Understanding } \\
\qquad\left(N_{\text {harmonic }}=10,786\right)\end{array}$} & \multicolumn{4}{|c|}{$\begin{array}{l}\text { Emotion Management } \\
\qquad\left(N_{\text {harmonic }}=10,736\right)\end{array}$} \\
\hline & $\beta$ & $\Delta R^{2}$ & RW & RW\% & $\beta$ & $\Delta R^{2}$ & RW & RW\% & $\beta$ & $\Delta R^{2}$ & RW & RW\% & $\beta$ & $\Delta R^{2}$ & RW & RW\% \\
\hline Step 1 & \multicolumn{4}{|c|}{$.152^{* *}$} & \multicolumn{4}{|c|}{$.152^{* *}$} & \multicolumn{4}{|c|}{$.152^{* *}$} & \multicolumn{4}{|c|}{$.152^{* *}$} \\
\hline Intelligence & $.41^{* *}$ & & .150 & $69.62 \%$ & $.39^{* *}$ & & .142 & $63.28 \%$ & .33 & & .115 & $45.48 \%$ & $.38^{* *}$ & & .138 & $54.98 \%$ \\
\hline Step 2 & \multicolumn{4}{|c|}{$.071^{* *}$} & \multicolumn{4}{|c|}{$.071^{* *}$} & \multicolumn{4}{|c|}{$.071^{* *}$} & \multicolumn{4}{|c|}{$.071^{* *}$} \\
\hline Openness & .00 & & .006 & $2.83 \%$ & .00 & & .006 & $2.63 \%$ & -.01 & & .005 & $1.88 \%$ & .00 & & .006 & $2.23 \%$ \\
\hline Conscientiousness & $.30^{* *}$ & & .049 & $22.50 \%$ & $.29^{* *}$ & & .049 & $21.76 \%$ & $.28^{* *}$ & & .048 & $18.79 \%$ & $.29^{* *}$ & & .048 & $19.28 \%$ \\
\hline Extraversion & $-.06^{* *}$ & & .003 & $1.53 \%$ & $-.06^{* *}$ & & .003 & $1.56 \%$ & $-.06^{* *}$ & & .003 & $1.26 \%$ & $-.07^{* *}$ & & .004 & $1.73 \%$ \\
\hline Agreeableness & -.01 & & .003 & $1.36 \%$ & -.03 & & .003 & $1.27 \%$ & $-.03^{* *}$ & & .003 & $1.12 \%$ & $-.06^{* *}$ & & .004 & $1.41 \%$ \\
\hline Neuroticism & $.10^{* *}$ & & .002 & $0.86 \%$ & $.10^{* *}$ & & .002 & $0.84 \%$ & $.09^{* *}$ & & .002 & $0.76 \%$ & $.10^{* *}$ & & .002 & $0.83 \%$ \\
\hline Step 3 & \multicolumn{4}{|c|}{.000} & \multicolumn{4}{|c|}{$.009^{* *}$} & \multicolumn{4}{|c|}{$.039^{* *}$} & \multicolumn{4}{|c|}{$.036^{* *}$} \\
\hline EI & -.02 & & .003 & $1.30 \%$ & $.10^{* *}$ & & .019 & $8.67 \%$ & $.22^{* *}$ & & .078 & $30.72 \%$ & $.20^{* *}$ & & .049 & $19.54 \%$ \\
\hline Total $R^{2}$ & \multicolumn{4}{|c|}{$.222^{* *}$} & \multicolumn{4}{|c|}{$.232^{* *}$} & \multicolumn{4}{|c|}{$.261^{* *}$} & \multicolumn{4}{|c|}{$.258^{* *}$} \\
\hline
\end{tabular}

${ }^{*} p<.05,{ }^{* *} p<.01$ 


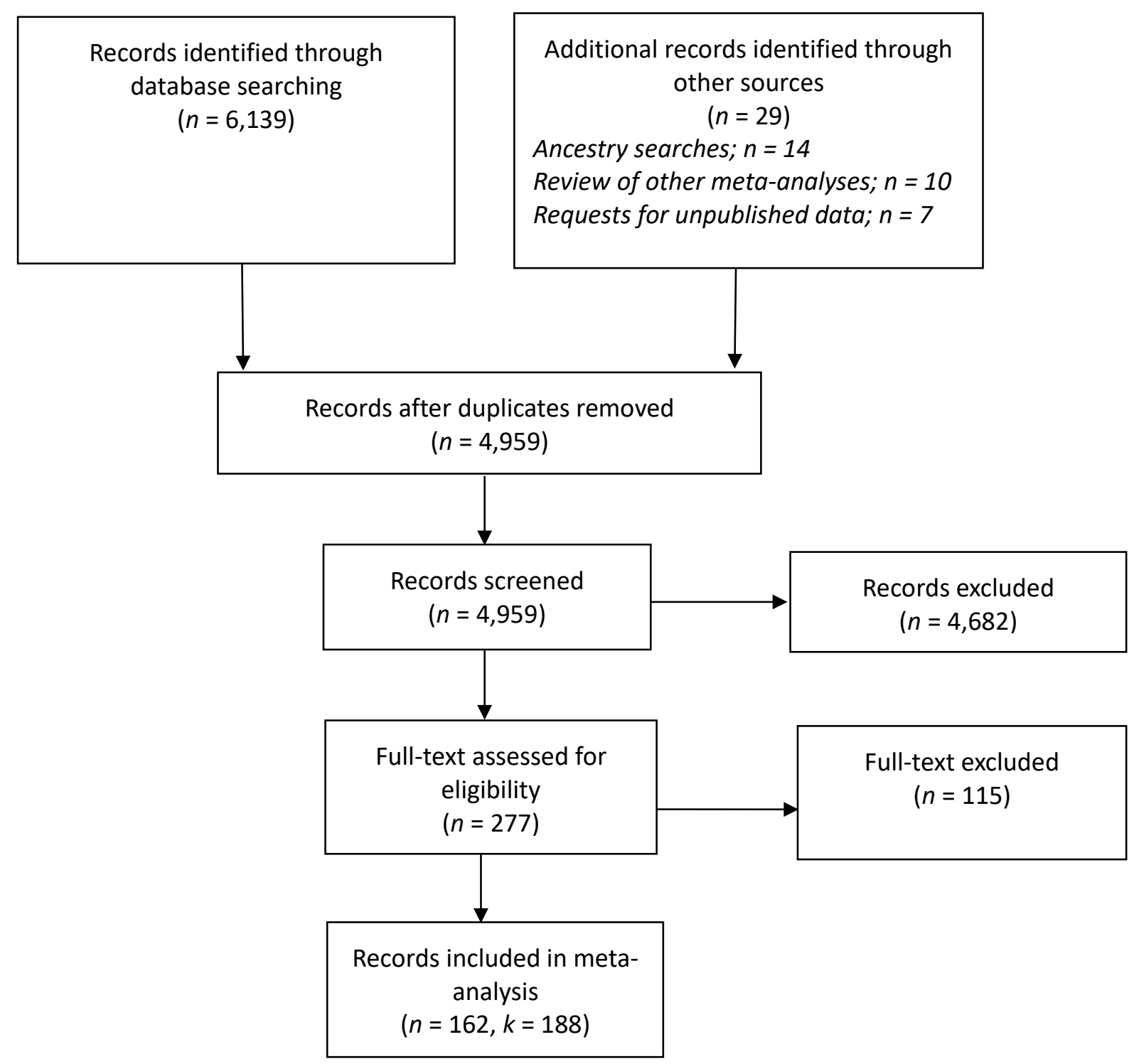

Figure 1. PRISMA flow chart for the identification, screening, and inclusion of publications in the meta-analyses. 


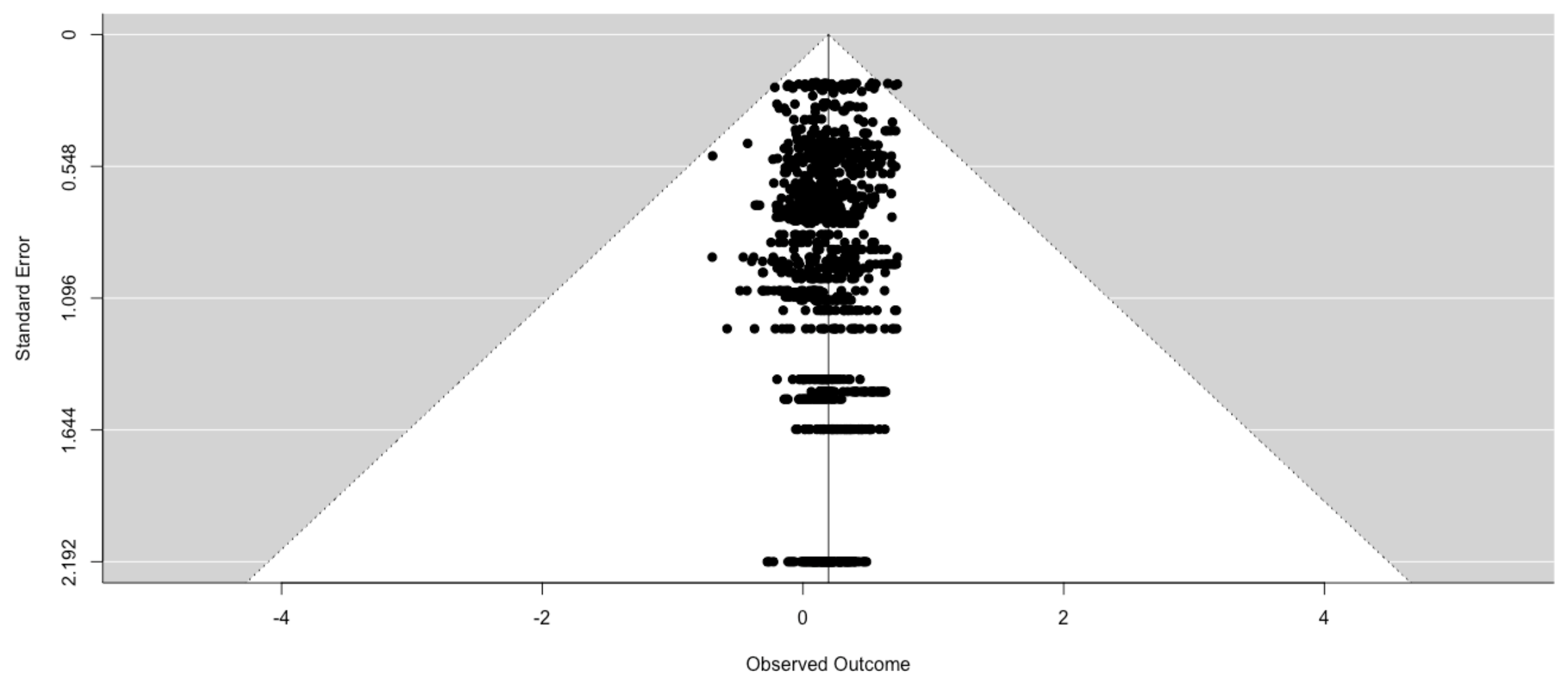

Figure 2. Funnel plot for overall analysis of EI with academic achievement. 


\section{Sub-group}

\section{Stream}

Ability

Self-report

Mixed

\section{Education level}

Primary

Secondary

Tertiary

Achievement measure

Course grade

Standardized test

\section{Publication Type}

Unpublished

Journal Article

\section{Subject Area}

General

Math/sciences

Humanities

\section{Overall}
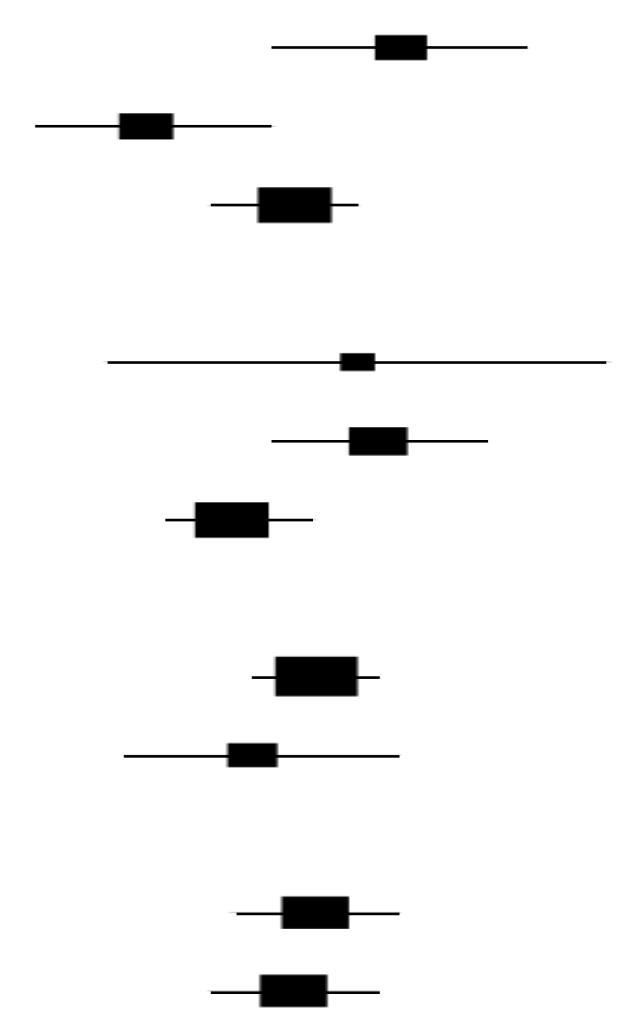

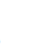




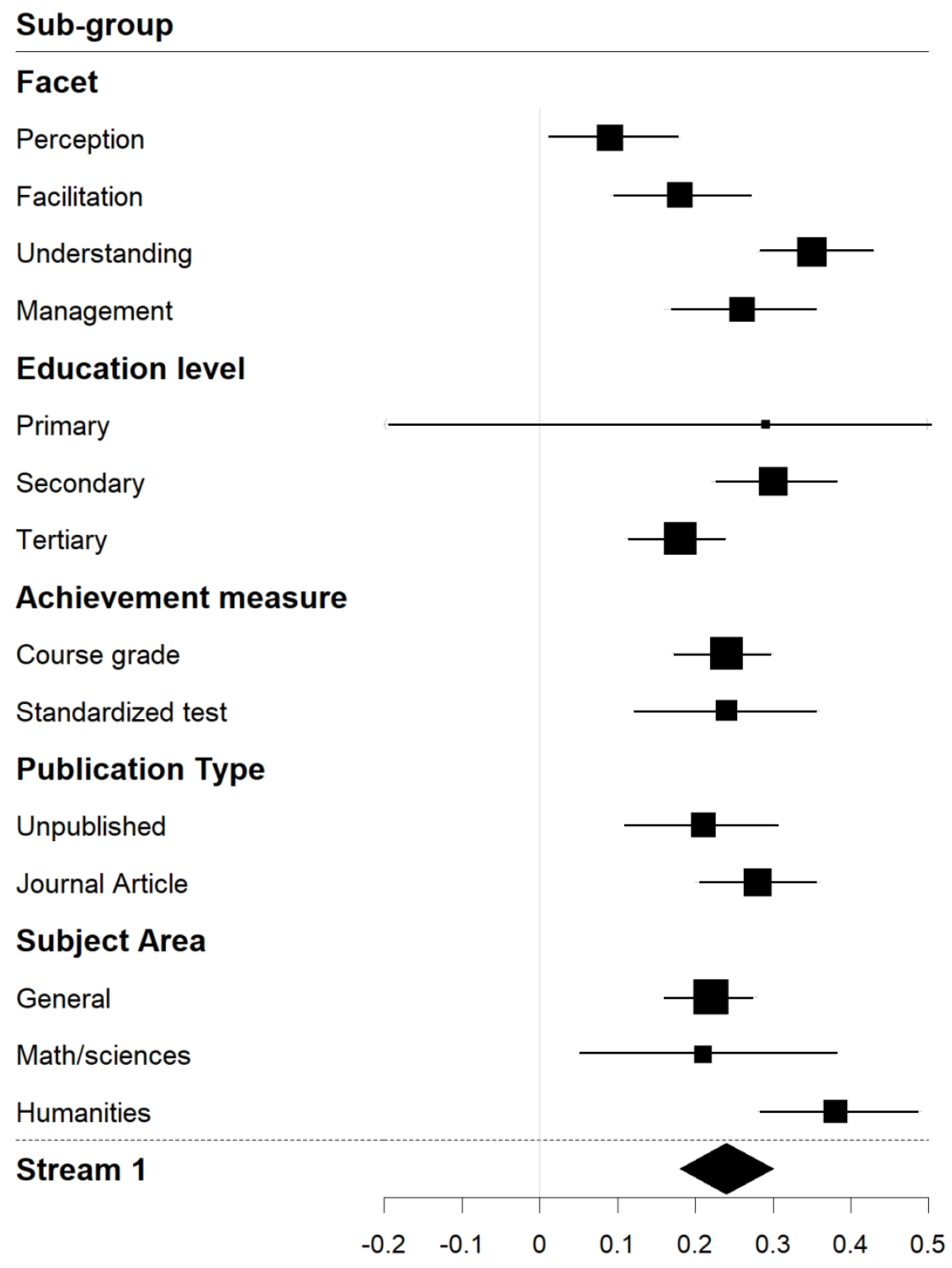

Figure 4. Forest plot for analysis of Stream 1 EI with academic achievement, showing separate effects by facet, education level, achievement measure, publication type and subject area 


\section{Sub-group}

\section{Education level}

Primary

Secondary

Tertiary

Achievement measure

Course grade

Standardized test

Publication Type

Unpublished

Journal Article

Subject Area

General

Math/sciences

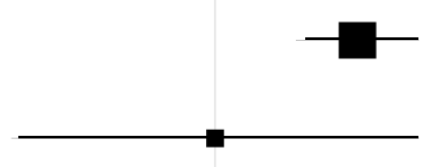

Humanities

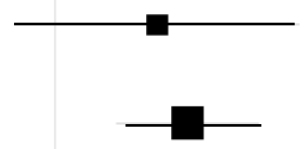

Stream 2

Figure 5. Forest plot for analysis of Stream 2 EI with academic achievement, showing separate effects by education level, achievement measure, publication type and subject area 
Sub-group

\section{Education level}

Primary

Secondary

Tertiary

Achievement measure

Course grade

Standardized test

Publication Type

Unpublished

Journal Article

Subject Area

General

Math/sciences

Humanities

Stream 3

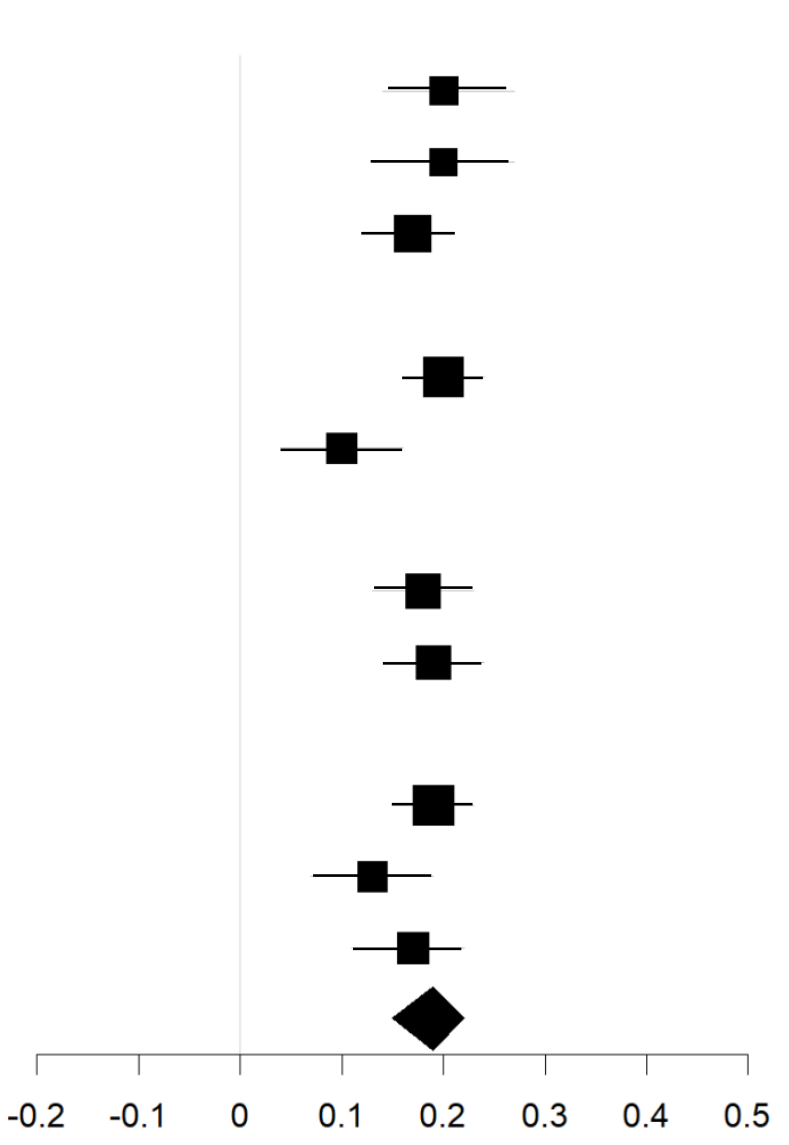

Figure 6. Forest plot for analysis of Stream 1 EI with academic achievement, showing separate effects by education level, achievement measure, publication type and subject area 


\section{Appendix A. Brief Descriptions of All Data Sources Meeting Inclusion Criteria}

\begin{tabular}{|c|c|c|c|c|c|c|c|}
\hline Authors & Year & $N^{\mathrm{a}}$ & Country & $\begin{array}{c}\begin{array}{c}\text { Education } \\
\text { level }\end{array} \\
\end{array}$ & $\begin{array}{c}\begin{array}{c}\text { Publication } \\
\text { type }\end{array} \\
\end{array}$ & Stream $^{\mathrm{c}}$ & $r^{d}$ \\
\hline Abdo & 2012 & 266 & $1 \mathrm{USA}$ & secondary & dissertation & 1 & .12 \\
\hline Abdullah et al. & 2004 & 205 & $\begin{array}{l}1 \text { Kuala Lumpur \& } \\
\text { Malaysia }\end{array}$ & secondary & article & 3 & .19 \\
\hline Abel & 2013 & 78 & $1 \mathrm{USA}$ & secondary & dissertation & 1 & .15 \\
\hline Adeyemo & 2007 & 300 & 1 Nigeria & tertiary & article & 2 & .33 \\
\hline Afolabi et al. & 2009 & 110 & 1 Nigeria & tertiary & article & 1 & .20 \\
\hline Agnoli et al. & 2012 & 352 & 2 Italy & primary & article & 1 & .16 \\
\hline Ahammed et al. & 2011 & 204 & $7 \mathrm{UAE}$ & tertiary & article & 3 & -.08 \\
\hline Ahmad & 2011 & 291 & 6 Pakistan & tertiary & article & 1 & .17 \\
\hline Ahmad \& Rana & 2012 & 538 & 1 Pakistan & tertiary & article & 1 & .08 \\
\hline Alhashemi & 2014 & 136 & 1 Bahrain & tertiary & article & 2 & .10 \\
\hline Alumran \& Punamaki & 2008 & 312 & 5 Bahrain & mixed & article & 1 & .08 \\
\hline Amdurer, et al. & 2014 & 266 & $1 \mathrm{USA}$ & tertiary & article & 1 & -.02 \\
\hline Anand, et al. & 2016 & 390 & 1 India & tertiary & article & 1 & .74 \\
\hline Arbabisarjou et al. & 2013 & 2501 & 12 Iran & tertiary & $\begin{array}{l}\text { conference } \\
\text { paper }\end{array}$ & 1 & .62 \\
\hline Aremu et al. & 2006 & 300 & 1 Nigeria & secondary & article & 2 & .31 \\
\hline Barchard & 2003 & 1501 & 13 USA & tertiary & article & 2,3 & .05 \\
\hline Barisonek & 2005 & 441 & 15 USA & primary & dissertation & 1 & .02 \\
\hline Bastian et al. & 2005 & 1851 & 10 Australia & tertiary & article & 2,3 & .09 \\
\hline Berenson et al. & 2008 & 82 & $1 \mathrm{USA}$ & tertiary & article & 2 & .33 \\
\hline Biggart & 2019 & 89 & $1 \mathrm{UK}$ & tertiary & unpublished & 3 & .19 \\
\hline Billings et al. & 2014 & 407 & 8 Australia & primary & article & 2 & .05 \\
\hline Bowman & 2007 & 482 & 27 USA & tertiary & dissertation & 3 & .15 \\
\hline Boyce & 2002 & 57 & 5 USA & tertiary & dissertation & 3 & .16 \\
\hline Brackett \& Mayer & 2003 & 207 & 9 USA & tertiary & article & $1,2,3$ & .10 \\
\hline Brackett et al. & 2004 & 330 & 6 USA & tertiary & article & 3 & .23 \\
\hline Bradshaw & 2008 & 60 & 7 USA & tertiary & dissertation & 1,3 & .17 \\
\hline Brouzos et al. & 2014 & 1032 & 20 Egypt & primary & article & 1 & .17 \\
\hline Carrothers et al. & 2000 & 147 & 2 USA & secondary & article & 1 & .11 \\
\hline Castro-Johnson \& Wang & 2003 & 520 & 2 USA & tertiary & article & 3 & .15 \\
\hline Catalina et al. & 2012 & 92 & 1 Romania & tertiary & article & 2 & -.08 \\
\hline Cavins & 2006 & 73 & $1 \mathrm{USA}$ & tertiary & dissertation & 1 & .33 \\
\hline Chapman \& Hayslip & 2005 & 292 & $1 \mathrm{USA}$ & tertiary & article & 2 & .08 \\
\hline Cheshire et al. & 2015 & 851 & 10 USA & tertiary & article & 3 & .11 \\
\hline Chew et al. & 2013 & 1631 & 14 Malaysia & tertiary & article & 3 & .17 \\
\hline Clark & 2004 & 161 & 2 USA & secondary & dissertation & 1 & .20 \\
\hline Codier \& Odell & 2014 & 72 & $2 \mathrm{USA}$ & tertiary & article & 3 & .25 \\
\hline Collins & 2013 & 65 & 5 USA & tertiary & dissertation & 3 & -.01 \\
\hline Colston & 2008 & 115 & $1 \mathrm{USA}$ & tertiary & dissertation & 1 & .17 \\
\hline Costa \& Faria & 2015 & 3805 & 54 Portugal & secondary & article & 2,3 & .21 \\
\hline Cyr, 2007 & 2007 & 2371 & 10 USA & tertiary & dissertation & 3 & .03 \\
\hline Di Fabio \& Palazzeschi & 2009 & 1241 & 10 Italy & secondary & article & 1,3 & .22 \\
\hline Di Fabio \& Palazzeschi & 2015 & 133 & 1 Italy & secondary & article & 1 & .53 \\
\hline Doring & 2006 & 72 & 4 USA & primary & dissertation & 2,3 & -.02 \\
\hline Downey et al. & 2014 & 242 & 4 Australia & secondary & article & 2 & .08 \\
\hline Downey et al. & 2008 & 1584 & 45 Australia & secondary & article & 2 & .10 \\
\hline Drago & 2005 & 32 & 5 USA & tertiary & dissertation & 3 & .31 \\
\hline Drati & 2010 & 165 & 5 USA & secondary & dissertation & 1 & .11 \\
\hline Edison & 2003 & 611 & 15 USA & tertiary & dissertation & 3 & .08 \\
\hline Evenson & 2008 & 100 & $6 \mathrm{USA}$ & tertiary & dissertation & 1 & .18 \\
\hline ETS & 2019 & 590 & 2 USA & Tertiary & Unpublished & 3 & .15 \\
\hline Fahim \& Pishghadam & 2007 & 508 & 6 Iran & tertiary & $\begin{array}{l}\text { conference } \\
\text { paper }\end{array}$ & 1 & .18 \\
\hline Fallahzadeh & 2011 & 223 & 6 Iran & tertiary & $\begin{array}{l}\text { conference } \\
\text { paper }\end{array}$ & 1 & .09 \\
\hline
\end{tabular}




\begin{tabular}{|c|c|c|c|c|c|c|}
\hline Fannin & 2002 & 1158 USA & secondary & dissertation & 3 & .37 \\
\hline Fatum & 2008 & 753 USA & primary & dissertation & 1 & .10 \\
\hline Fayombo & 2012 & 1517 Barbados & tertiary & article & 1 & .25 \\
\hline Feldman & 2004 & 7910 USA & tertiary & dissertation & 3 & -.12 \\
\hline Garg et al. & 2016 & 29912 Canada & tertiary & article & 1 & .08 \\
\hline Gibson & 2005 & 406 USA & tertiary & dissertation & 2,3 & -.01 \\
\hline Gilbert & 2003 & $17012 \mathrm{UK}$ & tertiary & dissertation & 2 & .04 \\
\hline Glickman-Rogers & 2010 & 2058 USA & secondary & dissertation & 3 & .32 \\
\hline Goodwin & 2016 & 1984 USA & tertiary & dissertation & 1 & .32 \\
\hline Hall \& West & 2011 & 743 USA & tertiary & article & 3 & .05 \\
\hline Hogan & 2003 & 67310 Canada & tertiary & dissertation & 1 & .05 \\
\hline Hogan et al. & 2010 & 441 Canada & secondary & dissertation & 1 & .35 \\
\hline Holt & 2007 & 12410 USA & tertiary & dissertation & 3 & .09 \\
\hline Humphrey-Murto et al. & 2014 & 11312 Canada & tertiary & article & 3 & .09 \\
\hline Izaguirre & 2008 & 1996 USA & tertiary & dissertation & 1 & .06 \\
\hline Jaeger & 2003 & 7524 USA & tertiary & article & 1 & .20 \\
\hline Jang et al. & 2019 & 27827 USA & tertiary & unpublished & $1,2,3$ & -.02 \\
\hline Johnson & 2008 & 1114 USA & tertiary & dissertation & 3 & .02 \\
\hline Jones & 2014 & $381 \mathrm{USA}$ & secondary & dissertation & 3 & .28 \\
\hline Jordan et al. & 2010 & 8620 Ireland & secondary & article & 1 & .08 \\
\hline Kaliska & 2015 & 16910 Slovak Republic & secondary & article & 1 & .19 \\
\hline Khajehpour & 2011 & 3001 Iran & secondary & $\begin{array}{l}\text { conference } \\
\text { paper }\end{array}$ & 2 & .32 \\
\hline Killen & 2016 & $472 \mathrm{USA}$ & secondary & dissertation & 1 & .60 \\
\hline Kracher & 2009 & $1091 \mathrm{USA}$ & tertiary & dissertation & 1 & .01 \\
\hline Kumar et al. & 2016 & 2001 India & tertiary & article & 1 & .24 \\
\hline Kumar et al. & 2013 & 4501 India & secondary & article & 1 & .08 \\
\hline Kvapil & 2007 & 23725 USA & secondary & dissertation & 3 & .30 \\
\hline Lanciano \& Curci & 2014 & 895 Italy & tertiary & article & 3 & .44 \\
\hline Lasser & 1997 & $641 \mathrm{USA}$ & tertiary & dissertation & 1 & .09 \\
\hline Lawrence \& Deepa & 2013 & 4001 India & secondary & article & 1 & .17 \\
\hline Leddy et al & 2011 & $3302 \mathrm{USA}$ & tertiary & article & 3 & -.09 \\
\hline Lewis & 2004 & 932 USA & tertiary & dissertation & 2,3 & -.01 \\
\hline Libbrecht et al. & 2014 & 3676 Europe & tertiary & article & 3 & .13 \\
\hline Lochner & 2016 & $1191 \mathrm{USA}$ & tertiary & dissertation & 2 & .05 \\
\hline Loera & 2013 & 10510 USA & tertiary & dissertation & 3 & .17 \\
\hline $\mathrm{Lu}$ & 2010 & $\begin{array}{r}219 \\
5\end{array}$ & tertiary & dissertation & 1 & .05 \\
\hline Lui & 2009 & 10848 USA \& Canada & secondary & dissertation & 1 & .08 \\
\hline MacCann & 2019 & 3914 Australia & tertiary & unpublished & 3 & -.03 \\
\hline MacCann \& Roberts & 2008 & 1756 Australia & tertiary & article & 3 & .30 \\
\hline MacCann \& Burrows & 2013 & 1202 Australia & tertiary & article & 2 & -.14 \\
\hline MacCann et al. & 2011 & 1865 USA & secondary & article & 3 & .34 \\
\hline Malik \& Shujja & 2013 & 2045 Pakistan & primary & article & 1 & .12 \\
\hline Margavio et al. & 2012 & 4091 China/USA & tertiary & article & 2 & .62 \\
\hline Marquez et al. & 2006 & 771 Spain & secondary & article & 3 & .46 \\
\hline Martin & 2011 & 17012 USA & primary & dissertation & 1 & .15 \\
\hline Matešić & 2015 & 3693 Croatia & secondary & article & 1 & .00 \\
\hline Mavroveli et al. & 2009 & $1402 \mathrm{UK}$ & primary & article & 1 & .25 \\
\hline Mavroveli et al. & 2008 & $7010 \mathrm{UK}$ & secondary & article & 1 & .21 \\
\hline McClain & 2009 & 851 USA & tertiary & dissertation & 2 & .23 \\
\hline Menzie & 2005 & $551 \mathrm{USA}$ & secondary & dissertation & 1 & .21 \\
\hline MHS & 2019 & $\begin{array}{r}177 \text { USA } \\
1\end{array}$ & tertiary & unpublished & 3 & .13 \\
\hline Mikolajczak & 2019 & 1 Belgium & tertiary & unpublished & 1 & .23 \\
\hline Mitrofan \& Cioricaru & 2014 & 1361 Romania & secondary & $\begin{array}{l}\text { conference } \\
\text { paper }\end{array}$ & 1 & -.06 \\
\hline Naeem et al. & 2014 & 4671 Saudi Arabia & tertiary & article & 2 & .14 \\
\hline Nelson & 2010 & $1411 \mathrm{USA}$ & secondary & dissertation & 3 & .38 \\
\hline Nesari et al. & 2011 & 1201 Iran & mixed & article & 1 & .14 \\
\hline
\end{tabular}




\begin{tabular}{|c|c|c|c|c|c|c|}
\hline Newsome et al. & 2000 & 1806 Canada & tertiary & article & 1 & -.02 \\
\hline Nwabuebo & 2013 & $601 \mathrm{USA}$ & tertiary & dissertation & 1 & .19 \\
\hline O'Connor, Little & 2003 & 9022 USA & tertiary & article & 1,3 & .15 \\
\hline Ogundokun et al. & 2010 & $\begin{array}{r}156 \text { 1 Nigeria } \\
3\end{array}$ & secondary & article & 1 & .74 \\
\hline Olatoye et al. & 2010 & 2351 Nigeria & tertiary & article & 2 & -.18 \\
\hline Olson & 2008 & 746 USA & tertiary & dissertation & 1 & .12 \\
\hline Opateye & 2014 & 6001 Nigeria & tertiary & article & 1 & .10 \\
\hline Parker et al. & 2004 & 6675 USA & secondary & article & 1 & .25 \\
\hline Parker et al. & 2005 & $\begin{array}{r}1425 \text { USA } \\
6\end{array}$ & tertiary & article & 1 & .12 \\
\hline Parker et al. & 2004 & 37210 Canada & tertiary & article & 1 & .10 \\
\hline Petersen & 2010 & 516 USA & secondary & dissertation & 1 & .11 \\
\hline Pishghadam & 2009 & 50830 Iran & tertiary & article & 1 & .12 \\
\hline Por et al. & 2011 & $1301 \mathrm{UK}$ & tertiary & article & 2 & -.11 \\
\hline Qualter et al. & 2012 & 20764 UK & secondary & article & 1,3 & .20 \\
\hline Radford & 2011 & $1151 \mathrm{USA}$ & tertiary & dissertation & 1 & .10 \\
\hline Rankin & 2013 & $1785 \mathrm{UK}$ & tertiary & article & 2 & .13 \\
\hline Rastegar \& Karami & 2013 & 1061 Iran & tertiary & article & 2 & .23 \\
\hline Rice & 2007 & $48613 \mathrm{USA}$ & secondary & dissertation & 1 & .14 \\
\hline Richardson & 2000 & 986 USA & primary & dissertation & 1 & .20 \\
\hline Rivers et al. & 2012 & 663 USA & primary & article & 3 & .51 \\
\hline Rodeiro, Emery \& Bell & 2012 & $8745 \mathrm{UK}$ & secondary & article & 1 & .26 \\
\hline Rodrigo-Ruiz & 2017 & 23219 Spain & secondary & dissertation & 1,3 & .24 \\
\hline Saklofske et al. & 2012 & $1635 \mathrm{UK}$ & tertiary & article & 1 & .05 \\
\hline Saklofske et al. & 2019 & 277 1 Canada & tertiary & unpublished & 1 & .01 \\
\hline Samples & 2010 & 1115 USA & tertiary & dissertation & 3 & .15 \\
\hline Sanchez-Ruiz et al. & 2013 & 323 1 Cyprus & tertiary & article & 1 & .35 \\
\hline Schutte et al. & 1998 & 641 USA & tertiary & article & 2 & .32 \\
\hline Shipley et al. & 2010 & 1934 USA & tertiary & article & 1 & .08 \\
\hline Sierra et al. & 2013 & 12915 Spain & tertiary & article & 3 & .06 \\
\hline Singh et al. & 2009 & 3894 Malaysia & tertiary & $\begin{array}{l}\text { conference } \\
\text { paper }\end{array}$ & 2 & .18 \\
\hline Skipper \& Brandenburg & 2013 & $1421 \mathrm{USA}$ & tertiary & article & 1 & .01 \\
\hline Song et al. & 2010 & 1732 China & tertiary & article & 2 & .27 \\
\hline Stewart \& Chrisholm & 2012 & 15490 UK or Canada & tertiary & article & 1 & .11 \\
\hline Stottlemyer & 2002 & 18526 USA & secondary & dissertation & 1 & .01 \\
\hline Suliman & 2010 & 981 Saudi Arabia & tertiary & article & 1 & -.15 \\
\hline Sunbul & 2007 & 3115 Turkey & tertiary & $\begin{array}{l}\text { conference } \\
\text { paper }\end{array}$ & 1 & .16 \\
\hline Szuberla & 2005 & 6112 USA & primary & dissertation & 3 & .30 \\
\hline Tok \& Morali & 2009 & 2953 Turkey & tertiary & article & 2 & .05 \\
\hline Trapp & 2011 & 1185 USA & tertiary & dissertation & 1 & .07 \\
\hline Vargas & 2014 & 40214 USA & tertiary & dissertation & 1 & .04 \\
\hline Veitch & 2011 & 25114 USA & tertiary & dissertation & 1 & .04 \\
\hline Vela & 2004 & 76014 USA & tertiary & dissertation & 1 & .07 \\
\hline Victoroff \& Boyatzis & 2013 & 10012 USA & tertiary & article & 1 & .06 \\
\hline Walker & 2006 & $\begin{array}{c}120 \\
5\end{array}$ & tertiary & dissertation & 1 & .03 \\
\hline Walsh-Portillo & 2011 & 451 USA & tertiary & dissertation & 1 & .18 \\
\hline Willis & 2015 & $5911 \mathrm{USA}$ & tertiary & dissertation & 1 & .06 \\
\hline $\begin{array}{l}\text { Woitaszewski \& } \\
\text { Aalsma }\end{array}$ & 2004 & 391 USA & secondary & article & 3 & .05 \\
\hline Wraight & 2008 & $2431 \mathrm{USA}$ & tertiary & dissertation & 1 & .17 \\
\hline Wurf \& Croft-Piggin & 2015 & 8110 Australia & tertiary & article & 2 & .14 \\
\hline $\mathrm{Xu}$ & 2016 & $\begin{array}{r}179 \text { 1 China } \\
9\end{array}$ & secondary & article & 2 & .08 \\
\hline Zandi & 2012 & 2396 Iran & tertiary & $\begin{array}{l}\text { conference } \\
\text { paper }\end{array}$ & 1 & .09 \\
\hline
\end{tabular}




\begin{tabular}{llllllll} 
Zarezadeh & 2013 & 330 & 6 Iran & tertiary & conference & 1 & .11 \\
& & & & paper & \\
Zirak \& Ahmadian & 2015 & 337 & 5 Iran & primary & article & 1 & .10 \\
Zysberg et al. & 2011 & 102 & 2 Israel & tertiary & article & 3 & .28 \\
\hline
\end{tabular}

${ }^{\mathrm{a}} N=$ number of participants (if multiple samples in the paper/source, $\mathrm{N}$ is the average)

${ }^{\mathrm{b}} k=$ number of correlation coefficients (e.g., if correlations of the 4 MSCEIT branches with GPA reported, $k=4)$

${ }^{\mathrm{c} S t r e a m}=1$ (ability EI), 2 (self-rated EI) or 3 (mixed EI)

${ }^{\mathrm{d}} r=$ unweighted, uncorrected average correlation across all observations in the citation 